DOC.20060901.0003

QA: QA

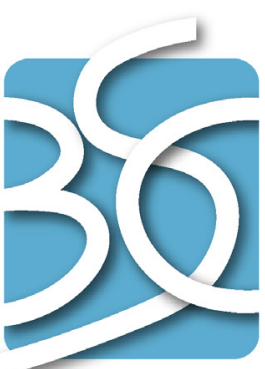

BECHTEL SAIC COMPANLLC
ANL-NBS-HS-000056 REV 00

August 2006

\title{
Analysis of Alcove 8/Niche 3 Flow and Transport Tests
}

\section{NOTICE OF OPEN CHANGE DOCUMENTS - THIS DOCUMENT IS IMPACTED BY} THE LISTED CHANGE DOCUMENTS AND CANNOT BE USED WITHOUT THEM.

1) ACN-001, DATED 12/01/2006

Prepared for:

U.S. Department of Energy

Office of Civilian Radioactive Waste Management

Office of Repository Development

1551 Hillshire Drive

Las Vegas, Nevada 89134-6321

Prepared by:

Bechtel SAIC Company, LLC

1180 Town Center Drive

Las Vegas, Nevada 89144

Under Contract Number

DE-AC28-01RW12101 


\section{DISCLAIMER}

This report was prepared as an account of work sponsored by an agency of the United States Government. Neither the United States Government nor any agency thereof, nor any of their employees, nor any of their contractors, subcontractors or their employees, makes any warranty, express or implied, or assumes any legal liability or responsibility for the accuracy, completeness, or any third party's use or the results of such use of any information, apparatus, product, or process disclosed, or represents that its use would not infringe privately owned rights. Reference herein to any specific commercial product, process, or service by trade name, trademark, manufacturer, or otherwise, does not necessarily constitute or imply its endorsement, recommendation, or favoring by the United States Government or any agency thereof or its contractors or subcontractors. The views and opinions of authors expressed herein do not necessarily state or reflect those of the United States Government or any agency thereof. 
QA: QA

Analysis of Alcove 8/Niche 3 Flow and Transport Tests

ANL-NBS-HS-000056 REV 00

August 2006 


\begin{tabular}{c|c|c} 
BSC & $\begin{array}{c}\text { Scientific Analysis Signature Pagel } \\
\text { Change History } \\
\text { Complete only applicable items. }\end{array}$ & Page iii \\
1. Total Pages: 94
\end{tabular}

2. Scientific Analysis Title

Analysis of Alcove 8/Niche 3 Flow and Transport Tests

3. DI (including Rev. No.)

ANL-NBS-HS-000056 REV 00

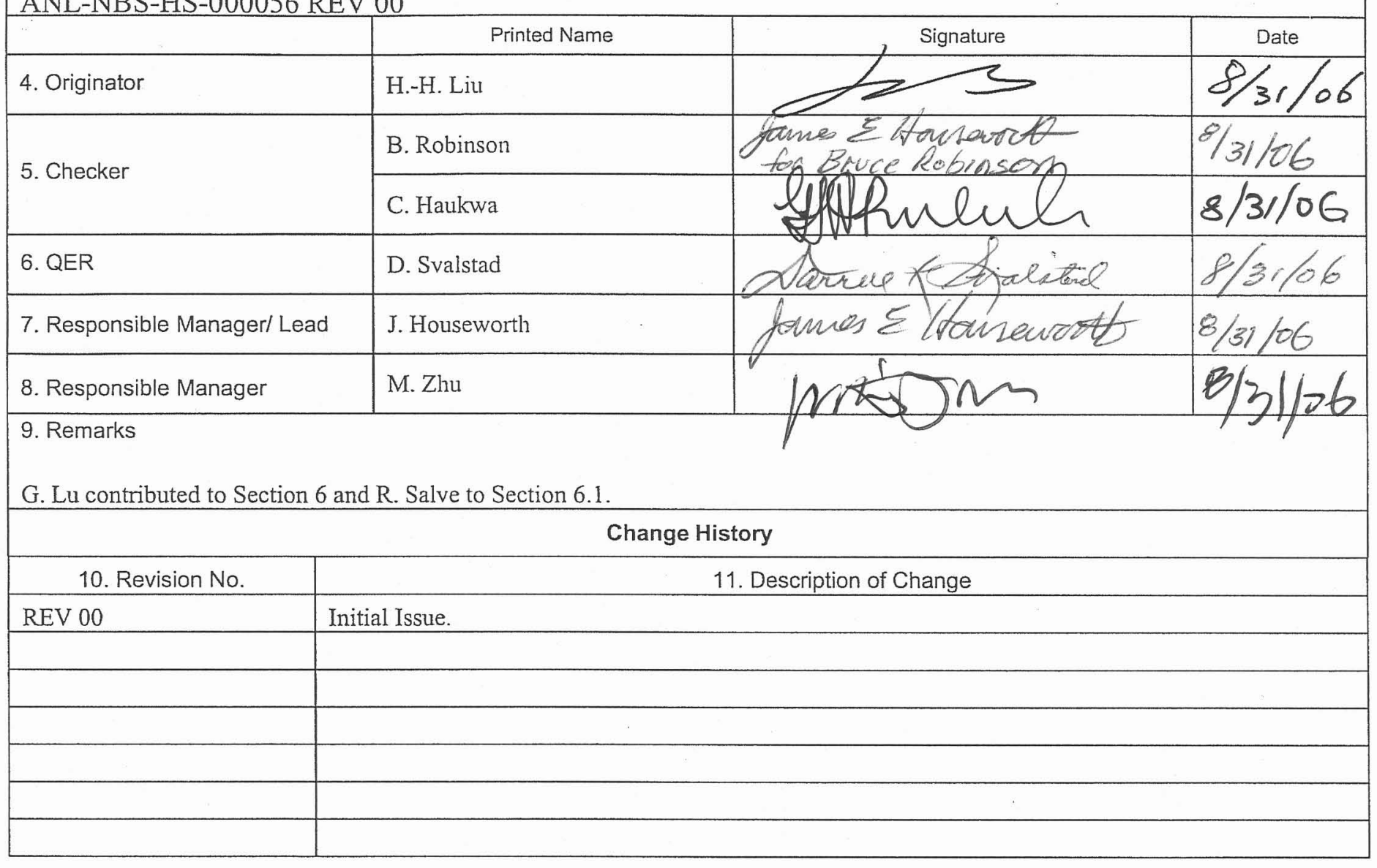




\section{INTENTIONALLY LEFT BLANK}




\section{CONTENTS}

Page

ACRONYMS xi

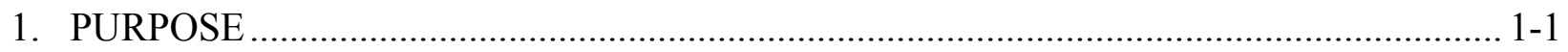

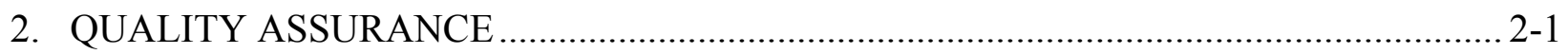

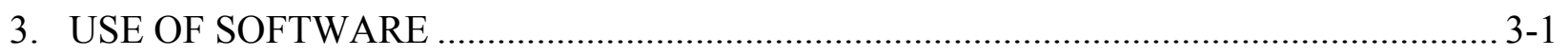

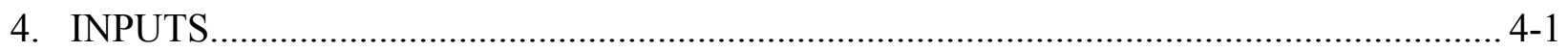

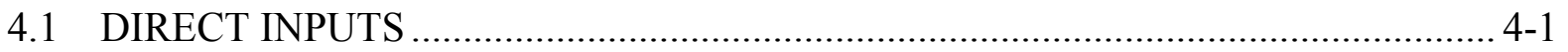

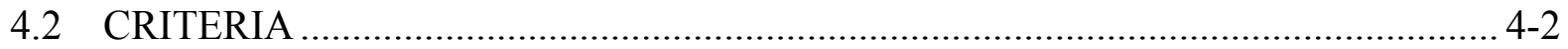

4.3 CODES, STANDARDS, AND REGULATIONS .................................................. 4-4

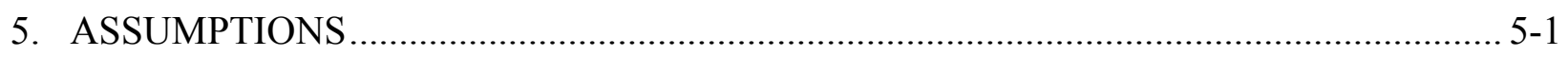

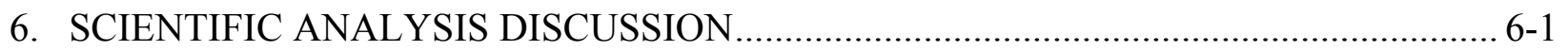

6.1 ALCOVE 8/NICHE 3 LARGE-INFILTRATION-PLOT TESTS ............................... 6-1

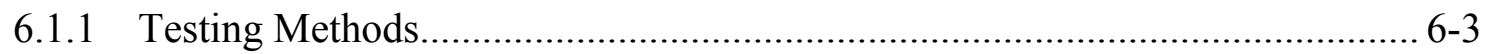

6.1.2 Testing Observations ………................................................................... 6-5

6.2 PRE-TEST PREDICTION OF LATE STAGE OF THE TESTS .............................. 6-12

6.2.1 Model Development........................................................................ 6-12

6.2.2 Model Calibration .............................................................................. 6-14

6.2.3 Model Prediction.................................................................................... 6-19

6.2.4 Comparison between Predicted and Observed Test Results........................... 6-26

6.3 MODELING ANALYSES OF TEST RESULTS ............................................. 6-27

6.3.1 Model Calibration with All the Available Infiltration and Seepage Data ...... 6-28

6.3.2 Sensitivity Study of Tracer Transport....................................................... 6-33

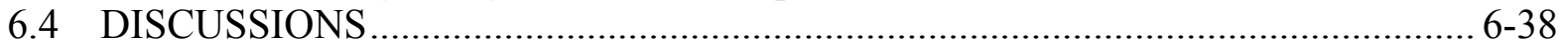

6.4.1 Effective Matrix Diffusion Coefficient and Its Enhancement ........................ 6-38

6.4.2 Uncertainties .................................................................................. 6-42

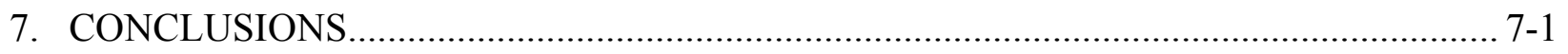

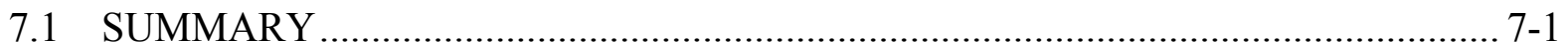

7.2 HOW ACCEPTANCE CRITERIA ARE ADDRESSED ………………………....... 7-2

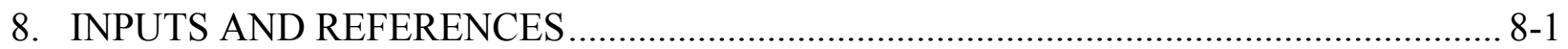

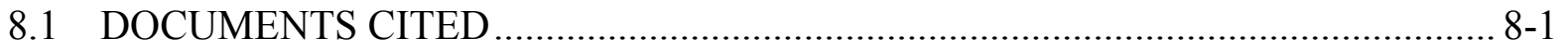

8.2 CODES, STANDARDS, REGULATIONS, AND PROCEDURES ……................... 8-4

8.3 SOURCE DATA, LISTED BY DATA TRACKING NUMBER ………….................. 8-4

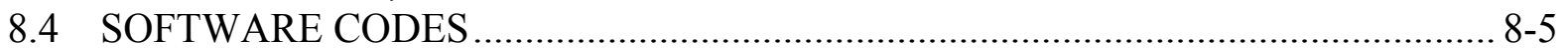




\section{CONTENTS (Continued)}

APPENDIX A: ESTIMATION OF FIELD-SCALE EFFECTIVE MATRIX DIFFUSION COEFFICIENT FROM RESULTS OF TRACER TESTS CONDUCTED AT THE C-WELLS COMPLEX....

APPENDIX B: DESCRIPTION OF DATA FILES AND PROCESSING

PROCEDURES. 


\section{FIGURES}

Page

6.1-1. (A) Location of Yucca Mountain, (B) Three-Dimensional View of the Test Bed in the Exploratory Studies Facility at Yucca Mountain, (C) Location of the Infiltration Plot along the Floor of Alcove 8, and (D) Location of Monitoring Boreholes around Niche 3 .

6.1-2. Schematic Illustration of the Infiltration Zones along the Floor of Alcove 8 Large-Plot Test with the Numbers Identifying the 12 Infiltration Subplots.....

6.1-3. Infiltration Rates Measured along 12 Subplots during Infiltration Test....................... 6-7

6.1-4. Total Infiltration Rate as a Function of Time .......................................................... 6-8

6.1-5. Schematic Configuration of the Seepage-Collection System and Boundaries of the Columns (T1 to T12)...................................................................................... 6-8

6.1-6. Seepage Rates Measured inside Niche 3 during Ponded Infiltration in the Large Plot in Alcove 8 .......................................................................................... 6-9

6.1-7. Total Seepage Rate as a Function of Time ........................................................... 6-10

6.1-8. Observed Tracer Concentrations as a Function of Time ........................................... 6-11

6.2-1. Illustration of Three-Dimensional Numerical Grids for the Large-Plot Tests............ 6-13

6.2-2. Matches between the Simulated (red) and Observed Seepage Rates Associated with Different Vertical Columns ............................................................................... 6-17

6.2-3. Comparison between Simulated and Observed Total Seepage Rate as a Function

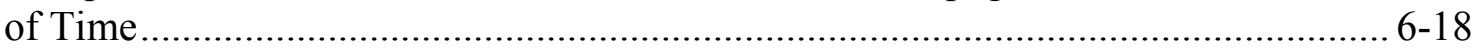

6.2-4. Simulated and Observed Total Seepage Rates....................................................... 6-21

6.2-5. Simulated (red) and Observed Total Seepage Rates for Different Vertical Rock

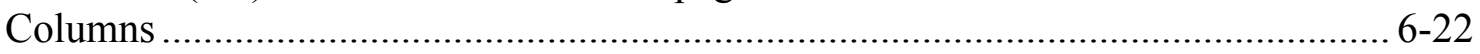

6.2-6. Predicted Tracer Breakthrough Curves and Observed Concentration Data for Tracers 1 and 2........................................................................................... 6-23

6.2-7. Predicted Tracer Breakthrough Curves and Observed Concentration Data for

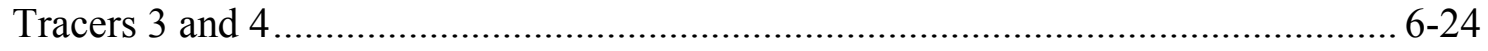

6.2-8. Predicted Tracer Breakthrough Curves and Observed Concentration Data for

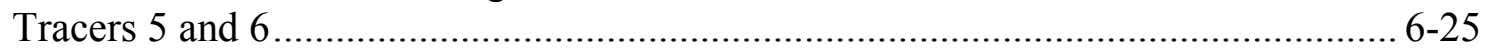

6.3-1. Matches between Simulated and Observed (red) Seepage Rates for the Base-Case Conceptual Model .............................................................................. 6-29

6.3-2. Matches between Simulated and Observed (red) Seepage Rates for the Alternative Conceptual Model................................................................................ 6-30

6.3-3. Simulated Tracer Breakthrough Curves at Niche 3 without Using the Increased Matrix Diffusion Coefficients for the Base-Case Flow Conceptual Model (Inorganic Tracers).

6.3-4. Simulated Tracer Breakthrough Curves at Niche 3 without Using the Increased Matrix Diffusion Coefficients for the Base-Case Flow Conceptual Model (Organic Tracers).... 6-36

6.3-5. Simulated Tracer Breakthrough Curves at Niche 3 without Using the Increased Matrix Diffusion Coefficients for the Alternative Flow Conceptual Model ....

6.4-1. Two-Dimensional Bond Percolation Network at the Percolation Threshold (after Renshaw 1999 [DIRS 169853]). 6-41 


\section{INTENTIONALLY LEFT BLANK}




\section{TABLES}

Page

3-1. Qualified Software Used in this Report ..................................................... 3-1

4-1. $\quad$ Input Data Source and Data Tracking Numbers ....................................................... 4-1

4-2. $\quad$ Project Requirements and YMRP Acceptance Criteria Applicable to

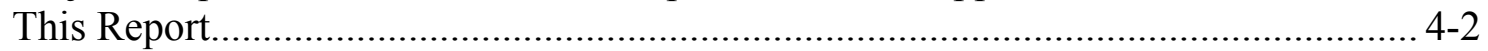

6-1. Scientific Notebooks Used in the Modeling Analyses Documented in

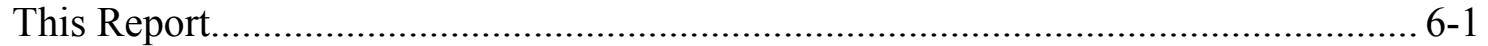

6.1-1. Plots Combined to Form Specific Zones and Duration of Tracer Application in Each Zone ....................................................................................................... 6-4

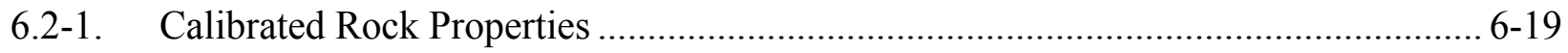

6.2-2. Information for Tracers Used in Phase I Tests ................................................ 6-20

6.3-1. Calibrated Rock Properties for the Base-Case Conceptual Model ............................ 6-32

6.3-2. Calibrated Rock Properties for the Alternative Conceptual Model .......................... 6-33

6.3-3. Simulated Peak (Relative) Concentrations Monitored at Niche 3 for the Increased Matrix Diffusion Coefficients 


\section{INTENTIONALLY LEFT BLANK}




\section{ACRONYMS}

DFBA Difluorobenzoic Acid

DTN data tracking number

ECRB Enhanced Characterization of Repository Block

ESF Exploratory Studies Facility

MINC multiple interacting continua

NRC U.S. Nuclear Regulatory Commission

QA Quality Assurance

TFBA Trifluorobenzoic Acid

Tptpmn Topopah Spring Tuff middle nonlithophysal zone

Tptpul Topopah Spring Tuff upper lithophysal zone

TSw Topopah Spring welded hydrogeologic unit

TWP technical work plan

UZ unsaturated zone

YMRP Yucca Mountain Review Plan, Final Report 


\section{INTENTIONALLY LEFT BLANK}




\section{PURPOSE}

The purpose of this report is to document analyses of the Alcove 8/Niche 3 flow and transport tests, with a focus on the large-infiltration-plot tests and compare pre-test model predictions with the actual test observations. The tests involved infiltration that originated from the floor of Alcove 8 (located in the Enhanced Characterization of Repository Block (ECRB) Cross Drift) and observations of seepage and tracer transport at Niche 3 (located in the Main Drift of the Exploratory Studies Facility (ESF)). The test results are relevant to drift seepage and solute transport in the unsaturated zone (UZ) of Yucca Mountain. The main objective of this analysis was to evaluate the modeling approaches used and the importance of the matrix diffusion process by comparing simulation and actual test observations. The pre-test predictions for the large plot test were found to differ from the observations and the reasons for the differences were documented in this report to partly address CR 6783, which concerns unexpected test results. These unexpected results are discussed and assessed with respect to the current baseline unsaturated zone radionuclide transport model in Sections 6.2.4, 6.3.2, and 6.4.

The information provided in this report for the large-infiltration-plot tests in Alcove 8/Niche 3 addresses the request for additional information related to U.S. Nuclear Regulatory Commission (NRC) Key Technical Issue RT 3.05. The characterization of fracture properties for modeling the Alcove 8/Niche 3 flow, drift seepage, and transport processes includes heterogeneous fracture properties in the fractured rock mass and specific fracture properties for the fault present in the test bed. This treatment of fracture properties provides a response to NRC Key Technical Issue SDS 3.01.

This work presented in this report was conducted under Technical Work Plan for: Unsaturated Zone Flow, Drift Seepage and Unsaturated Zone Transport Modeling (BSC 2006 [DIRS 177465], Sections 1, 2.1.2, and 2.2.1). No features, events, or processes are planned to be included or excluded as a result of the analyses performed for this report.

Limitations of this scientific analysis are largely determined by uncertainties involved in conceptually understanding the temporal variability of observed seepage rates and the tracer breakthrough signals observed (especially those observed right after the occurrence of the infiltration pulse due to scrubbing infiltration plots). Based on experimental observations and test conditions, the most plausible conceptual models are implemented in modeling analyses of the testing data. Discussions of conceptual models, their rationale, and the associated uncertainties are presented in Section 6 of this report. 


\section{INTENTIONALLY LEFT BLANK}




\section{QUALITY ASSURANCE}

Development of this report and the supporting analysis activities have been determined to be subject to the Yucca Mountain Project's Quality Assurance (QA) Program, as indicated in Technical Work Plan for: Unsaturated Zone Flow, Drift Seepage and Unsaturated Zone Transport Modeling (BSC 2006 [DIRS 177465], Section 8.1). Approved QA procedures identified in the technical work plan (TWP) (BSC 2006 [DIRS 177465], Section 4) have been used to conduct and document the activities described in this report. The report was prepared under LP-SIII.9Q-BSC, Scientific Analyses. The TWP also identifies the methods used to control the electronic management of data (BSC 2006 [DIRS 177465], Section 8.4) during the modeling analysis and documentation activities.

This report examines the properties of natural barriers (the Upper and Lower Natural Barriers) that are classified in Q-List (BSC 2005 [DIRS 175539]) as "Safety Category" because they are important to waste isolation, as defined in LS-PRO-0203, Q-List and Classification of Structures, Systems, Components and Barriers. The report contributes to the analysis used to support total system performance assessment. The conclusions of this report do not affect the repository design or engineered features important to safety, as defined in LS-PRO-0203. 


\section{INTENTIONALLY LEFT BLANK}




\section{USE OF SOFTWARE}

The software used in this study is listed in Table 3-1. These codes are appropriate for the intended application and were used strictly within the range of validation. The codes were obtained from Software Configuration Management in accordance with IT-PRO-0011, Software Management. All qualified software used in this report has been run on platform version numbers consistent with those listed in the Software Baseline Report readily available through Software Configuration Management.

Table 3-1. Qualified Software Used in this Report

\begin{tabular}{|l|c|c|c|c|}
\hline $\begin{array}{c}\text { Software Name, } \\
\text { Codes }\end{array}$ & Version & Software Tracking Number & $\begin{array}{c}\text { Reference } \\
\text { Number }\end{array}$ & \multicolumn{1}{c|}{ Operating Environment } \\
\hline iTOUGH2 & 5.0 & $10003-5.0-00$ & [DIRS 160106] & $\begin{array}{l}\text { Linux, Red Hat V7.3/Athlon } \\
\text { Cluster (AMD Athlon 2100+ } \\
\text { compute nodes) }\end{array}$ \\
\hline T2R3D & 1.4 & $10006-1.4-00$ & [DIRS 146654] & DEC ALPHA/OSF1 V4.0 \\
\hline
\end{tabular}

The use of the codes listed in Table 3-1 is documented in Section 6 and in the supporting scientific notebooks identified in Table 6-1. These codes have been qualified under IT-PRO-0011. The code iTOUGH2 V5.0 was used for model calibration against the seepage-rate data based on inverse modeling methodology, and T2R3D V1.4 was used for analyzing the tracer transport data.

Standard spreadsheet software (Microsoft Excel 1997 and 2002 with Windows 2000 operating system on desktop PC) is employed for simple data analyses and processing using standard functions, and plotting programs (Tecplot Version 9.0) are used for generating figures of test and simulation results. These programs are exempt from the software qualification requirements of IT-PRO-0011. All information needed to reproduce the work using these standard software programs, including the input, computation, and output is included in this report (Appendix B).

The iTOUGH2 V5.0 and T2R3D V1.4 codes are selected for use in this analysis report for flow and transport simulations because of their general capability in inverse modeling and in handling unsaturated zone flow and transport in fractured rock. There are no limitations on outputs when this software is used within the range of use for modeling unsaturated flow and transport through fractured rock. The use of the software is consistent with the intended use (modeling unsaturated flow and transport at the test site) and within the documented validation range of the software. 


\section{INTENTIONALLY LEFT BLANK}




\section{INPUTS}

This section documents inputs used in this study.

\subsection{DIRECT INPUTS}

Source information on the direct inputs is summarized in Table 4-1 and further documented below. The appropriateness of the inputs is also described.

Table 4-1. Input Data Source and Data Tracking Numbers

\begin{tabular}{|c|c|c|}
\hline Current DTN & Location in the Report & Description/Remarks \\
\hline $\begin{array}{l}\text { GS040308312242.001 } \\
\text { [DIRS 176441] } \\
\text { GS050608312242.003 } \\
\text { [DIRS 176442] } \\
\text { GS050408312242.002 } \\
\text { [DIRS 176443] } \\
\text { GS050608312242.004 } \\
\text { [DIRS 176444] }\end{array}$ & $\begin{array}{l}\text { Sections } 6.1 \text { and } 6.2 \\
\text { Appendix } B\end{array}$ & $\begin{array}{l}\text { Infiltration-rate data collected at the infiltration plots in } \\
\text { Alcove } 8\end{array}$ \\
\hline $\begin{array}{l}\text { LB0507A8N3SEEP.001 } \\
\text { [DIRS 176445] } \\
\text { LB0507A8N3SEEP.002 } \\
\text { [DIRS 176446] } \\
\text { LB0507A8N3SEEP.003 } \\
\text { [DIRS 176447] } \\
\text { LB0308A8N3SEEP.001 } \\
\text { [DIRS 166090] }\end{array}$ & $\begin{array}{l}\text { Sections } 6.1 \text { and } 6.2 \\
\text { Appendix } B\end{array}$ & Seepage-rate data collected from the ceiling of Niche 3 \\
\hline $\begin{array}{l}\text { MO0511UCC011JB.002 } \\
\text { [DIRS 176334] }\end{array}$ & $\begin{array}{l}\text { Sections } 6.1 \text { and } 6.2 \\
\text { Appendix } B\end{array}$ & $\begin{array}{l}\text { Tracer concentration data collected from the Alcove } \\
8 / \text { Niche } 3 \text { tests }\end{array}$ \\
\hline $\begin{array}{l}\text { LB0312A8N3MDLG.001 } \\
\text { [DIRS 169761] }\end{array}$ & $\begin{array}{l}\text { Section } 6.2 \\
\text { Appendix B }\end{array}$ & $\begin{array}{l}\text { Alcove } 8 / \text { Niche } 3 \text { analysis for pre-test prediction of the } \\
\text { tests (files: SrunA, SrunAi, alcove } 8 \text { daily infiltration } \\
\text { Rates.xIs, dailyseepage.txt, Trun3d_zone1A, } \\
\text { Trun3d_zone1B, Trun3d_zone } 2 A, \overline{T r u n} 3 d \text { _zone2B, } \\
\text { Trun3d_zone3A, Trun3d_zone3B) }\end{array}$ \\
\hline
\end{tabular}

DTN = data tracking number.

The observed data from the tests are further discussed in detail in Section 6 and the data processing is documented in Appendix B. The infiltration-rate data and seepage-rate data are used for model calibrations to obtain site-specific rock properties. The pre-test prediction analysis was partially documented in UZ Flow Models and Submodels (BSC 2004 [DIRS 169861], Section F2). It provides numerical grids, rock hydrologic properties that are fixed during inversions (see Section 6.3.1), local-scale matrix diffusion coefficient values and model initial conditions (DTN: LB0312A8N3MDLG.001 [DIRS 169761], files: SrunA, Trun3d_zone1A, Trun3d_zone1B, Trun3d_zone2A, Trun3d_zone2B, Trun3d_zone3A, Trun3d_zone $3 B$ ) for modeling studies in this report. Formatted data files for early-stage infiltration and seepage rates (DTN: LB0312A8N3MDLG.001 [DIRS 169761], files: alcove 8 daily infiltration Rates.xls and dailyseepage.txt) are used to develop input files for the modeling study in this work, as described in Appendix B. File SrunAi from DTN: LB0312A8N3MDLG.001 [DIRS 169761] is also modified for inverse modeling. The 
observed tracer concentration data are used in the sensitivity analyses to evaluate the importance of the matrix diffusion.

All of the direct input data mentioned above are appropriate for this study, because these data are either observations collected from the test sites or modeling results developed specifically for the Alcove 8/Niche 3 tests.

\subsection{CRITERIA}

Technical requirements to be satisfied by performance assessment are based on 10 CFR 63.114 [DIRS 173273] ("Requirements for Performance Assessment") and 10 CFR 63.115 [DIRS 173273] ("Requirements for Multiple Barriers"). The acceptance criteria that will be used by the NRC to determine whether the technical requirements have been met are identified in Yucca Mountain Review Plan, Final Report (YMRP) (NRC 2003 [DIRS 163274]). The pertinent requirements and acceptance criteria for this report are summarized in Table 4-2.

Table 4-2. Project Requirements and YMRP Acceptance Criteria Applicable to This Report

\begin{tabular}{|c|l|}
\hline Requirement & \multicolumn{1}{c|}{ YMRP Acceptance Criteria } \\
\hline 10 CFR 63.114(a-c) & $\begin{array}{l}\text { Criteria 2 and 3 for Flow Paths in the Unsaturated Zone and } \\
\text { Radionuclide Transport in the Unsaturated Zone }\end{array}$ \\
\hline
\end{tabular}

${ }^{a}$ From NRC 2003 [DIRS 163274], Sections 2.2.1.3.6.3 and 2.2.1.3.7.3.

The acceptance criteria identified in Sections 2.2.1.3.6 and 2.2.1.3.7 of the YMRP (NRC 2003 [DIRS 163274]) are included below. In cases where subsidiary criteria are listed in the YMRP for a given criterion, only the subsidiary criteria addressed by this report are listed below. Where a subcriterion includes several components, only some of those components may be addressed. How these components are addressed is summarized in Section 7 of this report.

\section{Acceptance Criteria from Section 2.2.1.3.6, Flow Paths in the Unsaturated Zone}

\section{Acceptance Criterion 2 - Data Are Sufficient for Model Justification:}

(1) Hydrological and thermal-hydrological-mechanical-chemical values used in the license application are adequately justified. Adequate descriptions of how the data were used, interpreted, and appropriately synthesized into the parameters are provided.

(2) The data on the geology, hydrology, and geochemistry of the unsaturated zone, are collected using acceptable techniques.

(3) Estimates of deep-percolation flux rates constitute an upper bound, or are based on a technically defensible unsaturated zone flow model that reasonably represents the physical system. The flow model is calibrated, using site-specific hydrologic, geologic, and geochemical data. Deep-percolation flux is estimated, using the appropriate spatial and temporal variability of model parameters, and boundary conditions that consider climate-induced change in soil depths and vegetation. 
(6) Accepted and well-documented procedures are used to construct and calibrate numerical models.

(7) Reasonably complete process-level conceptual and mathematical models are used in the analyses. In particular: (i) mathematical models are provided that are consistent with conceptual models and site characteristics; and (ii) the robustness of results from different mathematical models is compared.

\section{Acceptance Criterion 3-Data Uncertainty Is Characterized and Propagated through the Model Abstraction:}

(1) Models use parameter values, assumed ranges, probability distributions, and bounding assumptions that are technically defensible, reasonably account for uncertainties and variabilities, and do not result in an under-representation of the risk estimate.

(4) The initial conditions, boundary conditions, and computational domain used in sensitivity analyses and/or similar analyses are consistent with available data. Parameter values are consistent with the initial and boundary conditions and the assumptions of the conceptual models for the Yucca Mountain site.

(6) Uncertainties in the characteristics of the natural system and engineered materials are considered.

\section{Acceptance Criteria from Section 2.2.1.3.7, Radionuclide Transport in the Unsaturated Zone}

\section{Acceptance Criterion 2 - Data Are Sufficient for Model Justification:}

(1) Geological, hydrological, and geochemical values, used in the license application are adequately justified (e.g., flow-path length, sorption coefficients, retardation factors, colloid concentrations, etc.). Adequate descriptions of how the data were used, interpreted, and appropriately synthesized into the parameters are provided.

(2) Sufficient data have been collected on the characteristics of the natural system to establish initial and boundary conditions for the total system performance assessment abstraction of radionuclide transport in the unsaturated zone.

(3) Data on the geology, hydrology, and geochemistry of the unsaturated zone, including the influence of structure features, fracture distributions, fracture properties, and stratigraphy, used in the total system performance assessment abstraction are based on appropriate techniques. These techniques may include laboratory experiments, sitespecific field measurements, natural analog research, and process-level modeling studies. As appropriate, sensitivity or uncertainty analyses, used to support the U.S. Department of Energy total system performance assessment abstraction, are adequate to determine the possible need for additional data. 


\section{Acceptance Criterion 3-Data Uncertainty Is Characterized and Propagated through the Model Abstraction:}

(1) Models use parameter values, assumed ranges, probability distributions, and bounding assumptions that are technically defensible, reasonably account for uncertainties and variabilities, and do not result in an under-representation of the risk estimate.

(2) For those radionuclides where the total system performance assessment abstraction indicates that transport in fractures and matrix in the unsaturated zone is important to waste isolation: (i) estimated flow and transport parameters are appropriate and valid, based on techniques that may include laboratory experiments, field measurements, natural analog research, and process-level modeling studies, conducted under conditions relevant to the unsaturated zone at Yucca Mountain; and (ii) models are demonstrated to adequately reproduce field transport test results. For example, if a sorption coefficient approach is used, the assumptions implicit in that approach are verified.

(4) Uncertainty is adequately represented in parameter development for conceptual models, process-level models, and alternative conceptual models, considered in developing the abstraction of radionuclide transport in the unsaturated zone. This may be done either through sensitivity analyses or use of conservative limits.

\subsection{CODES, STANDARDS, AND REGULATIONS}

No codes, standards, or regulations were used in this report other than those identified in Table 4-2 and determined to be applicable. 


\section{ASSUMPTIONS}

Alcove 8/Niche 3 tests involve a number of important processes relating to fluid flow and solute transport in fractured rock. The assumptions made to develop conceptual understandings and modeling approaches for these processes are presented in Section 6. This report does not include assumptions used in the absence of directly confirming data or evidence to perform the model activity. Per LP-SIII.9Q-BSC, only the latter assumptions need to be presented in this section. 


\section{INTENTIONALLY LEFT BLANK}




\section{SCIENTIFIC ANALYSIS DISCUSSION}

This section documents Alcove 8/Niche 3 flow and transport tests, with a focus on the largeinfiltration-plot test results (Section 6.1), pre-test prediction of the late stage of the test (Section 6.2), model analyses of test results (Section 6.3), and uncertainties and relevant issues regarding the model analyses (Section 6.4). A flow and transport test for a fault was also conducted near the large-infiltration-plot test site. The test results have been previously documented in In Situ Field Testing of Processes (BSC 2004 [DIRS 170004], Section 6.12.4). A discussion of fault test results and a modeling analysis of the results were presented in UZ Flow Models and Submodels (BSC 2004 [DIRS 169861], Section 7.6). The information provided in this report for the large-infiltration-plot tests in Alcove 8/Niche 3 addresses the request for additional information related to NRC Key Technical Issue RT 3.05 and SDS 3.01.

The scientific notebooks (with relevant page numbers) used for the modeling analysis activities described in this report are listed in Table 6-1.

Table 6-1. Scientific Notebooks Used in the Modeling Analyses Documented in This Report

\begin{tabular}{|l|l|l|}
\hline \multicolumn{1}{|c|}{ Scientific Notebook ID } & \multicolumn{1}{c|}{ Relevant Pages } & \multicolumn{1}{c|}{ Citation } \\
\hline SN-LBNL-SCI-246-V1 & pp. 19 to 50 & Lu 2006 [DIRS 176702] \\
\hline SN-LBNL-SCI-215-V1 & pp.160 to 165 & Liu 2006 [DIRS 176703] \\
\hline
\end{tabular}

\subsection{ALCOVE 8/NICHE 3 LARGE-INFILTRATION-PLOT TESTS}

This section documents Alcove 8/Niche 3 large-infiltration-plot test results. The largeinfiltration-plot study was conducted in the ESF in the Yucca Mountain unsaturated zone. The test bed extends from about $190 \mathrm{~m}$ to about $215 \mathrm{~m}$ (BSC 2004 [DIRS 170004], Section 6.12; Salve 2005 [DIRS 176336]) below the ground surface of Yucca Mountain (Figure 6.1-1). The upper and lower boundaries of the test bed were accessed through two tunnels, referred to as the Cross Drift and the Main Drift, respectively. Alcove 8 is located within the Topopah Spring Tuff upper lithophysal zone (Tptpul). The Tptpul contains large, naturally occurring cavities called lithophysae that are attributed to gas- and vapor-phase constituents entrapped and redistributed during the initial deposition, compaction, and gas migration out of the Topopah Spring welded hydrogeologic unit (TSw). Niche 3 is located within the Topopah Spring Tuff middle nonlithophysal zone (Tptpmn). There is a vertical distance of about $20 \mathrm{~m}$ between the floor of Alcove 8 and the crown of Niche 3. The location of the Tptpul-Tptpmn contact is at about $3 \mathrm{~m}$ above Niche 3 (BSC 2004 [DIRS 170004], Section 6.12; Salve 2005 [DIRS 176336]). 


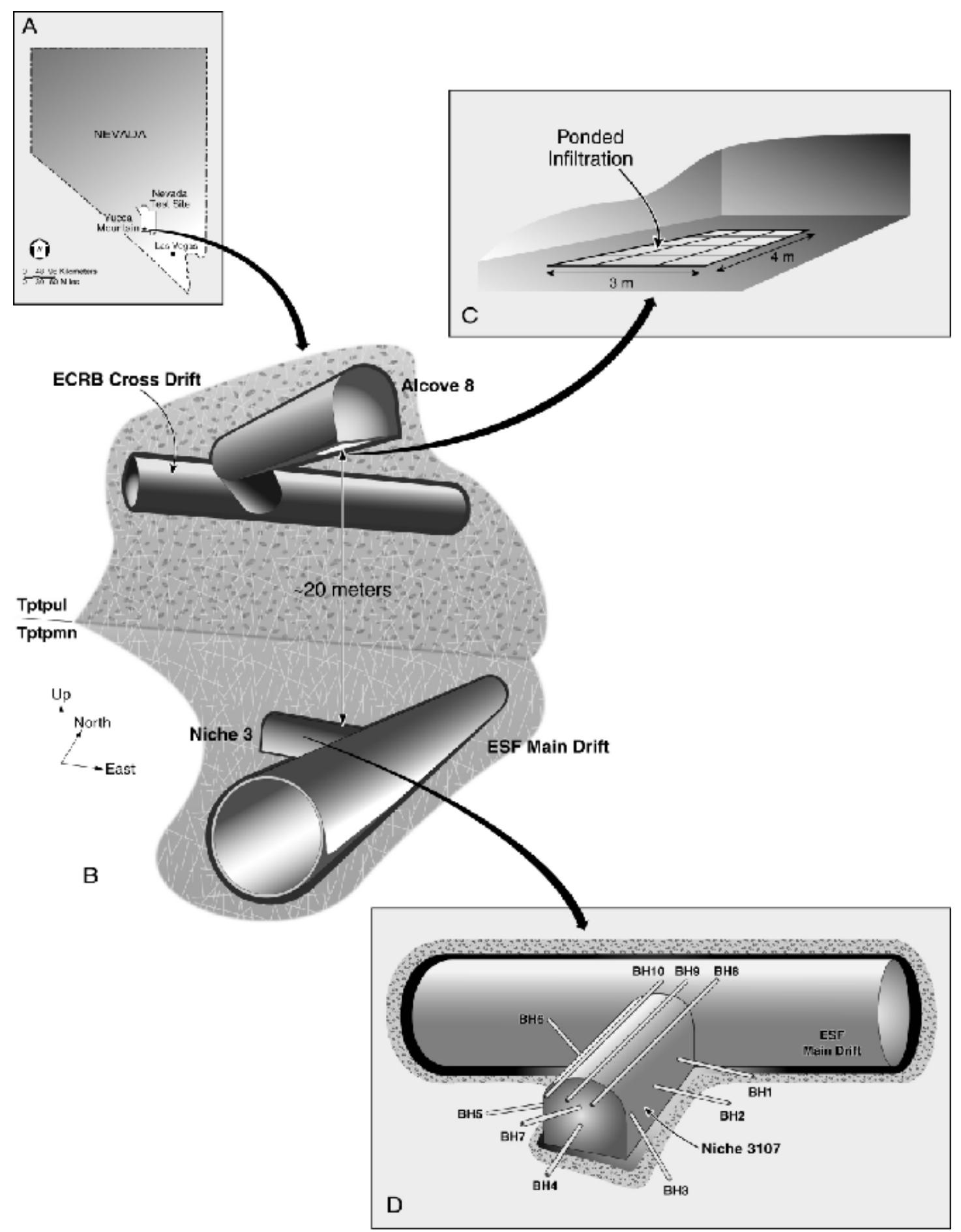

Source: BSC 2004 [DIRS 170004], Figures 6-149 and 6-151; Salve 2005 [DIRS 176336].

NOTE: The test bed is located at the crossover point of the two tunnels, i.e., the Main Drift and the Cross Drift.

Figure 6.1-1. (A) Location of Yucca Mountain, (B) Three-Dimensional View of the Test Bed in the Exploratory Studies Facility at Yucca Mountain, (C) Location of the Infiltration Plot along the Floor of Alcove 8, and (D) Location of Monitoring Boreholes around Niche 3 


\subsubsection{Testing Methods}

Water was released along a surface of fractured welded tuff over a period of about 25 months, between August 2002 and October 2004, during which spatial and temporal variability in infiltration rates was continuously monitored. In addition to the ponded release of water, subsections of the infiltration zone were also perturbed by interruptions to the supply of water and alterations to the plot surface. Observations from this extended infiltration event, with sporadic disruptions, were then analyzed to elucidate mechanisms that influenced the rate at which water moved through the fractured rock surface.

A $3 \times 4 \mathrm{~m}^{2}$ infiltration plot is located on the floor of Alcove 8 (Figure 6.1-2). The boundary of the plot is made with steel sheets embedded into the floor. The plot is further divided into 12 square subplots, of similar size (i.e., $1 \mathrm{~m}^{2}$ ). Each subplot is connected to a permeameter, designed to maintain the desired height of ponded water (approximately $0.02 \mathrm{~m}$ ) while continuously monitoring the rate at which water is released into the infiltration plot. To minimize losses through evaporation, each infiltration subplot is covered with a plastic sheet, and the Alcove 8 cavity is isolated from ventilation effects by bulkhead doors.

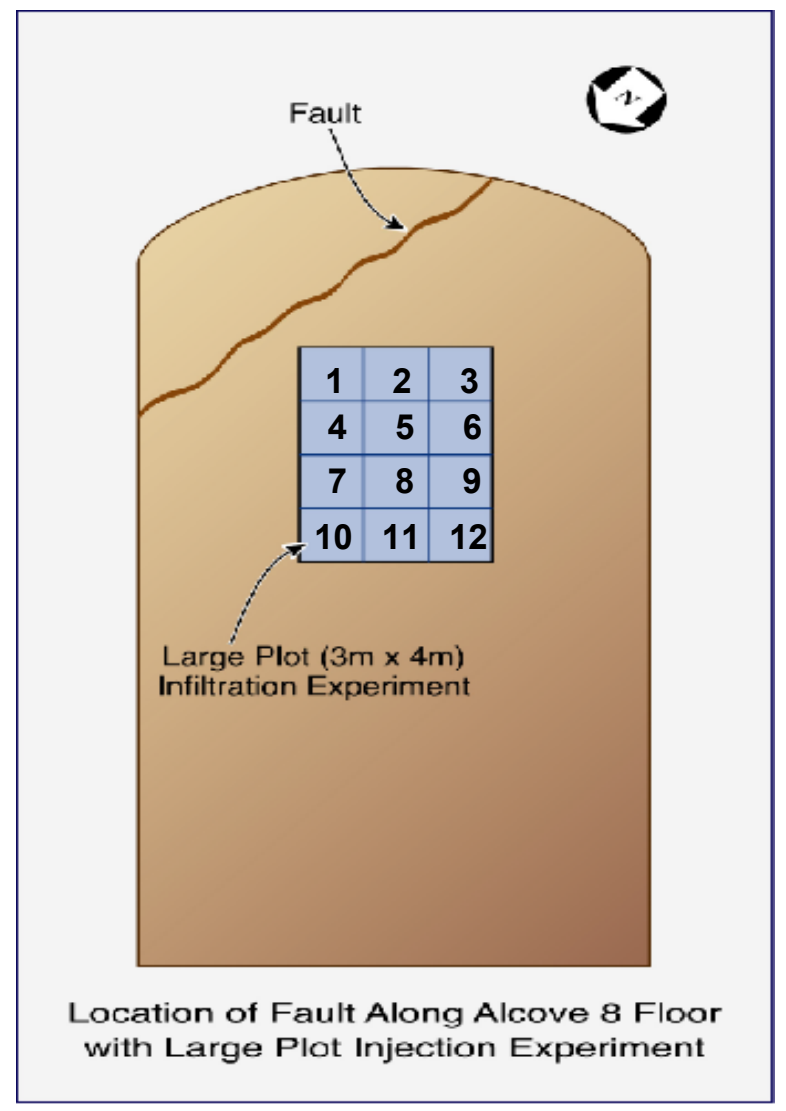

Source: BSC 2004 [DIRS 170004], Figure 6.12.4-1.

Figure 6.1-2. Schematic Illustration of the Infiltration Zones along the Floor of Alcove 8 Large-Plot Test with the Numbers Identifying the 12 Infiltration Subplots 
The ponded infiltration test along the 12 subplots began in August 2002 and continued until October 2004 (DTNs: GS040308312242.001 [DIRS 176441]; GS050608312242.003 [DIRS 176442]; GS050408312242.002 [DIRS 176443]; GS050608312242.004 [DIRS 176444]). During this period, there were three distinct stages of liquid release. Stage 1 began with the ponding of the 12 subplots and continued through March 2003. During Stage 2, which extended from March 2003 until August 2003, water was ponded in subplots 2 and 12 while the surface of the remaining 10 subplots was kept free of standing water. Stage 3 began in August 2003, when ponded water was reintroduced in the 10 subplots. During this phase, in six of the subplots, the infiltration was briefly terminated and the surface was scrubbed to remove biofilms that had developed.

To facilitate the application of tracers, the infiltration plot was divided into three zones. In each zone, two separate tracers were introduced under ponded conditions on March 1, 2004. Table 6.1-1 summarizes the subplots in each zone, as well as the type of tracer and duration of tracers applied to the subplots. Radionuclide transport in the UZ is expected to experience physical processes some of which are similar to those for transport of these tracers (such as advection and matrix processes).

Table 6.1-1. Plots Combined to Form Specific Zones and Duration of Tracer Application in Each Zone

\begin{tabular}{|c|c|c|c|c|}
\hline Zone & Stations/Plots in Zone & Start Date & End Date & Tracers \\
\hline 1 & Plot 1, Plot 2 & $3 / 1 / 2004$ & $4 / 13 / 2004$ & $\begin{array}{l}\text { 2-6-Difluorobenzoic Acid } \\
\text { Potassium lodide }\end{array}$ \\
\hline 2 & $\begin{array}{l}\text { Plot 3, Plot 4, Plot 5, Plot 6, Plot 7, } \\
\text { Plot 8, Plot 9 }\end{array}$ & $3 / 1 / 2004$ & $3 / 17 / 2004$ & $\begin{array}{l}\text { 2, 5-Difluorobenzoic Acid } \\
\text { Calcium Bromide }\end{array}$ \\
\hline 3 & Plot 10, Plot 11, Plot 12 & $3 / 1 / 2004$ & $4 / 13 / 2004$ & $\begin{array}{l}\text { 2, 4, 5-Trifluorobenzoic Acid } \\
\text { Potassium Fluoride }\end{array}$ \\
\hline
\end{tabular}

Source: DTN: MO0511UCC011JB.002 [DIRS 176334].

Within the fractured rock, changes in saturation (and water potential) were monitored using boreholes drilled around Niche 3 to monitor water-front travel times. Within each borehole, electrical resistivity probes recorded the electrical resistivity of fracture water over the entire test period. The observed travel times from these boreholes are given in the file Travel time for predictive model1.xls in DTN: LB0308A8N3TRTM.001 [DIRS 176448].

Seepage was collected at the ceiling of Niche 3 by a capture system consisting of compartments constructed of transparent lexan plastic. Water dripping into each of the tray units was collected into a container connected with the tray unit; the container was in turn connected to a pressure transducer used to remotely monitor seepage rates and volume, and the seepage rates (in L/day) were recorded for the container. The seepage rates in different tray units reflected the spatial variability in the seepage on the niche ceiling. To minimize the effects of evaporation resulting from the Main Drift ventilation, the bulkhead door at the entrance to the niche was closed and sealed. 


\subsubsection{Testing Observations}

As previously indicated in Section 6.1.1, infiltration (water release) consists of three stages. Stage 1 of the infiltration experiment extended over a period of 216 days. The infiltration response measured at various locations along the plot suggests that there was large spatial and temporal variability in the movement of water through the $3 \times 4 \mathrm{~m}^{2}$ surface (Figure 6.1-3).

Stage 2 of the test was designed to evaluate the impact of neighboring subplots on infiltration rates. To achieve this, at the start of Stage 2, water was removed from 10 of the 12 subplots, while in the two subplots with the highest near-constant infiltration rates (i.e., subplots 2 and 12), ponding continued uninterrupted. For the duration of this phase, which extended for a period of 157 days, this upper boundary condition was maintained along infiltration plots 2 and 12, respectively. Measured fluxes in these subplots suggest that infiltration in the subplots was not significantly impacted when the adjacent subplots were dried.

Stage 3 of the infiltration test was configured to evaluate the impact of two specific perturbations on infiltration rates. For the first, the supply of water to individual plots was terminated for varying periods. The second perturbation involved the removal of a thin layer of biomass that had grown over the infiltration surface from six of the 12 subplots.

When ponded infiltration was resumed along the entire plot during Stage 3, the surface of 10 of the 12 subplots had been dry for approximately five months, while the remaining two (i.e., subplots 2 and 12) had been dry for approximately three weeks. With the resumption of ponding, infiltration rates in 10 subplots (i.e., subplots 3 to 12), were found to be similar to those at the end of Phase 1. It appears that during the long dry period, the near-surface hydrologic properties in these 10 plots remained relatively unchanged, such that there was no measurable difference in the infiltration rates.

Subplots 1 and 2 were the only plots that showed some impact of the dryout that preceded Phase 3. In subplot 1 the infiltration rate at the resumption of ponding was $\sim 30 \mathrm{~L} /$ day, much higher than at the end of Phase 1 when it was $\sim 5 \mathrm{~L} /$ day. However, the higher infiltration rates did not persist, and the daily flux along this subplot rapidly approached a relatively steady rate of $\sim 10 \mathrm{~L} /$ day. In subplot 2 , when water was reintroduced into the plot after three weeks of drying, the infiltration rates were initially slightly lower than at the end of Phase 2 (i.e., 12 L/day, versus $14 \mathrm{~L} /$ day), but steadily increased to $30 \mathrm{~L} /$ day in the next 30 days. The infiltration rate then began to decline gradually, reaching a near-constant rate of 12 L/day approximately 200 days after Phase 3 ponding began.

When ponded water was briefly removed from subplots $1,6,9$, and 12,734 days after the start of the infiltration experiment, there was no measurable difference in infiltration rates once ponding was resumed a few hours later. Similarly, in subplots 3,6,9, and 12, infiltration rates did not change after the surface of each of these plots had been briefly scrubbed.

Subplots 1 and 2 were the only plots that showed a measurable response to scrubbing of their surfaces. Subplot 1, which had not shown any response to a brief interruption in the supply of ponded water, responded almost immediately after the surface had been cleaned. Here, the near-constant infiltration rate of $\sim 5 \mathrm{~L} /$ day that had persisted for over a year rapidly increased 
to $\sim 70 \mathrm{~L} /$ day and continued to increase over the next five days before peaking at $\sim 110 \mathrm{~L} /$ day. After peaking, the infiltration rates then rapidly decreased over the next 30 days, during which ponded conditions were maintained along the plot.

In subplot 2 , the infiltration rate increased from $\sim 12 \mathrm{~L} /$ day to $20 \mathrm{~L} /$ day, immediately after the plot was scrubbed on day 734 of the test. Following this steep increase, infiltration rates gradually increased to $30 \mathrm{~L}$ /day in the next 12 days, and then sharply to $70 \mathrm{~L} /$ day over a period of nine days before dropping to $\sim 30 \mathrm{~L} /$ day over a period of 24 hours. This dramatically reduced infiltration rate coincided with perturbations to the surface of subplot 1 . As the infiltration rates jumped in subplot 1 , they dropped in subplot 2 , suggesting that there was some mechanism by which flow through the surface of subplot 2 was reduced as the permeability of the surface of subplot 1 was increased. The reduced infiltration rates in subplot 2 persisted for the next 30 days before gradually declining over the remaining few days of the test.

Immediately after the surface of subplot 1 was scrubbed 756 days into the infiltration test, there were two significant changes observed along the infiltration plot. In subplot 1 , there was an immediate increase in infiltration rates from less than $5 \mathrm{~L} /$ day to $70 \mathrm{~L} /$ day, while in subplot 2, which had been showing a continuous increase in infiltration rates over the preceding three weeks, there was an immediate decrease in infiltration rates (Figure 6.1-3.). The total infiltration rate as a function of a time is presented in Figure 6.1-4.

Seepage was first visually observed in Niche 3 on September 10, 2002, on the back wall where the wall meets the ceiling. Measurable seepage was recorded for a week after these initial observations. Early seepage was measured approximately 30 days after the initial application of water along the infiltration plot (Figure 6.1-6). Note that the ceiling of Niche 3 is divided into 12 zones with the about same coverage areas (called columns in Figure 6.1-5). One zone may cover one or more seepage tray units (Figure 6.1-5). The seepage rates are presented here for each zone (column) in Figure 6.1-6, because these are the data directly used in model calibrations (Sections 6.2 and 6.3). Following the arrival of the wetting front, seepage at most monitored locations appeared to increase over a period of about one to four weeks before gradually decreasing. The highest seepage rates measured during this peak event were about $30 \mathrm{~L} /$ day. Following peak values, the seepage rates at all locations continuously decreased, with maximum rates measured at about $5 \mathrm{~L} /$ day in March of 2003. 

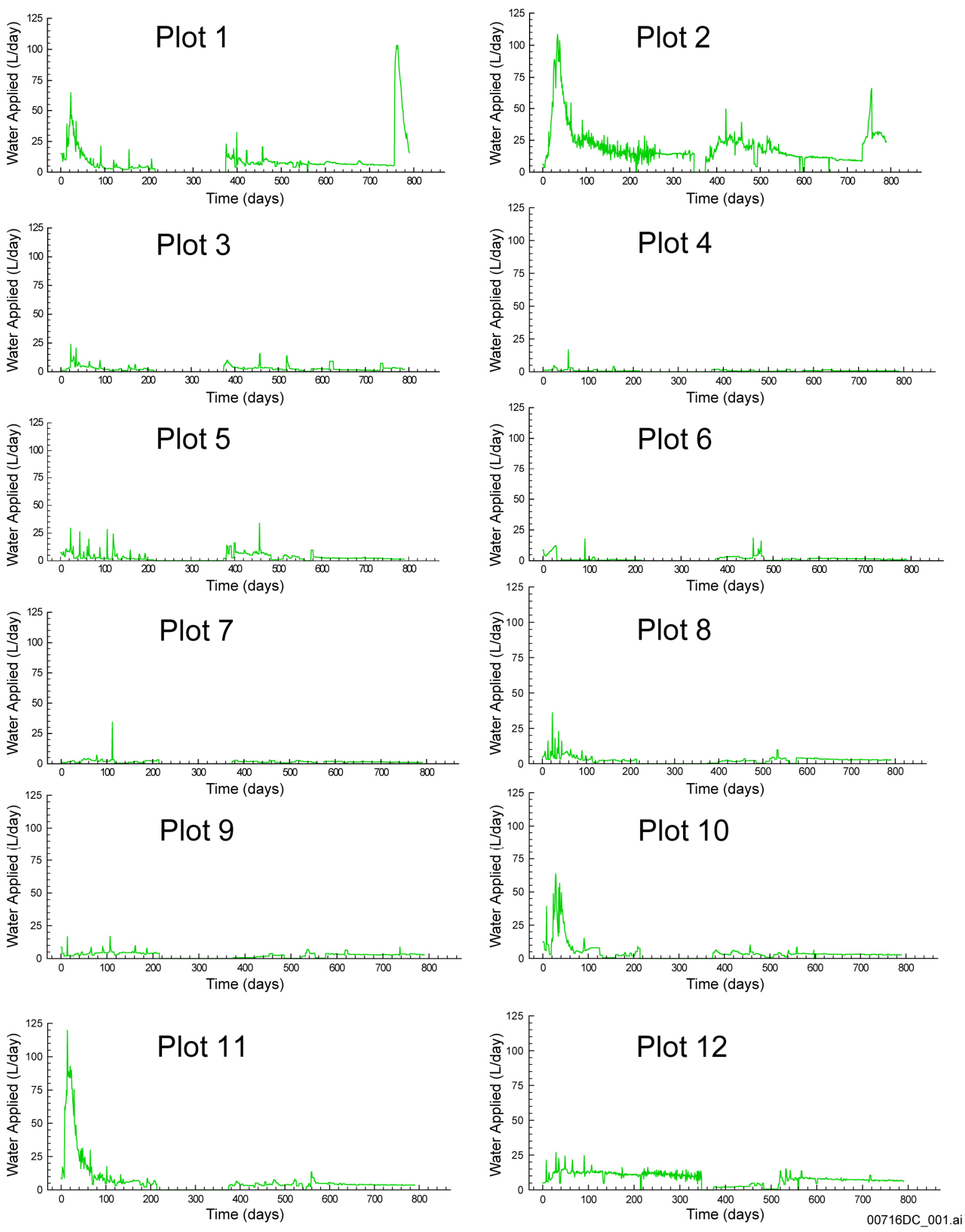

Source: DTNs: GS040308312242.001 [DIRS 176441]; GS050608312242.003 [DIRS 176442]; GS050408312242.002 [DIRS 176443]; GS050608312242.004 [DIRS 176444].

NOTE: Data processing procedures are given in Appendix B.

Figure 6.1-3. Infiltration Rates Measured along 12 Subplots during Infiltration Test 


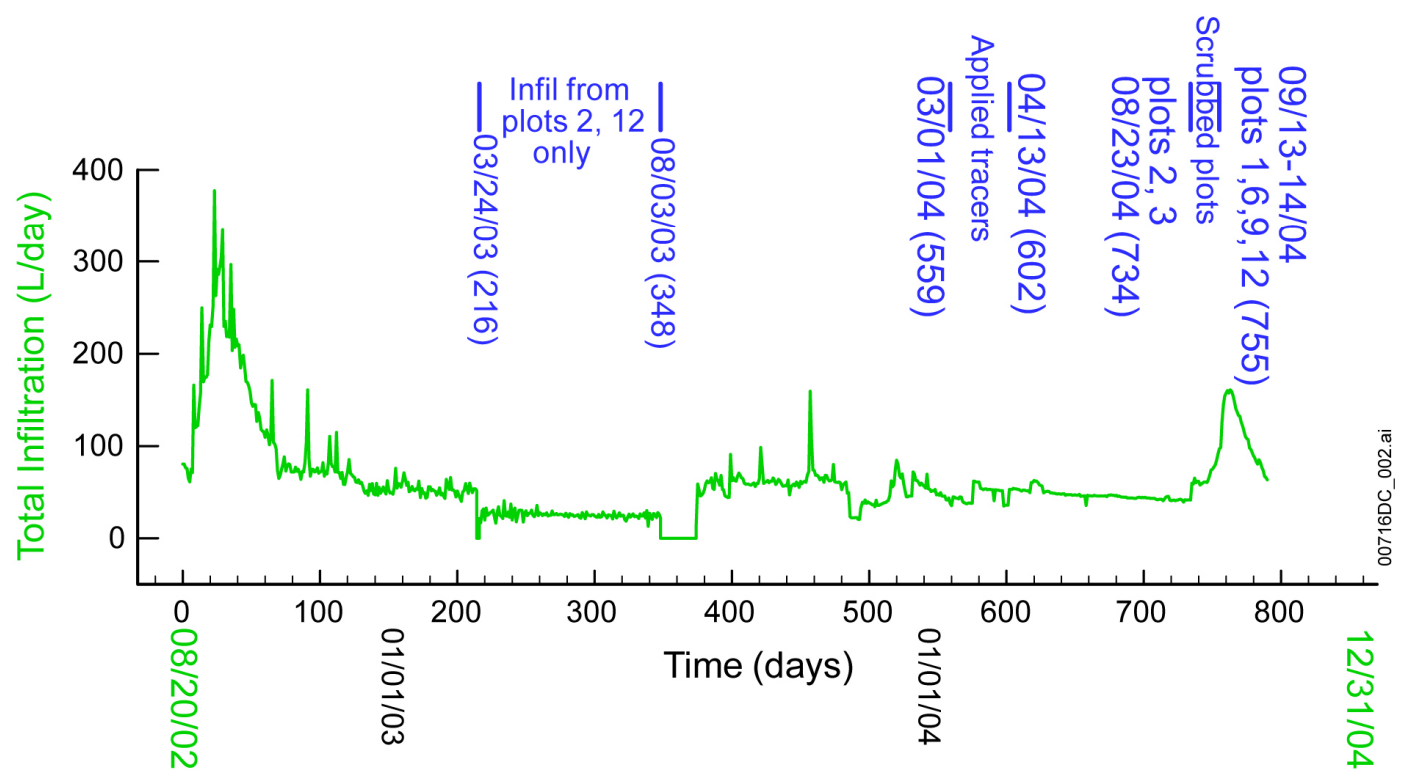

Source: DTNs: GS040308312242.001 [DIRS 176441]; GS050608312242.003 [DIRS 176442]; GS050408312242.002 [DIRS 176443]; GS050608312242.004 [DIRS 176444].

NOTE: Data processing procedures are given in Appendix B.

Figure 6.1-4. Total Infiltration Rate as a Function of Time

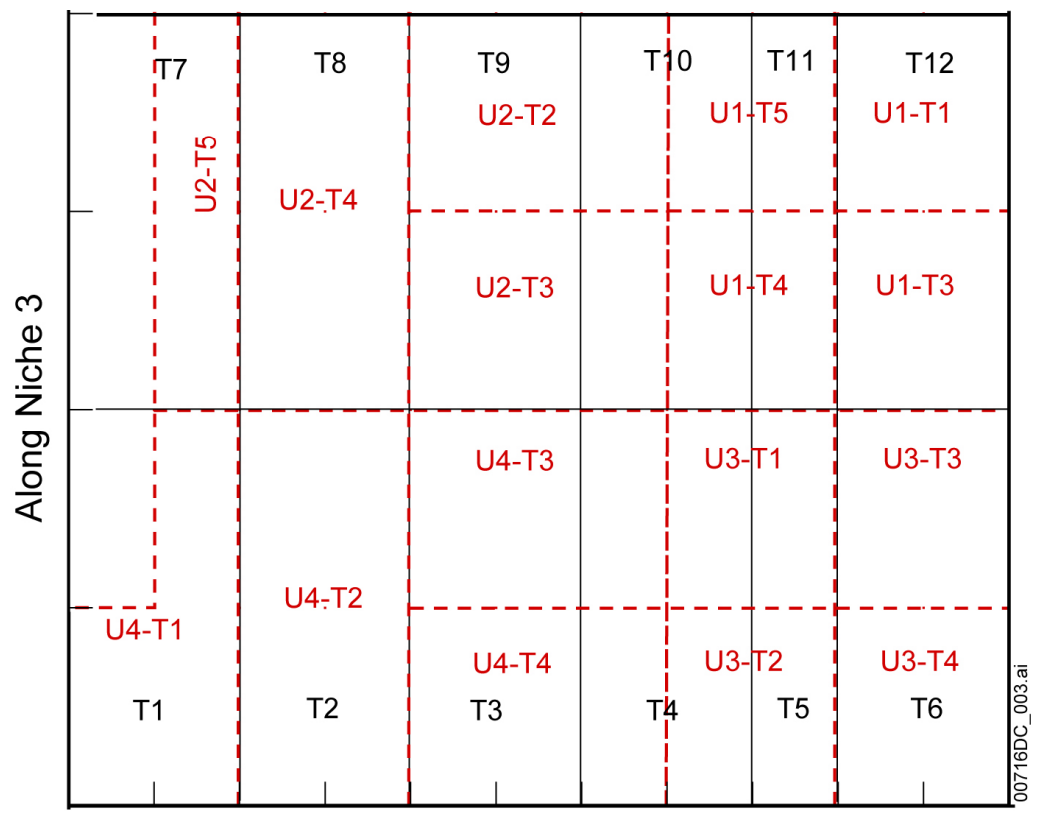

Cross Niche 3

Source: Output DTN: LB0602A8N3FTR0.001; Lu 2006 [DIRS 176702], p. 20.

NOTE: Black solid lines delineate the column boundaries, and red dashed lines the seepage tray unit's boundaries.

Figure 6.1-5. Schematic Configuration of the Seepage-Collection System and Boundaries of the Columns (T1 to T12) 

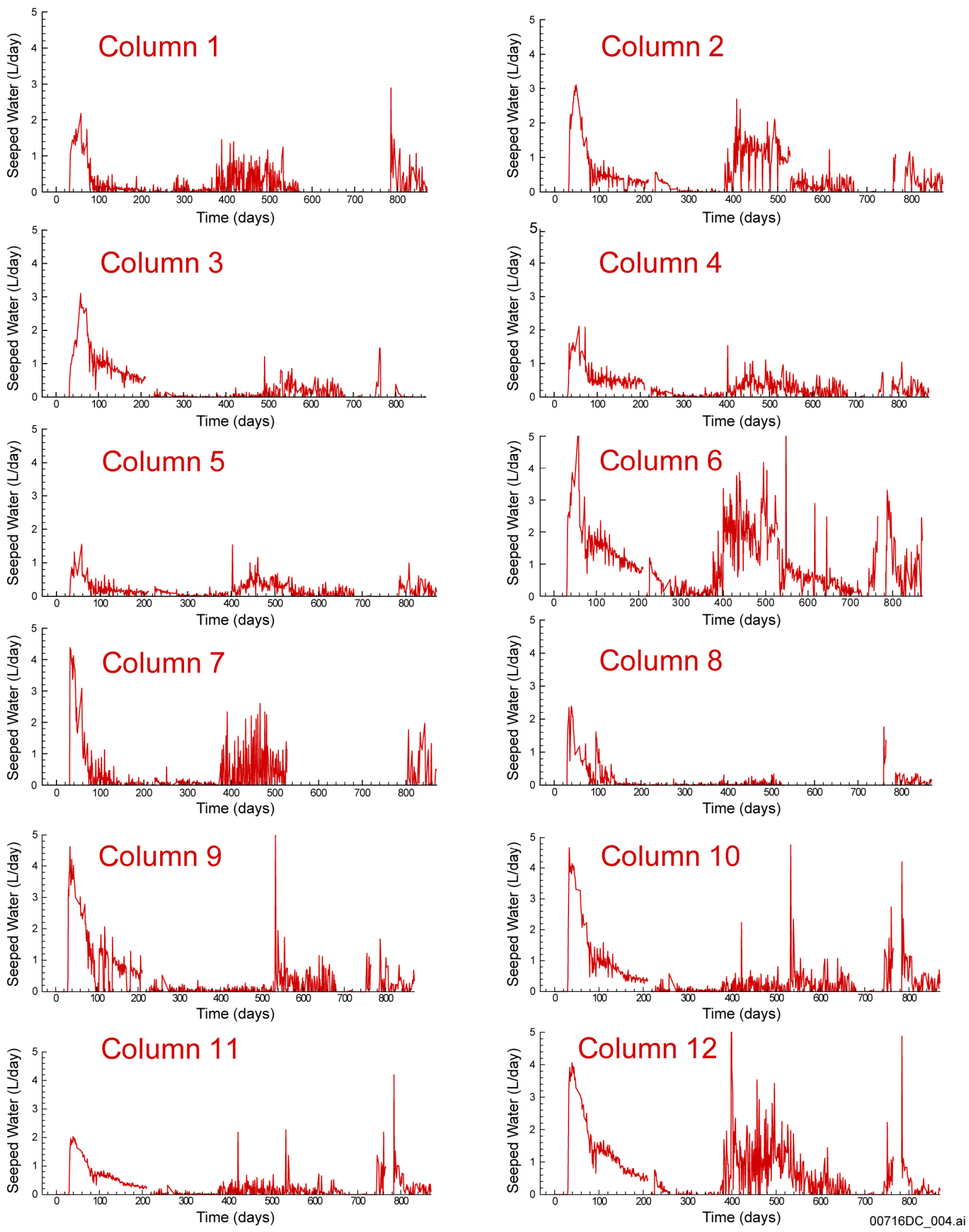

Source: DTNs: LB0507A8N3SEEP.001 [DIRS 176445]; LB0507A8N3SEEP.002 [DIRS 176446]; LB0507A8N3SEEP.003 [176447]; LB0308A8N3SEEP.001 [DIRS 166090]; LB0312A8N3MDLG.001 [DIRS 169761].

NOTE: $\quad$ Between March 24, 2003, and August 28, 2003, water was released into only two of the 12 subplots. Data processing procedures are given in Appendix B.

Figure 6.1-6. Seepage Rates Measured inside Niche 3 during Ponded Infiltration in the Large Plot in Alcove 8 
When water was released into only two of the 12 subplots, the seepage rate dropped to very small values over a period of two months. When infiltration was resumed on all 12 plots in late August 2003, after a lag of about 30 days the seepage rates quickly climbed to 10-15 L/day. Over the next five months, daily seepage rates fluctuated significantly more than observed earlier, and then after January 2003, these rates gradually dropped to near zero. The total seepage rate as a function of time is presented in Figure 6.1-7.

Tracer concentrations in seeping water collected at Niche 3 were measured after tracers were injected from infiltration plots at Alcove 8. The measured results are presented in Figure 6.1-8. Note that no tracer concentrations (excluding background concentrations) were essentially observed until the infiltration pulse occurred, owing to scrubbing of the infiltration plots. Also note that the observed relative concentrations (the concentration divided by the average concentration of injected tracer at the infiltration plots) are small for these breakthrough signals. Further discussion of these tracer data is given in Section 6.2.4.

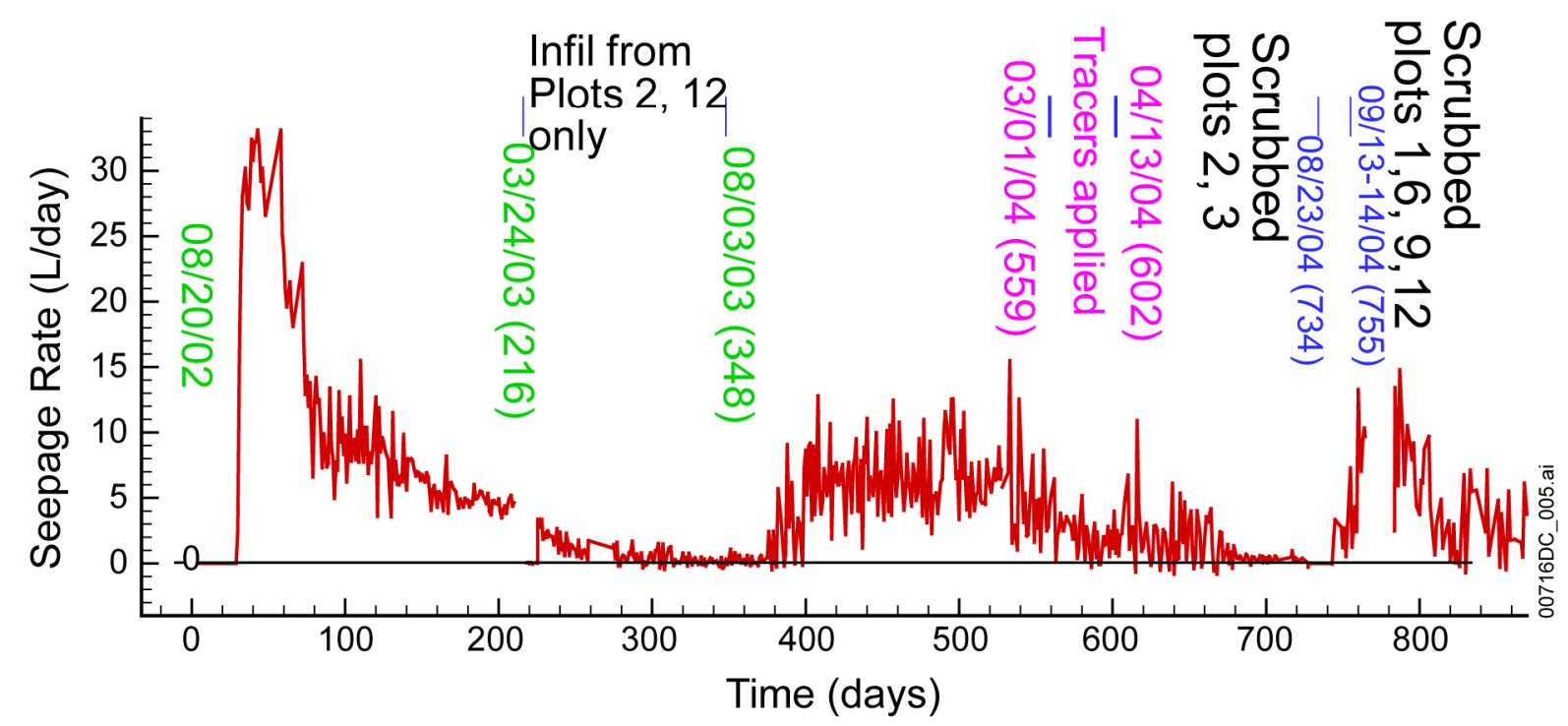

Source: DTNS: LB0507A8N3SEEP.001 [DIRS 176445]; LB0507A8N3SEEP.002 [DIRS 176446]; LB0507A8N3SEEP.003 [DIRS 176447]; LB0308A8N3SEEP.001 [DIRS 166090]; LB0312A8N3MDLG.001 [DIRS 169761].

NOTE: Data processing procedures are given in Appendix B.

Figure 6.1-7. Total Seepage Rate as a Function of Time 

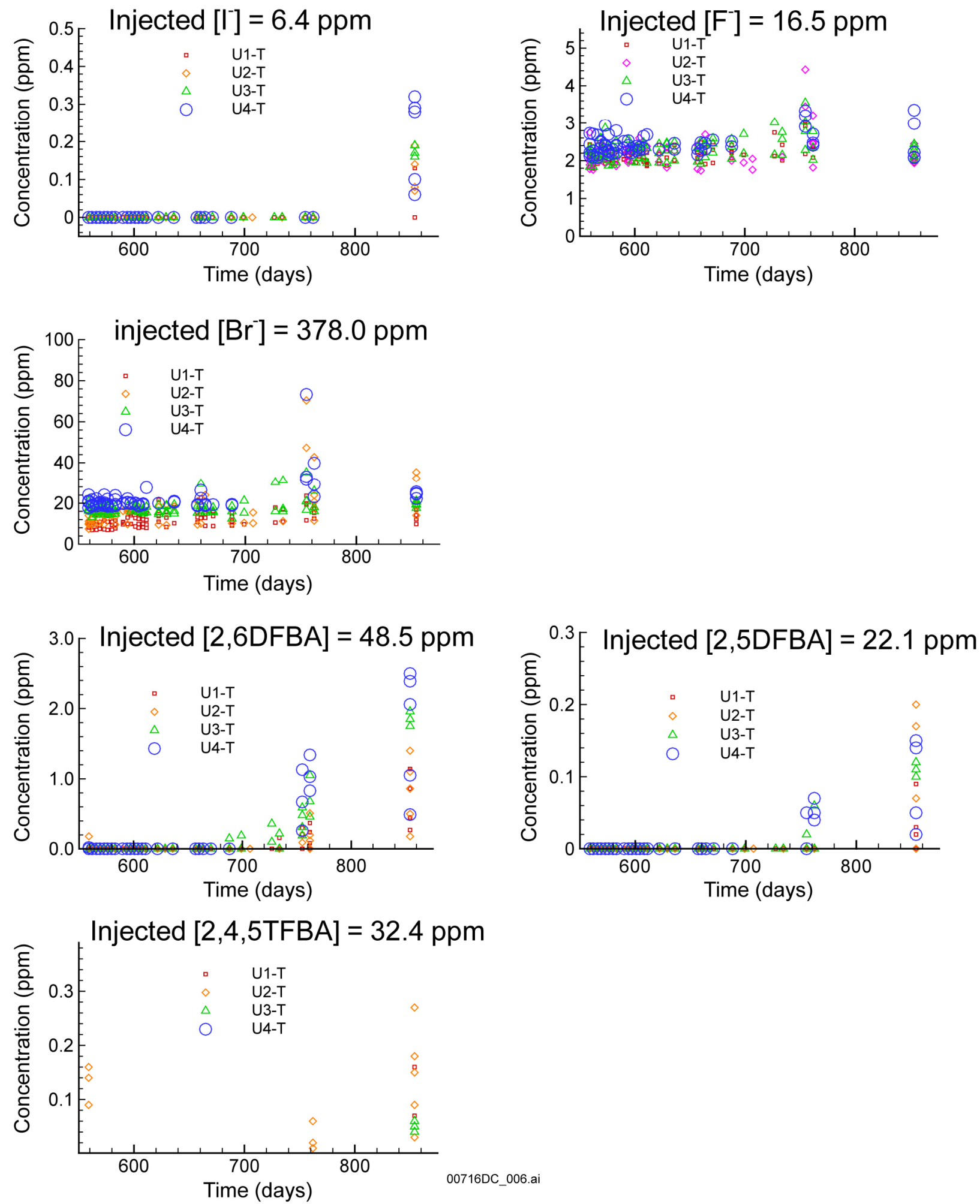

Source: DTN: MO0511UCC011JB.002 [DIRS 176334].

Figure 6.1-8. Observed Tracer Concentrations as a Function of Time 


\subsection{PRE-TEST PREDICTION OF LATE STAGE OF THE TESTS}

As described in Section 6.1, the Alcove 8/Niche 3 tests consisted of several different stages. Based on test data from the earliest stage of the tests (for the first 210 days), a numerical model for flow and transport at the test site was developed. During that stage of the tests, water was applied in all of the 12 infiltration plots. The seepage and infiltration-rate data (collected from that stage of the tests) were used to calibrate the model to obtain the site-specific rock properties. The calibrated model was then used to predict results for subsequent tests planned at that time. A comparison of predicted and observed test results provides a useful way to evaluate the modeling methodology used for modeling UZ flow and transport processes and to improve understanding of physical mechanisms behind those processes in the UZ. This subsection documents the development of the model for pre-test prediction and a comparison between observed and predicted test results.

Note that the pre-test prediction discussed here is the updated pre-test prediction. An initial version of pre-test prediction was documented in Pre-Test Predictions of Alcove 8 -Niche 3 Cross-Over Test (BSC 2001 [DIRS 155827]). Because the test conditions were later considerably adjusted during actual tests and some site-specific data were available at the early stage of the tests, a numerical model, as previously discussed, was developed to more accurately account for the test conditions and calibrate against the test data available at that time (BSC 2004 [DIRS 169861], Section F2.1). The model was then used to provide pre-test predictions for the subsequent tests (including tracer tests). The updated pre-test prediction results are contained in DTN: LB0312A8N3MDLG.001 [DIRS 169761].

\subsubsection{Model Development}

A three-dimensional numerical grid was constructed for modeling the large-plot tests (Figure 6.2-1) (DTN: LB0312A8N3MDLG.001 [DIRS 169761]). The top of the grid corresponds to the floor of Alcove 8, where infiltration occurred. The 12 infiltration plots and the projected outline boundary of the Niche 3 ceiling (under which seepage trays were installed) are also shown in Figure 6.2-1. Small grid sizes were used above the niche ceiling and near the interface between model layers tsw33 and tsw34, to capture diverted water flow around the niche and rock-property transition at the interface between model layers. (Model layers tsw33 and tsw34 correspond to upper low and middle nonlithophysal geological units.) For simplicity, the niche ceiling was approximated as a flat surface. To capture the transient flow and transport behavior, the multiple interacting continua (MINC) model (Pruess and Narasimhan 1985 [DIRS 101707]) was used. The MINC model can handle steep pressure and concentration gradients near fracture-matrix interfaces. In the numerical grid shown in Figure 6.2-1, each gridblock includes one fracture element and five matrix elements. The grid spacings for the five matrix elements are $0.004 \mathrm{~m}, 0.027 \mathrm{~m}, 0.073 \mathrm{~m}, 0.143 \mathrm{~m}$, and $0.472 \mathrm{~m}$ for tsw 33 , and $0.003 \mathrm{~m}, \quad 0.019 \mathrm{~m}, \quad 0.051 \mathrm{~m}, 0.099 \mathrm{~m}$, and $0.326 \mathrm{~m}$ for tsw 34 , respectively (DTN: LB0312A8N3MDLG.001 [DIRS 169761], file: SrunA). The smallest grid spacing corresponds to the elements closest to fractures.

To handle the spatial variabilities observed from both the infiltration rates at Alcove 8 and seepage rates at Niche 3 , heterogeneous distributions of fracture properties within a given model layer were considered in the three-dimensional model. Within a model layer, fractured rock is 
divided into a number of vertical columns within zones below the infiltration plots (for tsw33) or above the ceiling of Niche 3 (for tsw34). Therefore, there are two sets of vertical columns that are located in tsw33 and tsw34, respectively. Each column corresponds to an infiltration plot (in tsw33) or one or more adjacent seepage collection units (in tsw34). The rest of the rock was considered to have homogeneous property distributions within each model layer. The homogeneous property distributions were also used for each column (Section 6.2.2). Also note that for tsw33, the column numbers (Table 6.2-1) are the same as infiltration plot numbers (Figure 6.1-2). For example, Column 1 corresponds to the first infiltration plot for tsw33.

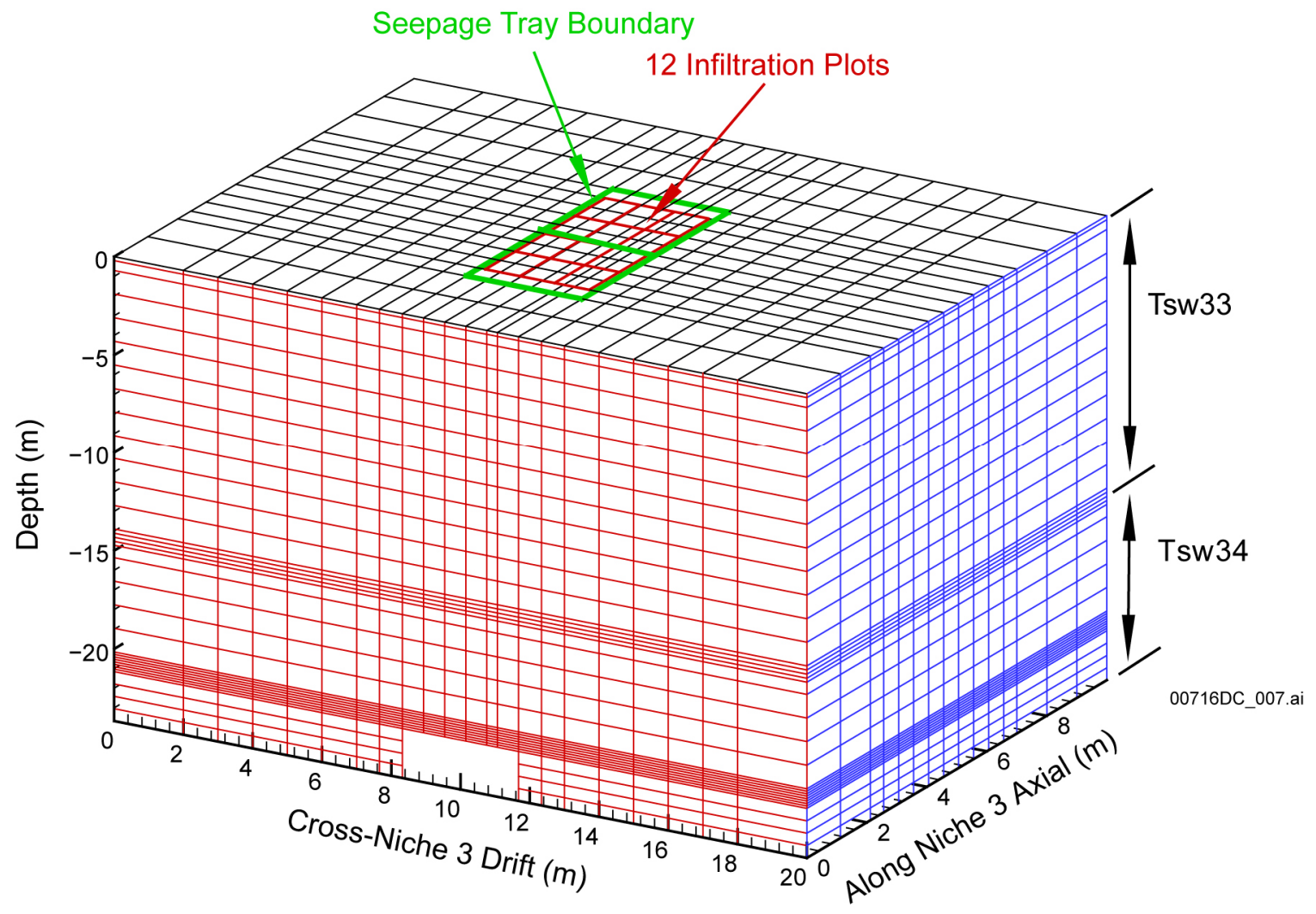

3-D MINC Mesh: 67,320 Elements $(22 \times 15 \times 34 \times 6), 140,000$ Connections

Source: DTN: LB0312A8N3MDLG.001 [DIRS 169761]; BSC 2004 [DIRS 169861], Figure F-1.

Figure 6.2-1. Illustration of Three-Dimensional Numerical Grids for the Large-Plot Tests

Previous fracture-network modeling demonstrated that unsaturated flow paths within a fracture network are generally vertical (as a result of gravity-dominated flow behavior) (Liu et al. 2002 [DIRS 160230]), supporting the use of the column-based heterogeneous distributions. Use of these vertical columns may be able to approximately capture flow behavior associated with these flow paths. Another consideration for using the simple column-based approach is data limitation. As in any field test in the area of subsurface hydrology, not enough data are available for characterizing detailed flow paths between Alcove 8 and Niche 3. A simple model of 
heterogeneity generally involves a relatively small number of parameters that need to be calibrated.

Considerable temporal variability in the infiltration rate occurred during the large plot tests, although a constant water-pressure head $(2 \mathrm{~cm})$ was applied at the infiltration plot (Section 6.1). This may result from in-filled materials (or moving dust particles or bio-materials) within the fractures just below the infiltration plots (BSC 2004 [DIRS 169861], Section 7.6). In other words, the effective permeability of fractures just below the plot changed with time. Based on these considerations, infiltration rates (that are both spatially and temporally variable) at Alcove 8 , rather than the pressure head, were used as the boundary condition at the large infiltration plot. This treatment is expected to maintain the correct values for influx into the test site (below the zone with temporally variable permeabilities). Also note that this treatment is generally equivalent to the use of temporally variable fracture permeabilities for zones just below the infiltration plots (for a constant pressure-head boundary condition). This is because for a gravity-dominated flow process in fractures, a fracture hydraulic conductivity (related to its permeability) is approximately equal to the corresponding infiltration rate for a ponding boundary condition. The side boundary corresponds to zero-flow conditions (in the direction perpendicular to the simulation domain). The niche wall boundary was modeled by a zero-capillary-pressure condition, representing capillary barrier effects. The bottom boundary corresponds to free drainage conditions. As previously noted, Flint (1998 [DIRS 100033], p. 44, Table 7) reported that under ambient conditions, matrix saturation is 0.72 for tsw 33 and 0.85 for tsw34. Because of the disturbance by nearby fault tests, the actual matrix saturations are expected to be higher than these values. In the model, a value of 1.0 averaged with the saturation value reported by Flint (1998 [DIRS 100033], p. 44, Table 7) was used as the initial matrix saturation value for each model layer (DTN: LB0312A8N3MDLG.001 [DIRS 169761]). Because of this approximation, a larger degree of uncertainty is expected to exist for initial conditions assigned in the model, although effects of initial conditions on water flow and solute transport are not considered to be significant at the late stage of the tests when tracer tests were performed. Other initial conditions for the rock mass within the model domain are that the rock is solute-free and has a small water saturation $\left(1.05 \times 10^{-2}\right)$ in fractures (DTN: LB0312A8N3MDLG.001 [DIRS 169761]).

\subsubsection{Model Calibration}

Model calibration is needed to develop site-specific rock properties before a meaningful prediction of future test results can be made. Model calibration was performed using the inverse modeling code iTOUGH2 V5.0. The observed spatial distribution of seepage rate on the ceiling of Niche 3 was explicitly considered. In addition to the observed total seepage rate as a function of time, the seepage rates from individual intersections between the niche ceiling and the vertical columns in tsw34 were matched in the model calibration procedure.

Model calibration adjusts rock properties such that modeling results match field observations. The initial conditions (as discussed in Section 6.2.1) correspond to test-site conditions at time $\mathrm{t}=0$ day. For model layer tsw33, calibrated rock properties are fracture permeabilities and van Genuchten alphas for vertical columns (corresponding to individual infiltration plots) and for the rest of the rock mass. An initial guess of fracture permeability for a column was determined by the largest infiltration rate (for time $t>1$ day) at the infiltration plot under water pressure head 
of $2 \mathrm{~cm}$. The largest infiltration rate (per unit area) is considered to be the saturated hydraulic conductivity for the column. A scale factor was used to calibrate all of these fracture permeability values for the columns in tsw33, such that calibrated fracture permeability for a vertical column is equal to its initial guess, multiplied by the calibrated scale factor. In this way, the effects of observed spatial variability in the infiltration rate were approximately captured by the model calibration. (Note that a vertical column in tsw33 has a uniform property distribution.) For model layer tsw34, calibrated rock properties are again fracture permeabilities and van Genuchten alphas for vertical columns (corresponding to seepage trays) and for the rest of the rock mass. While most vertical columns have uniform distributions in this model layer, Columns 1, 6, 11, and 12 were further divided into two parts, upper and lower. These two parts have different rock properties for each of the columns mentioned above, in order to consider rock-damage effects on rock properties near the niche ceiling. The lower parts correspond to rock between the niche ceiling and $0.4 \mathrm{~m}$ above the ceiling. Fracture porosity calibrated from the fault tests and matrix properties used in fault-test modeling studies are used here and in Section 6.3 because the fault-test site is close to the test site for this study. These properties were not varied during model calibration (Tables 6.3-1 and 6.3-2). Initial guesses for fracture properties (except fracture permeabilities for tsw 33) are set to those calibrated from the fault (DTN: LB0303A8N3MDLG.001 [DIRS 162773], file: Irun4Ni.par).

As previously indicated, fracture permeability and van Genuchten alpha are parameters that are varied during calibrations, while the other fracture and matrix properties are fixed. Note that for the given test conditions with relatively high water fluxes in fractures, contributions of the matrix flow component to the overall flow and transport process at the test site are not significant. In this case, it is reasonable to fix the matrix properties during inversions. Some fracture properties (including fracture porosity, van Genuchten $\mathrm{m}$, and the active fracture model parameter) are also fixed because these parameters were calibrated in modeling analyses of the fault tests near the current test site, and they are not expected to be as important as fracture permeability and van Genuchten alpha for water flow and seepage processes under test conditions with relatively high values for water flux (and saturation) in fractures.

Experimental observations from boreholes about $1 \mathrm{~m}$ above the niche ceiling indicate that water-front travel times from the infiltration plots to the niche ceiling are fairly uniform (about 30 days) (DTN: LB0308A8N3TRTM.001 [DIRS 176448]). Simulated water travel time is related to initial matrix saturation because of the matrix imbibition process. Considering the large degree of uncertainty in initial matrix saturation values used in the model, water travel time data were used as "soft" data only. To do so, zero vertical water flux along the columns at locations about $0.4 \mathrm{~m}$ above the ceiling were treated as observed data for a period of 0 to 20 days. Use of these "data" is equivalent to making sure that water travel times are generally larger than 20 days in the model. Since the major purpose of model calibration is to develop a calibrated model for predicting future test results, and considering that a large degree of uncertainty exists about the initial conditions of the model, relatively high weights were given to the seepage-rate data at a later stage of the Phase I test (time $t>90$ day). The inverse modeling approach used by iTOUGH2 V5.0 is based on the classic weighted least-squared method in which the objective function is defined as the sum of the squared weighted residuals where the weighting factor is the inverse of the standard deviations for measurements. In this study, the standard deviations for seepage rates are set to two for times less than 90 days and one for later times, such that measured seepage rates at the later times have larger weights in the objective 
function. (Note that the relative values (rather than absolute values) for the standard deviations matter for the inverse modeling here.)

Matches between the simulated and observed seepage rates associated with different vertical columns are shown in Figure 6.2-2. Fairly good matches were obtained except for a few columns (e.g., Columns 1, 4, and 7). Note that the use of a three-dimensional model to match observed seepage rates at different locations from the niche ceiling is both computationally and conceptually challenging. Figure 6.2-3 shows a comparison between simulated and observed total seepage rate as a function of time. In general, matches shown in the two figures are reasonable. Table 6.2-1 lists calibrated rock properties. DTN: LB0312A8N3MDLG.001 [DIRS 169761] also contains results of linear uncertainty analysis for the calibrated parameters. However, for highly nonlinear unsaturated flow, the linear uncertainty analysis is not reliable, and therefore the analysis results are not documented here. A more detailed discussion of this issue is given in Conceptual Model and Numerical Approaches for Unsaturated Zone Flow and Transport (BSC 2004 [DIRS 170035], Section 6.4.2). The calibrated properties in Table 6.2-1 are generally consistent with the calibrated drift-scale property set (DTNs: LB0208UZDSCPLI.002 [DIRS 161788]; LB0210AMRU0035.002 [DIRS 166712]), and their average values are approximately within the ranges of the calibrated drift-scale properties. The range is defined as the calibrated property value \pm the corresponding standard deviation multiplied by two. For tsw33, the ranges for $\log \left(\right.$ permeability in $\left.\mathrm{m}^{2}\right)$ and $\log (\alpha)(\alpha$ in $\left.\mathrm{Pa}^{-1}\right)$ for the calibrated drift-scale property set are -13.88 to -11.92 and -3.61 to -3.32 , respectively. For the same unit, the averaged $\log \left(\right.$ permeability in $\left.\mathrm{m}^{2}\right)$ and $\log (\alpha)\left(\alpha\right.$ in $\left.\mathrm{Pa}^{-1}\right)$ calculated from Table 6.2-1 are -13.20 and -3.59 , respectively. For tsw34, the ranges for $\log \left(\right.$ permeability in $\left.\mathrm{m}^{2}\right)$ and $\log (\alpha)\left(\alpha\right.$ in $\left.\mathrm{Pa}^{-1}\right)$ for the calibrated drift-scale property set are -14.72 to -11.36 and -3.62 to -2.27 , respectively. For the same unit, the averaged $\log$ (permeability in $\left.\mathrm{m}^{2}\right)$ and $\log (\alpha)\left(\alpha\right.$ in $\left.\mathrm{Pa}^{-1}\right)$ calculated from Table 6.2-1 are -13.12 and -2.93 , respectively. 

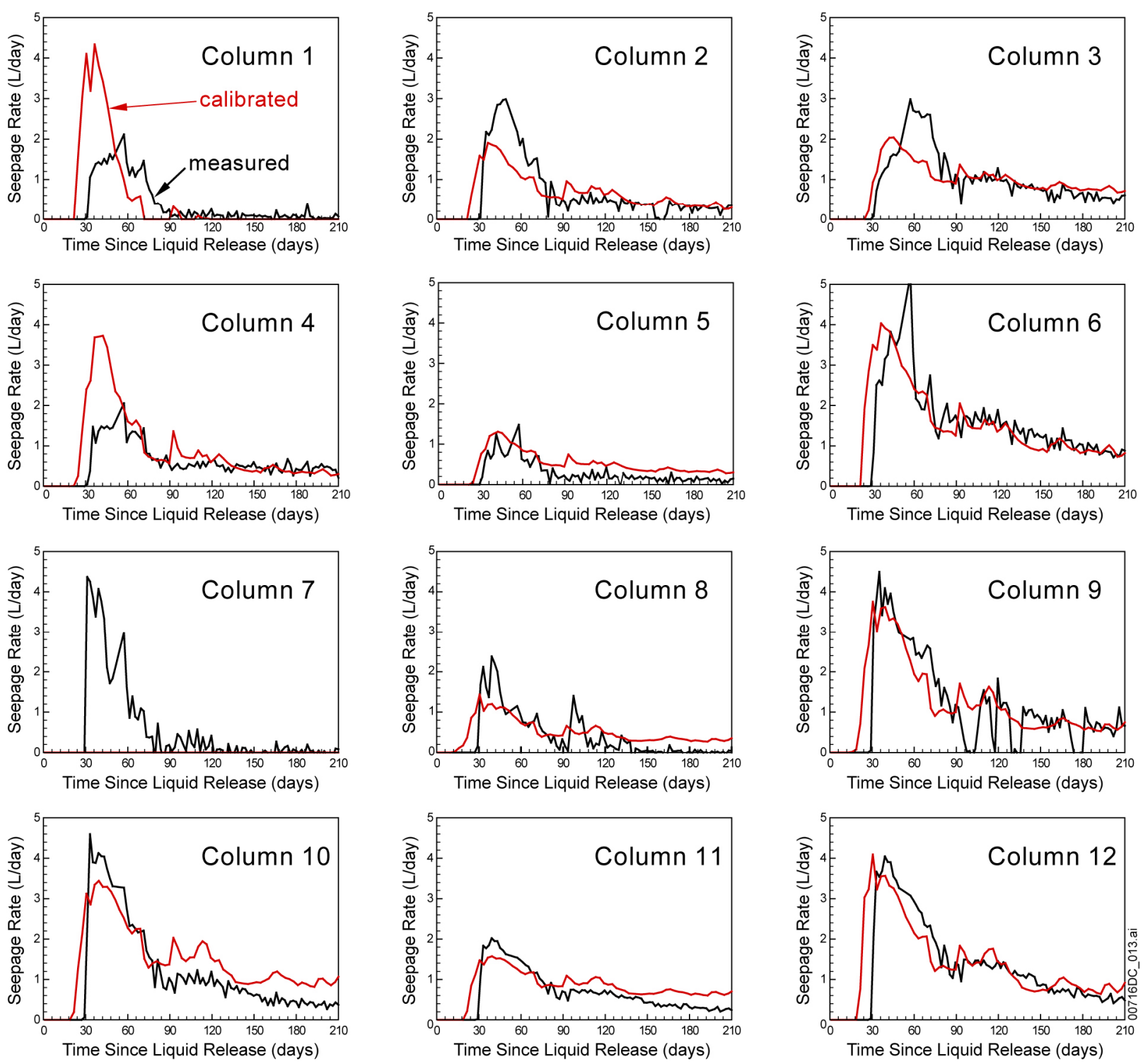

Source: DTN: LB0312A8N3MDLG.001 [DIRS 169761].

Figure 6.2-2. Matches between the Simulated (red) and Observed Seepage Rates (black) Associated with Different Vertical Columns 


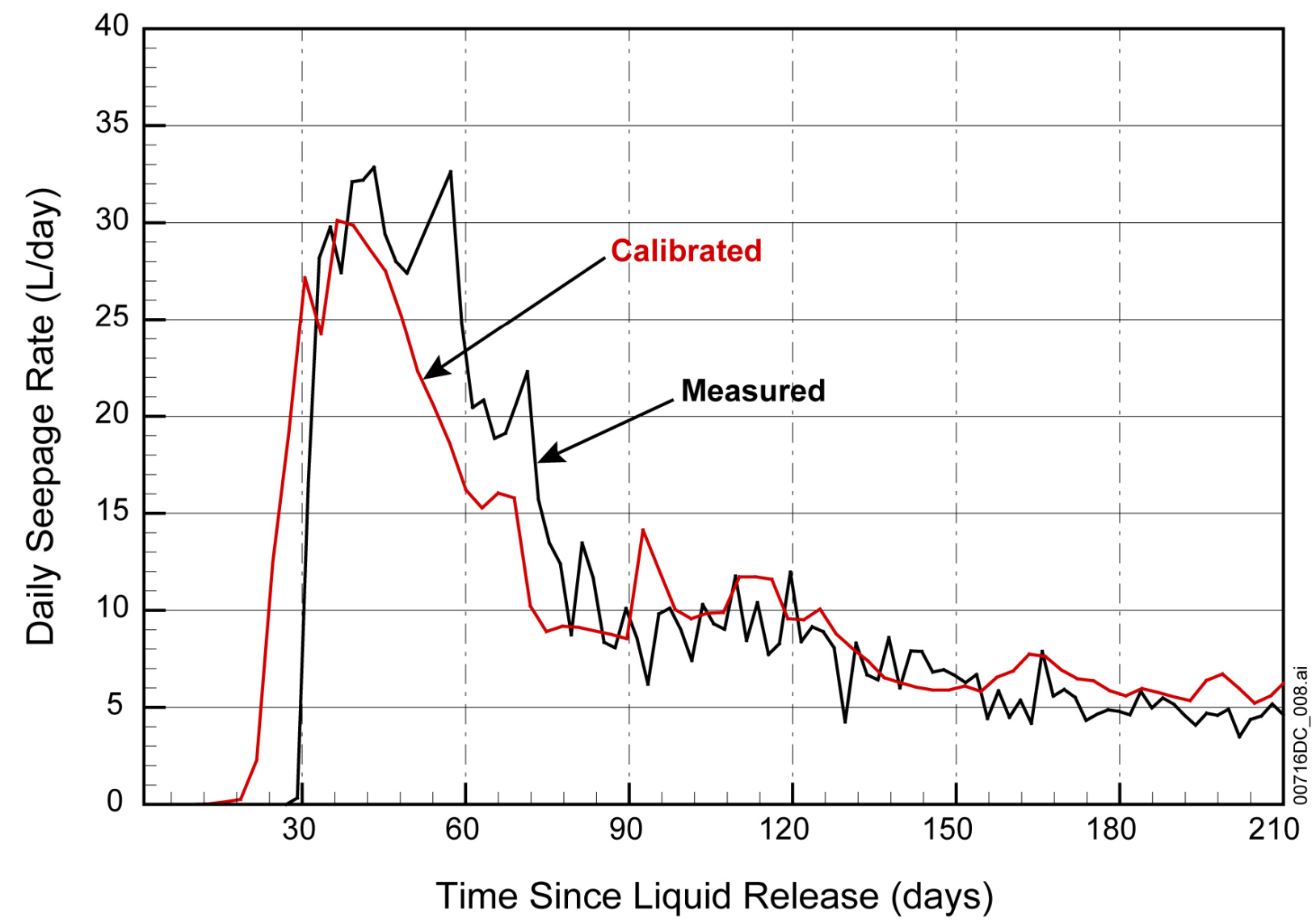

Source: DTN: LB0312A8N3MDLG.001 [DIRS 169761]

Figure 6.2-3. Comparison between Simulated and Observed Total Seepage Rate as a Function of Time 
Table 6.2-1. Calibrated Rock Properties

\begin{tabular}{|c|c|c|c|c|c|}
\hline & Model Layer & $\begin{array}{c}\text { Permeability } \\
\left(\mathrm{m}^{2}\right)\end{array}$ & $\begin{array}{c}\text { van } \\
\text { Genuchten } \\
\alpha\left(\mathrm{Pa}^{-1}\right) \\
\end{array}$ & van Genuchten $m$ & Porosity \\
\hline \multirow{13}{*}{ tsw33 } & Column 1 & $0.9926 \times 10^{-13}$ & \multirow{12}{*}{$0.2453 \times 10^{-3}$} & \multirow{13}{*}{$0.608^{(a)}$} & \multirow{13}{*}{$0.066^{(a)}$} \\
\hline & Column 2 & $0.1685 \times 10^{-12}$ & & & \\
\hline & Column 3 & $0.2959 \times 10^{-13}$ & & & \\
\hline & Column 4 & $0.3146 \times 10^{-13}$ & & & \\
\hline & Column 5 & $0.5569 \times 10^{-13}$ & & & \\
\hline & Column 6 & $0.1845 \times 10^{-13}$ & & & \\
\hline & Column 7 & $0.1314 \times 10^{-13}$ & & & \\
\hline & Column 8 & $0.6757 \times 10^{-13}$ & & & \\
\hline & Column 9 & $0.2470 \times 10^{-13}$ & & & \\
\hline & Column 10 & $0.9786 \times 10^{-13}$ & & & \\
\hline & Column 11 & $0.1864 \times 10^{-12}$ & & & \\
\hline & Column 12 & $0.3332 \times 10^{-13}$ & & & \\
\hline & Rest rock mass & $0.1190 \times 10^{-11}$ & $0.4787 \times 10^{-3}$ & & \\
\hline \multirow{17}{*}{ tsw34 } & Column 1 (upper) & $0.225 \times 10^{-11}$ & $0.5677 \times 10^{-3}$ & \multirow{17}{*}{$0.608^{(\mathrm{a})}$} & \multirow{17}{*}{$0.010^{(a)}$} \\
\hline & Column 2 & $0.704 \times 10^{-12}$ & $0.1480 \times 10^{-2}$ & & \\
\hline & Column 3 & $0.448 \times 10^{-14}$ & $0.1152 \times 10^{-2}$ & & \\
\hline & Column 4 & $0.171 \times 10^{-13}$ & $0.3857 \times 10^{-2}$ & & \\
\hline & Column 5 & $0.304 \times 10^{-14}$ & $0.8647 \times 10^{-3}$ & & \\
\hline & Column 6 (upper) & $0.149 \times 10^{-13}$ & $0.2932 \times 10^{-3}$ & & \\
\hline & Column 7 & $0.434 \times 10^{-11}$ & $0.1891 \times 10^{-2}$ & & \\
\hline & Column 8 & $0.614 \times 10^{-13}$ & $0.3208 \times 10^{-2}$ & & \\
\hline & Column 9 & $0.104 \times 10^{-13}$ & $0.5316 \times 10^{-2}$ & & \\
\hline & Column 10 & $0.616 \times 10^{-14}$ & $0.9825 \times 10^{-3}$ & & \\
\hline & Column 11 (upper) & $0.189 \times 10^{-14}$ & $0.3107 \times 10^{-3}$ & & \\
\hline & Column 12 (upper) & $0.143 \times 10^{-13}$ & $0.2424 \times 10^{-3}$ & & \\
\hline & Rest rock mass & $0.495 \times 10^{-12}$ & $0.7399 \times 10^{-3}$ & & \\
\hline & Column 1 (lower) & $0.5012 \times 10^{-12(a)}$ & $0.1275 \times 10^{-2}$ & & \\
\hline & Column 6 (lower) & $0.5012 \times 10^{-12(a)}$ & $0.2052 \times 10^{-2}$ & & \\
\hline & Column 11 (lower) & $0.5012 \times 10^{-12(a)}$ & $0.2360 \times 10^{-2}$ & & \\
\hline & Column 12 (lower) & $0.5012 \times 10^{-12(a)}$ & $0.1721 \times 10^{-2}$ & & \\
\hline
\end{tabular}

Source: DTN: LB0312A8N3MDLG.001 [DIRS 169761].

(a) These properties are not varied during model calibration.

\subsubsection{Model Prediction}

This subsection documents predictions of future Alcove 8/Niche 3 test results. After about 210 days of ponded release of water to 12 infiltration plots, the test condition was changed on March 24, 2003, such that water was released to plots 2 and 12 only (Section 6.1). These two plots have the largest infiltration rates at the late stage of the ponded water release. Seepage responses to this focused infiltration into plots 2 and 12 are expected to provide information regarding connectivity of flow paths between infiltration plots and individual seepage trays. 
Then the original test condition (ponded release of water to 12 infiltration plots) will be restored. After approximately steady-state infiltration and seepage processes were re-established, different tracers were simultaneously introduced into the infiltrating water applied at different infiltration plots (Table 6.1-1). Table 6.2-2 gives the information regarding tracers to be used. In all the tracer tests, tracer concentrations as a function of time were analyzed for water samples collected at Niche 3.

Seepage rate data collected for the first 210 days (after the large-plot tests started) were used for model calibration (Section 6.2.2). The calibrated model was used to predict test results after the first 210 days. Then, forward simulations using iTOUGH2 V5.0 were performed for predicting seepage rates, and T2R3D V1.4 was used for simulating tracer transport. The dispersion process was ignored in tracer simulations, because the dispersion process is not considered to be important for the similar test conditions (Liu et al. 2003 [DIRS 162470]). Again, following Moridis et al. (2003 [DIRS 161902], Table 1), the tortuosity factor for the tuff matrix is approximated by the corresponding matrix porosity.

Figure 6.2-4 shows simulated total seepage rate. Figure 6.2-5 presents the corresponding (simulated) seepage rates for different vertical rock columns corresponding to individual seepage trays. The model calibration matches observed seepage rates for most rock columns except column 7 (the model calibration gives essentially zero seepage rate for column 7). Shown in Figures 6.2-6 through 6.2-8 are predicted tracer breakthrough curves for different vertical rock columns. These predicted tracer breakthrough curves are also compared with relative tracer concentration measurements determined as the ratio of differences between measured concentration values (Figure 6.1-8) and the background concentration for the given tracer to the difference between the applied tracer concentration values in the infiltration plots (Figure 6.1-8) and the background concentration. Since no breakthrough signal was observed for the first 100 days after the tracer test started, the background concentration for a given tracer was determined as the average measured concentration of seeped water for these 100 days. Note that in pre-test predictions (Figures 6.2-4 to 6.2-8), two phases of tests were assumed. Phase I corresponds to ponding conditions and Phase II to hypothetical future nonponding water-release conditions. Since Phase II was not actually implemented in tests, it will not be discussed in the remainder of this report.

Table 6.2-2. Information for Tracers Used in Phase I Tests

\begin{tabular}{|c|l|c|c|c|}
\hline $\begin{array}{c}\text { Tracer } \\
\text { Number }\end{array}$ & \multicolumn{1}{|c|}{ Tracer Name } & \multicolumn{1}{|c|}{$\begin{array}{c}\text { Molecular Diffusion } \\
\text { Coefficient }\left(\mathbf{m}^{\mathbf{2}} \mathbf{s}\right)\end{array}$} & $\begin{array}{c}\text { Infiltration } \\
\text { Zone Number }\end{array}$ & $\begin{array}{c}\text { Duration of Tests } \\
\text { (days) }\end{array}$ \\
\hline 1 & 2-6-Difluorobenzoic Acid (DFBA) & $8.1 \times 10^{-10}$ & 1 & 55.08 \\
\hline 2 & Potassium lodide & $2.045 \times 10^{-9}$ & 1 & 55.08 \\
\hline 3 & 2,5-Difluorobenzoic Acid (DFBA) & $8.1 \times 10^{-10}$ & 2 & 36.46 \\
\hline 4 & Calcium Bromide & $2.080 \times 10^{-9}$ & 2 & 36.46 \\
\hline 5 & 2,4,5-Trifluorobenzoic Acid (TFBA) & $7.9 \times 10^{-10}$ & 3 & 55.49 \\
\hline 6 & Potassium Fluoride & $1.475 \times 10^{-9}$ & 3 & 55.49 \\
\hline
\end{tabular}

Source: DTN: LB0312A8N3MDLG.001 [DIRS 169761].

NOTE: The matrix diffusion coefficient values refer to those for anions for tracers 2, 4, and 6 . 

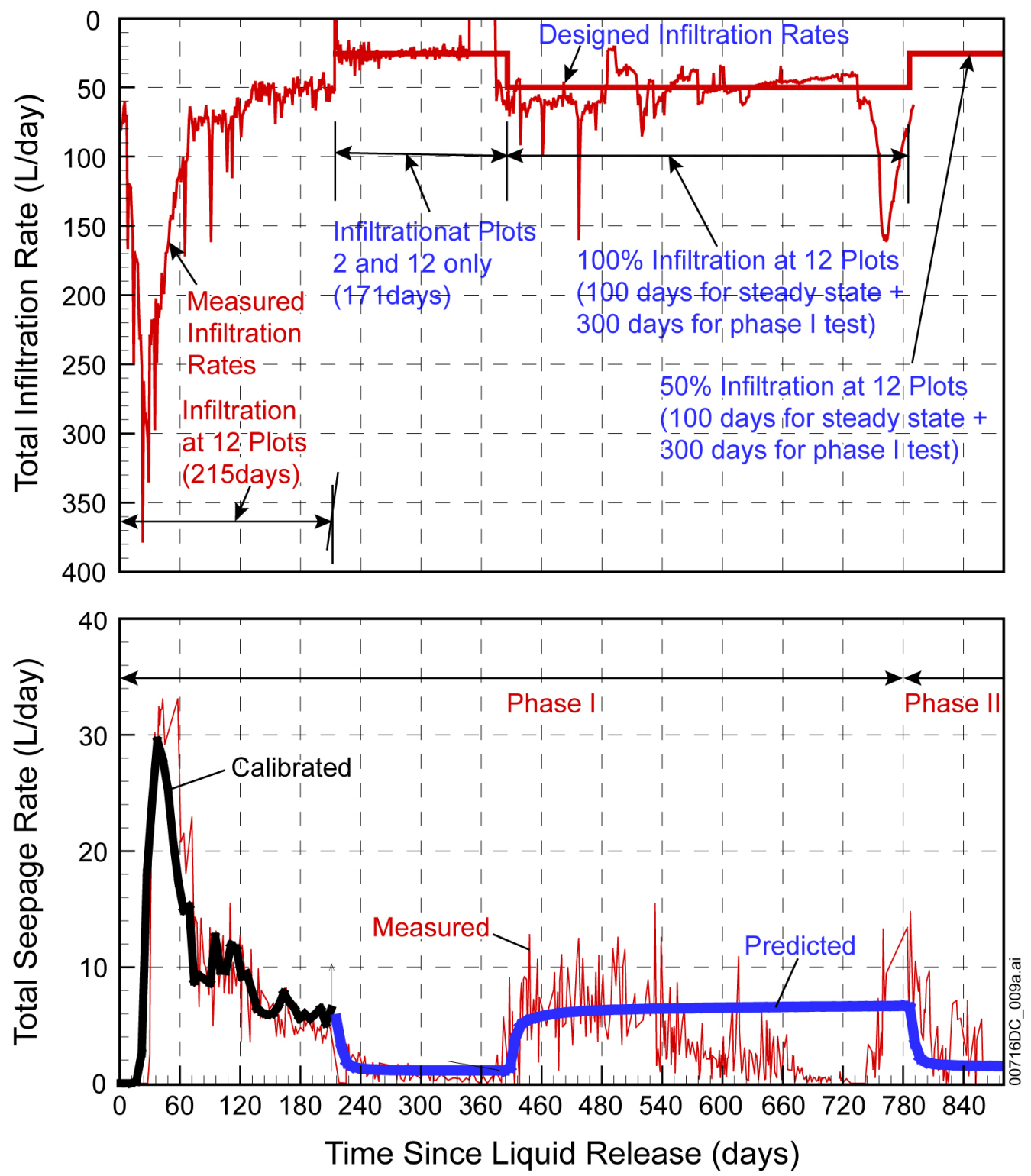

Source: DTNs: LB0312A8N3MDLG.001 [DIRS 169761]; GS040308312242.001 [DIRS 176441]; GS050608312242.003 [DIRS 176442]; GS050408312242.002 [DIRS 176443]; GS050608312242.004 [DIRS 176444]; LB0507A8N3SEEP.001 [DIRS 176445]; LB0507A8N3SEEP.002 [DIRS 176446]; LB0507A8N3SEEP.003 [DIRS 176447]; LB0308A8N3SEEP.001 [DIRS 166090].

NOTE: The observed seepage rate data used for model calibration are also shown here.

Figure 6.2-4. Simulated and Observed Total Seepage Rates 

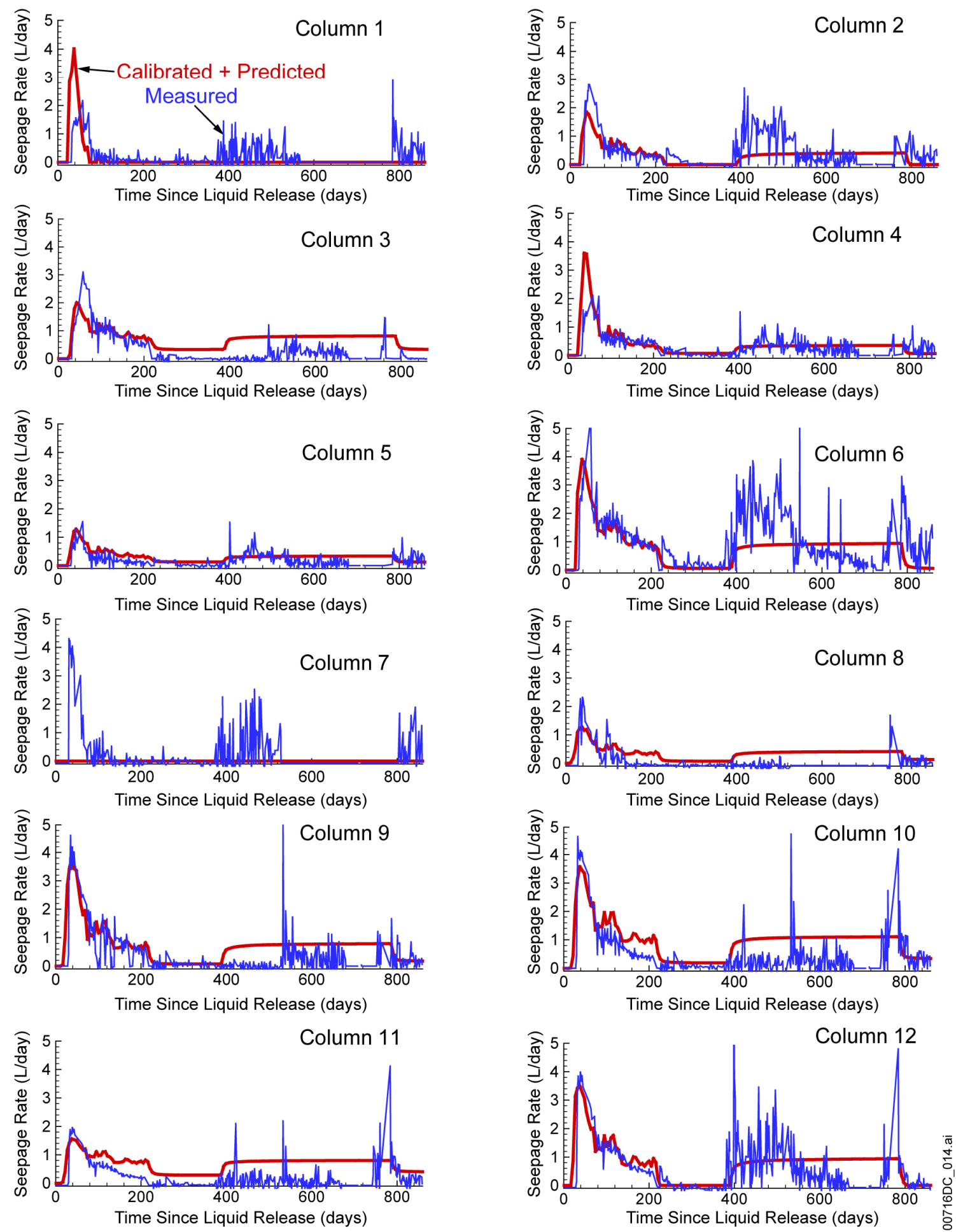

Source: DTNs: LB0312A8N3MDLG.001 [DIRS 169761]; LB0507A8N3SEEP.001 [DIRS 176445]; LB0507A8N3SEEP.002 [DIRS 176446]; LB0507A8N3SEEP.003 [DIRS 176447]; LB0308A8N3SEEP.001 [DIRS 166090].

NOTE: The observed seepage rate data used for model calibration are also shown here.

Figure 6.2-5. Simulated (red) and Observed (blue) Total Seepage Rates for Different Vertical Rock Columns 

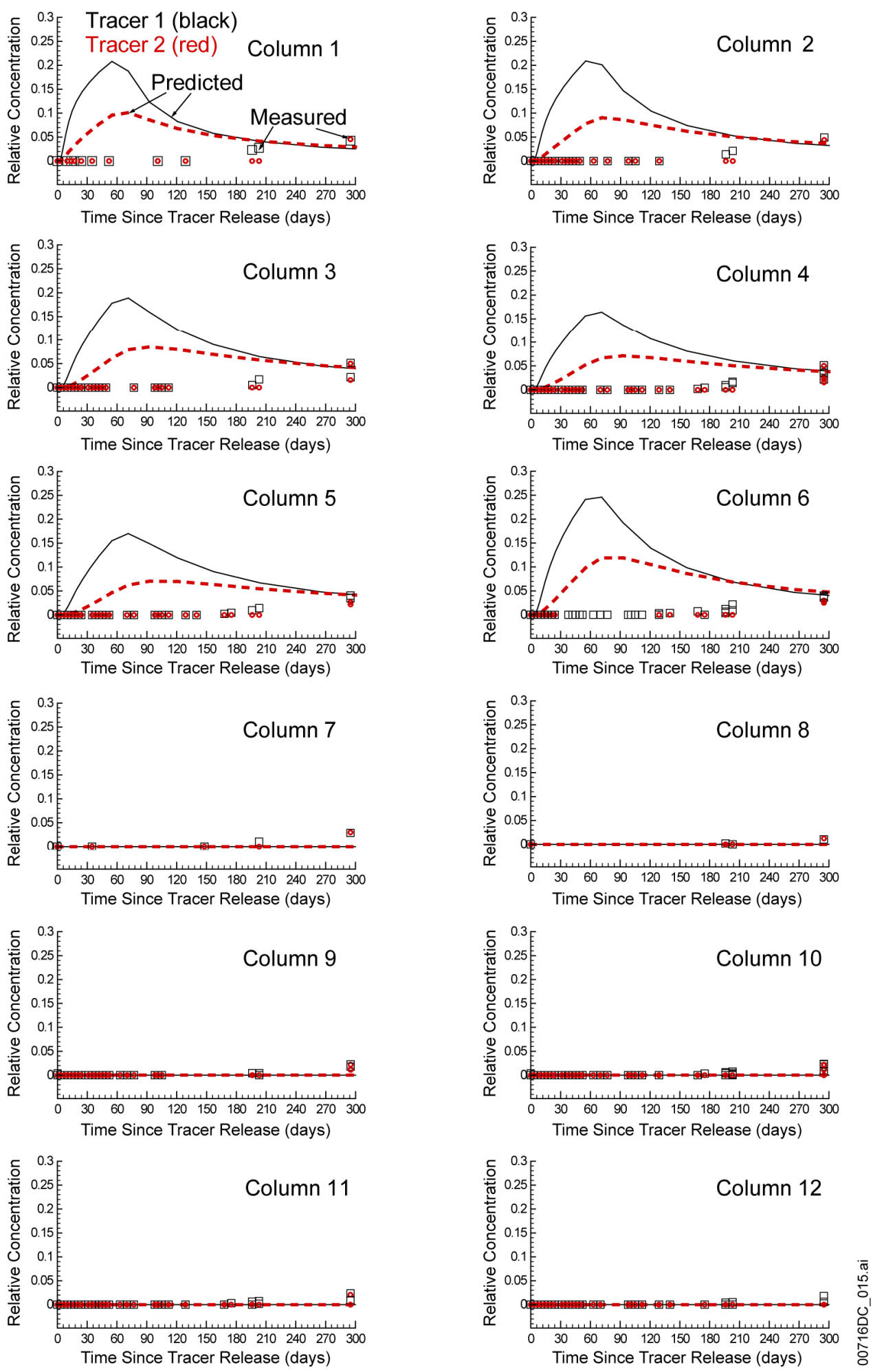

Source: DTNs: LB0312A8N3MDLG.001 [DIRS 169761]; MO0511UCC011JB.002 [DIRS 176334].

NOTE: No tracer concentrations are observed from simulation results for some columns.

Figure 6.2-6. Predicted Tracer Breakthrough Curves and Observed Concentration Data for Tracers 1 and 2 

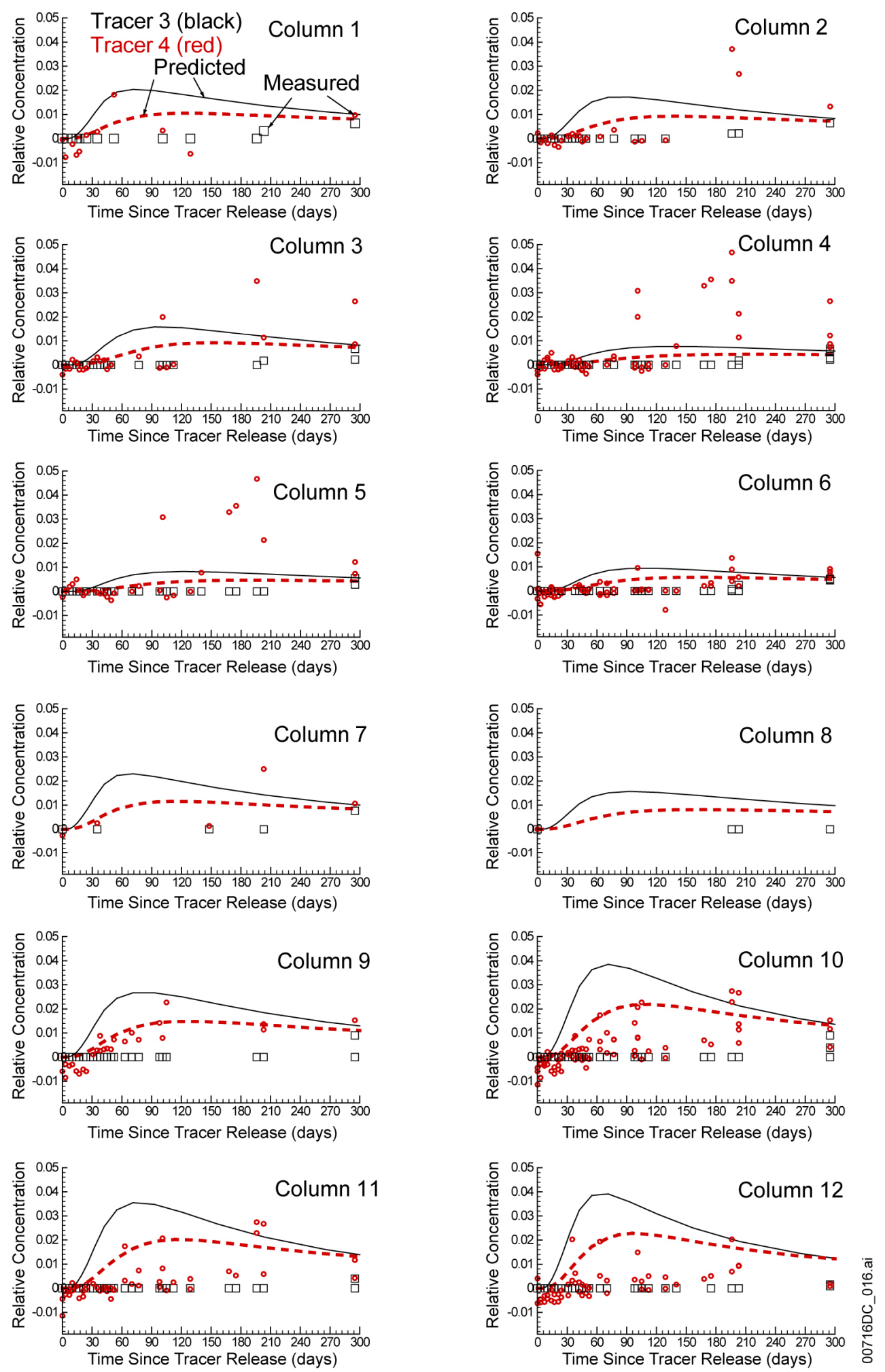

Source: DTNs: LB0312A8N3MDLG.001 [DIRS 169761]; MO0511UCC011JB.002 [DIRS 176334].

Figure 6.2-7. Predicted Tracer Breakthrough Curves and Observed Concentration Data for Tracers 3 and 4 

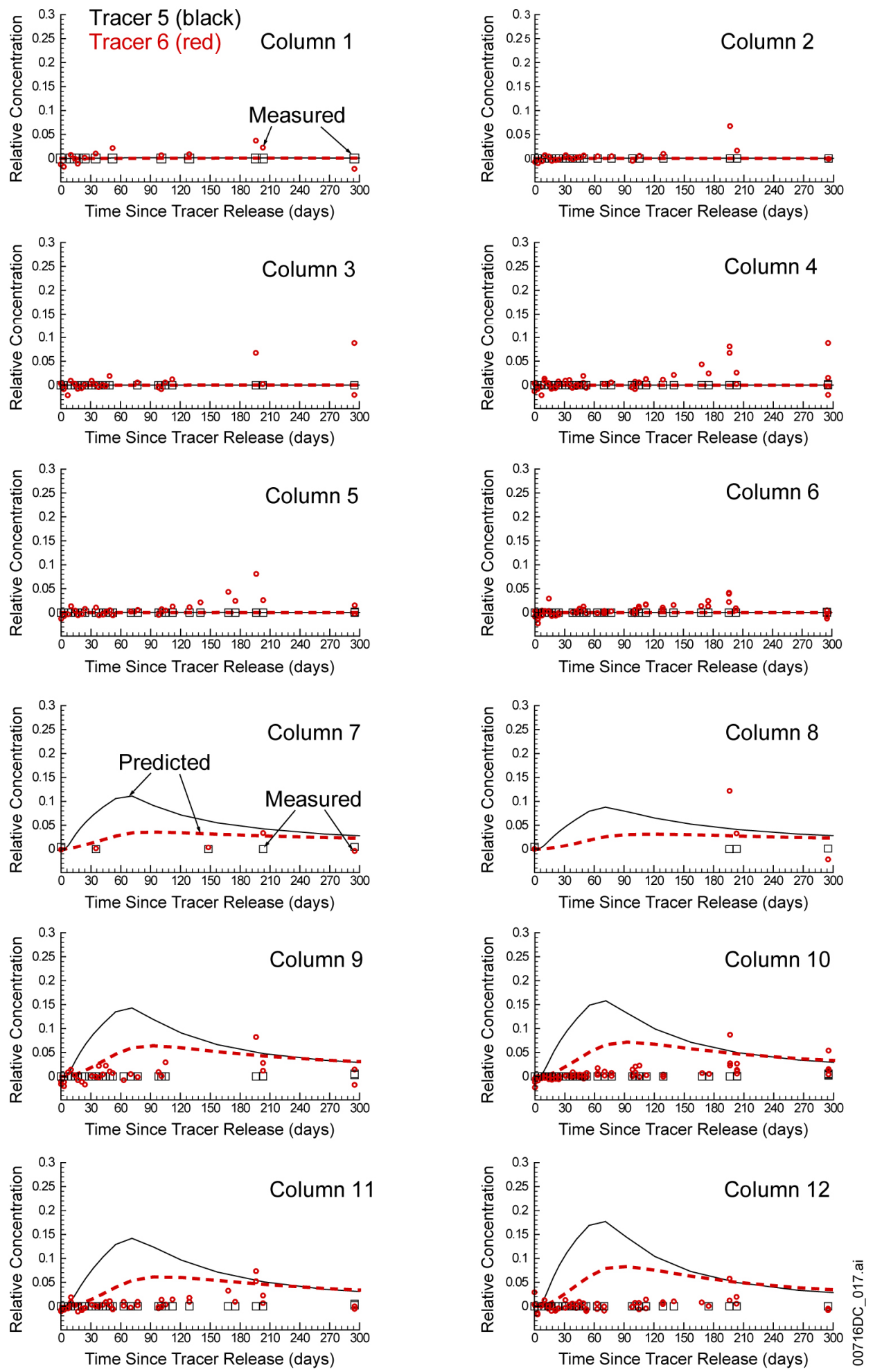

Source: DTNs: LB0312A8N3MDLG.001 [DIRS 169761]; MO0511UCC011JB.002 [DIRS 176334].

NOTE: No tracer concentrations are observed from simulation results for some columns.

Figure 6.2-8. Predicted Tracer Breakthrough Curves and Observed Concentration Data for Tracers 5 and 6 


\subsubsection{Comparison between Predicted and Observed Test Results}

As previously indicated in Section 6.2, a comparison between predicted and observed test results provides a useful way to evaluate the methodology used for modeling UZ flow and transport processes and to improve understanding of physical mechanisms behind those processes in the UZ. This subsection documents such a comparison, with a focus on results for the total seepage rates and tracer breakthrough curves.

During the pre-test prediction, the infiltration rate for each infiltration plot was assumed to be constant and the same as that at the end of the time period for the model calibration. The assumed total infiltration rates are comparable to the observed values before the infiltration plots were scrubbed, although the observation shows a considerable degree of temporal variability (Figures 6.1-4 and 6.2-4). The predicted total seepage rates, on average, are also comparable to the observations before 550 days (Figures 6.1-7 and 6.2-4). However, between day 550 and the time when some infiltration plots were scrubbed, the observed seepage rates are considerably reduced and different from the prediction, whereas the total infiltration rates did not show a significant change compared with those during the time period between 400 to 550 days. (Note that the considerable changes in seepage rates cannot be adequately explained by measurement uncertainties due to possible evaporation and the other effects.) In particular, observed seepage rates essentially became zero from 680 to 740 days, although no significant drop in infiltration rate was observed during the same time period. This discrepancy highlights the complexity of flow processes at the test site and the difficulties in model interpretation of the test results. One possible explanation is that there were some in-filled materials or dust particles (due to construction of Alcove 8) in fractures. Initially, these particles below the Alcove 8 floor were close to infiltration plots, which is why there was a significant temporal variability in infiltration rate at the early stage of the tests (Figure 6.1-4). These moving particles were then pushed downstream by infiltrating water and far away from the infiltration plots. This can explain why the observed infiltration rates were stabilized between 400 to 700 days. When these moving particles were close to Niche 3, they might have had important effects on flow structures near the ceiling of the niches and considerably reduced the seepage rates. Obviously, the model was not able to handle the effects of moving particles, resulting in the discrepancy between observed and simulated seepage rates. Also note that if the above reasoning is valid, the particle effects should be localized during 680 to 740 days, when the seepage rate was significantly reduced, because they are close to Niche 3. These arguments are consistent with a recent laboratory and field study of particle transport in unsaturated fractured rock by Weisbrod et al. (2002 [DIRS 177044]). They concluded that particle deposition controls the flow channel's structure and therefore varies the flow rates through the fracture, and large particles may accumulate near the water table due to the air-water-interface trapping mechanism. Note that the similar trapping mechanism exists above the ceiling of Niche 3 , as a result of high fracture water saturation above the ceiling owing to capillary-barrier effects.

Predicted and observed tracer-transport results are significantly different. To make a meaningful comparison, the possible mechanisms behind the observations must be understood. The observed concentration distributions from seeping water at Niche 3 consist of two stages (Figure 6.1-8). At the first stage between the time when the tracers were injected and about 740 days, when an infiltration pulse occurred as a result of scrubbing infiltration plots, essentially no tracer breakthrough was observed. The second stage corresponds to the time 
period between 740 days and the end of the tests, when effects of the infiltration pulses on seepage were observed. At this stage, reliable tracer breakthrough signals were observed for tracers introduced from Zone 1 ( $\mathrm{I}^{-}$and 2,6 DFBA). Breakthrough signals for the other tracers are not considered reliable, based on the following two considerations: First, there might be a significant measurement error for low concentrations (on the order of $0.1 \mathrm{ppm}$ ) of organic tracers 2,4,5 DFBA and/or 2,5 DFBA. For example, the measured concentrations of 2,4,5 DFBA before the tracer injection are on the same order of magnitude of the observed concentration at later times (Figure 6.1-8), while the tracer concentration before the injection is supposed to be zero. Second, no obvious breakthrough signals were observed for the inorganic tracers $\left(\mathrm{F}^{-}\right.$and $\left.\mathrm{Br}^{-}\right)$ that were simultaneously injected into the same infiltration plots with the two organic tracers mentioned above. The tracers introduced from Zone 1 ( $\mathrm{I}^{-}$and 2,6 DFBA) do not have those problems. On the other hand, the tracer breakthrough signals were observed right after the infiltration pulse from Zone 1 as a result of scrubbing infiltration plots. The mechanisms for tracer transport related to the observed breakthrough signals are not entirely clear at this time. There are two possible interpretations for these signals. The biofilms near the infiltration plots (Zone 1) might (chemically and/or physically) adsorb a certain amount of tracers (especially organic tracers). During the scrubbing, the films were disturbed, resulting in the release of the tracers. The tracers were then transported to Niche 3 along relatively fast flow paths, owing to the significant increase in infiltration rate in Zone 1 after the scrubbing. Another possible interpretation is related to the changes in flow paths during the tests as a result of particle movement. During the tracer application period, some flow paths (with tracers) stopped conducting water, leaving the traced water in some dead zones while new flow paths started to conduct water. The infiltration pulse resulting from the scrubbing might have made the "dead" flow paths active again and washed the "entrapped" traced water into Niche 3. Nevertheless, it is difficult to meaningfully model these observed tracer breakthrough signals for $\mathrm{I}^{-}$and 2,6 DFBA, because the amount of tracers (contributing to the signals) and tracer locations before the scrubbing are unknown.

Based on the above discussion, a comparison is made between the pre-test prediction and observed results for tracer transport (between the time when the tracers were injected and about 740 days into the test when an infiltration pulse occurred as a result of scrubbing infiltration plots). Essentially no concentrations of the applied tracers (excluding the background concentrations) were observed during the time period, while considerable concentrations for different tracers as a function of time are predicted. An important reason for this discrepancy is that matrix diffusion may be underestimated in the pre-test prediction. Model analyses of test results based on the conceptual understanding of the test data (discussed in this subsection) and the related uncertainties will be further discussed in sections to follow.

\subsection{MODELING ANALYSES OF TEST RESULTS}

As previously discussed in Section 6.2.2, the seepage data collected at an early stage of the tests were used to calibrate the initial version of the numerical model used for the pre-test predictions of the subsequent tests. To better understand the flow and transport processes at the test sites and obtain more representative site-specific rock properties, it is necessary to calibrate the model with additional data that became available subsequently. This subsection documents the model calibration with all the infiltration and seepage data. Two different conceptual models for water 
flow at the test site were considered. The sensitivity study on tracer transport was performed using the calibrated models.

\subsubsection{Model Calibration with All the Available Infiltration and Seepage Data}

The model developed in Section 6.2 was refined by further model calibrations using all the infiltration and seepage data. Observed flow and transport data at the test site exhibit very complex features (such as a large degree of temporal variability in seepage rate) that provide a significant challenge for model calibration.

To deal with uncertainties resulting from such complexities, different conceptual models were explored in the model calibration process. The base-case conceptual model is the same as that used for the pre-test prediction and considered flow paths from all the infiltration plots to be connected to the ceiling of Niche 3. However, during the testing period, when infiltrating water was applied to plots 2 and 12 only, the observed seepage rates are close to zero (Figure 6.1-6). Therefore, it is possible that only a small amount of water from these two infiltration plots contributed to seepage rates observed from Niche 3. The alternative conceptual model is that flow paths from infiltration plots 2 and 12 did not contribute to the seepage into Niche 3 . To implement this conceptual model, zero infiltration rates were used for the two plots when simulating the seepage into the niche.

Model calibration procedures were the same as those described in Section 6.2.2, except that the entire infiltration rate and seepage rate data collected in the whole test period were used for each conceptual model. Matches between simulated and observed seepage rates and calibrated properties are presented in Figures 6.3-1 (output DTN: LB0602A8N3FTR0.001, file: SrunAflowci.tec) and 6.3-2 (output DTN: LB0602A8N3FTR0.001, file: tryli.tec), and Tables 6.3-1 (output DTN: LB0602A8N3FTR0.001, file: SrunAflowci.par) and 6.3-2 (output DTN: LB0602A8N3FTR0.001, file: tryli.par), respectively. Given the complexity of the problem, matches are considered fairly reasonable. Different conceptual models give generally similar matches (especially for the total seepage rates), although the base-case conceptual model gives a better match. This highlights the need to develop multiple conceptual models for test-result interpretation, because the use of different conceptual models with the similar matches can cover a relatively large range of flow behavior, and therefore may be able to better capture (or bound) the actual flow processes. 

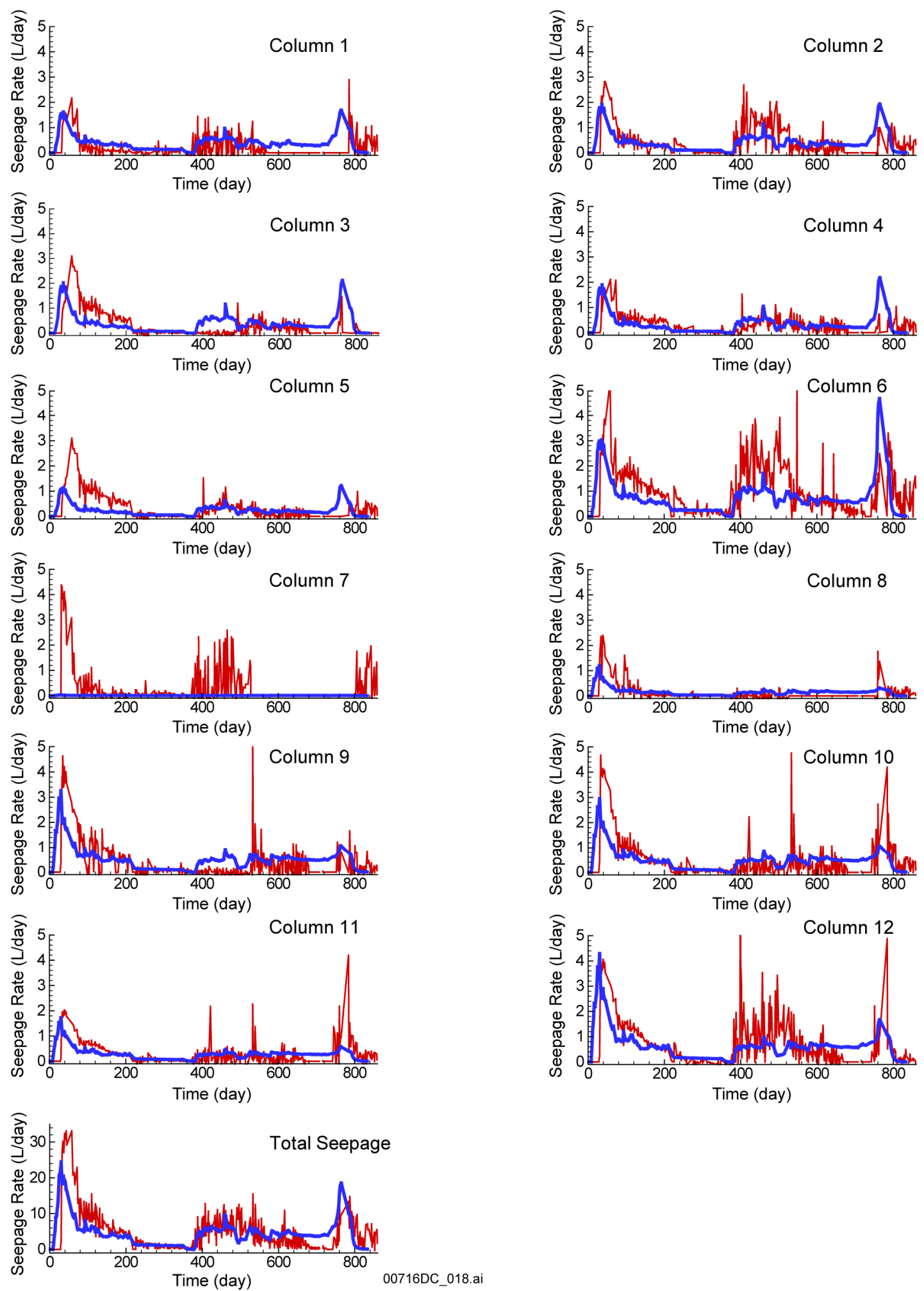

Source: Output DTN: LB0602A8N3FTR0.001.

Figure 6.3-1. Matches between Simulated (blue) and Observed (red) Seepage Rates for the Base-Case Conceptual Model 

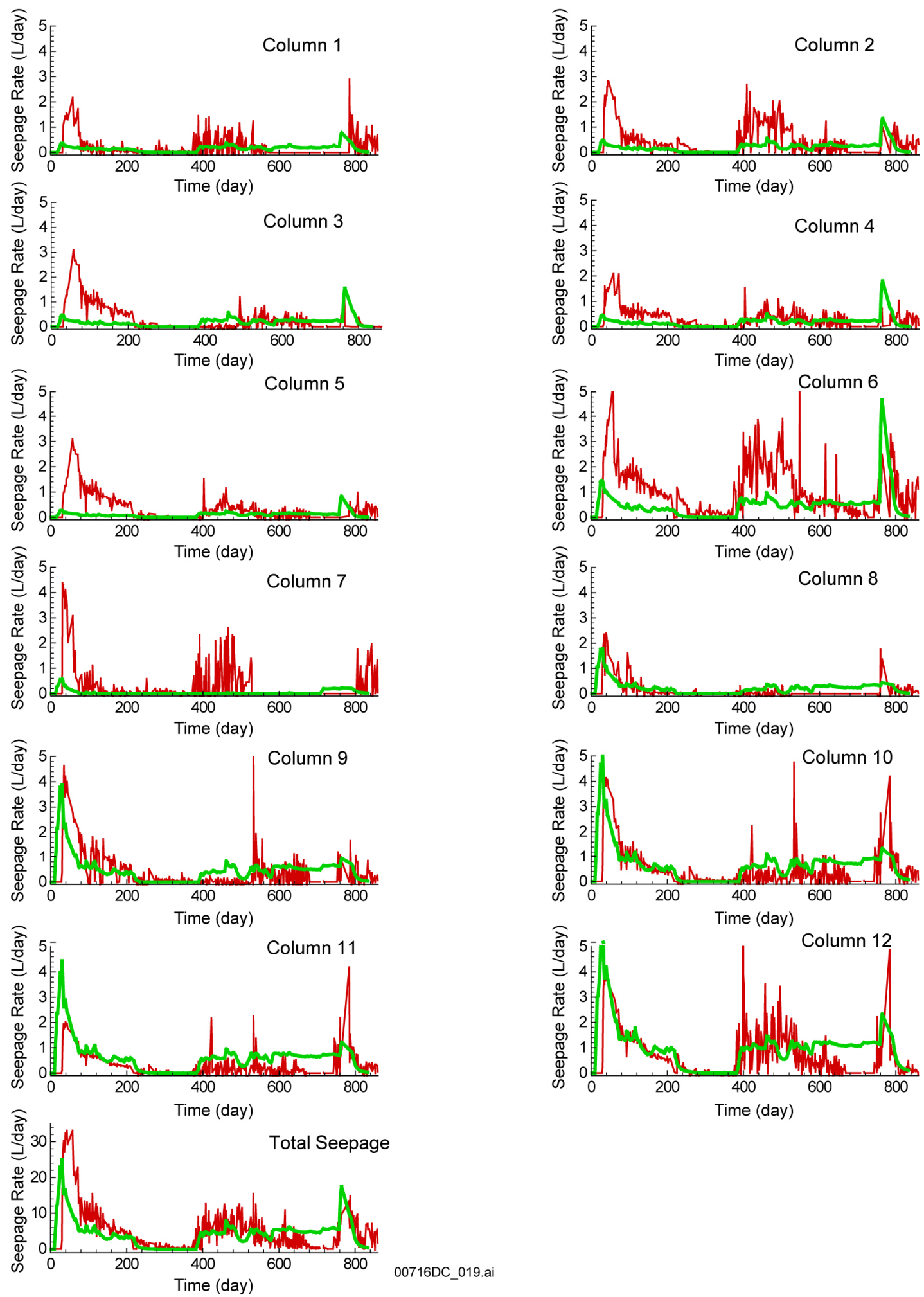

Source: Output DTN: LB0602A8N3FTR0.001.

Figure 6.3-2. Matches between Simulated (green) and Observed (red) Seepage Rates for the Alternative Conceptual Model 
The calibrated property sets are generally similar for the two different conceptual models (Tables 6.3-1 and 6.3-2). They are also comparable to the properties calibrated based on the data collected at the early stage of the test (Table 6.2-1), although the latter calibrated properties exhibit a slightly larger degree of heterogeneity in terms of fracture permeability. The calibrated property sets discussed in this section should give more accurate estimates of site-specific properties because more infiltration and seepage data were used. The differences between calibrated properties here and those in Table 6.2-1 may also be a result of rock property changes owing to the particle movement in the test site. Matrix properties used here and in the next section are not varied during model calibration, and are the same as those calibrated from the fault tests (DTN: LB0303A8N3MDLG.001 [DIRS 162773]; BSC 2004 [DIRS 169861], Table 7.6-1). The calibrated properties in Tables 6.3-1 and 6.3-2 are generally consistent with the calibrated drift-scale property set (DTNs: LB0208UZDSCPLI.002 [DIRS 161788]; LB0210AMRU0035.002 [DIRS 166712]), and their average values are within the ranges of the calibrated drift-scale properties. Again, the range is defined as the calibrated property value \pm the corresponding standard deviation multiplied by two. For tsw33, the ranges for $\log \left(\right.$ permeability in $\left.\mathrm{m}^{2}\right)$ and $\log (\alpha)\left(\alpha\right.$ in $\left.\mathrm{Pa}^{-1}\right)$ for the calibrated drift-scale property set are 13.55 to -11.92 and -3.48 to -3.45 , respectively. For the same unit, the averaged $\log \left(\right.$ permeability in $\left.\mathrm{m}^{2}\right)$ and $\log (\alpha)\left(\alpha\right.$ in $\left.\mathrm{Pa}^{-1}\right)$ are -12.89 and -3.45 for Table $6.3-1$, and -13.06 and -3.19 for Table $6.3-2$, respectively. For tsw34, the ranges for $\log \left(\right.$ permeability in $\mathrm{m}^{2}$ ) and $\log (\alpha)\left(\alpha\right.$ in $\left.\mathrm{Pa}^{-1}\right)$ for the calibrated drift-scale property set are -13.09 to -11.12 and -2.87 to 2.00 , respectively. For the same unit, the averaged $\log \left(\right.$ permeability in $\left.\mathrm{m}^{2}\right)$ and $\log (\alpha)\left(\alpha\right.$ in $\left.\mathrm{Pa}^{-1}\right)$ are -12.06 and -2.46 for Table $6.3-1$, and -12.39 and -2.67 for Table $6.3-2$, respectively.

One common discrepancy between observed and simulated seepage rates is that relatively uniform seepage-rate distributions are simulated between 500 and 740 days as a result of a relatively stabilized infiltration-rate distribution, while during the same time period a significant temporal variability of seepage rate was observed. In particular, observed seepage rates essentially become zero from 680 to 740 days, although no significant drop in infiltration rate was observed during the same period. This issue was discussed in Section 6.2.4 and is discussed further in Section 6.4.2. Also note that this discrepancy is not expected to have a significant effect on the calibrated property sets because the time period associated with occurrence of the discrepancy is relatively short compared with the whole test period. 
Table 6.3-1. Calibrated Rock Properties for the Base-Case Conceptual Model

\begin{tabular}{|c|c|c|c|c|c|}
\hline & Model Layer & $\begin{array}{c}\text { Permeability } \\
\left(\mathrm{m}^{2}\right)\end{array}$ & $\begin{array}{c}\text { van Genuchten } \\
\alpha\left(\mathrm{Pa}^{-1}\right)\end{array}$ & van Genuchten m & Porosity \\
\hline \multirow{13}{*}{ tsw33 } & Column 1 & $0.2130 \times 10^{-12}$ & \multirow{12}{*}{$0.3571 \times 10^{-3}$} & \multirow{13}{*}{$0.608^{(a)}$} & \multirow{13}{*}{$0.066^{(a)}$} \\
\hline & Column 2 & $0.3615 \times 10^{-12}$ & & & \\
\hline & Column 3 & $0.6305 \times 10^{-13}$ & & & \\
\hline & Column 4 & $0.6750 \times 10^{-13}$ & & & \\
\hline & Column 5 & $0.1368 \times 10^{-12}$ & & & \\
\hline & Column 6 & $0.3960 \times 10^{-13}$ & & & \\
\hline & Column 7 & $0.2820 \times 10^{-13}$ & & & \\
\hline & Column 8 & $0.1450 \times 10^{-12}$ & & & \\
\hline & Column 9 & $0.5300 \times 10^{-13}$ & & & \\
\hline & Column 10 & $0.2100 \times 10^{-12}$ & & & \\
\hline & Column 11 & $0.4000 \times 10^{-12}$ & & & \\
\hline & Column 12 & $0.7150 \times 10^{-13}$ & & & \\
\hline & Rest rock mass & $0.1190 \times 10^{-11}$ & $0.3348 \times 10^{-3}$ & & \\
\hline \multirow{17}{*}{ tsw34 } & Column 1 (upper) & $0.7533 \times 10^{-11}$ & $0.2389 \times 10^{-2}$ & \multirow{17}{*}{$0.608^{(a)}$} & \multirow{17}{*}{$0.010^{(a)}$} \\
\hline & Column 2 & $0.9784 \times 10^{-12}$ & $0.2835 \times 10^{-2}$ & & \\
\hline & Column 3 & $0.3828 \times 10^{-11}$ & $0.6123 \times 10^{-2}$ & & \\
\hline & Column 4 & $0.2359 \times 10^{-11}$ & $0.5478 \times 10^{-2}$ & & \\
\hline & Column 5 & $0.8830 \times 10^{-12}$ & $0.3529 \times 10^{-2}$ & & \\
\hline & Column 6 (upper) & $0.6338 \times 10^{-12}$ & $0.1352 \times 10^{-2}$ & & \\
\hline & Column 7 & $0.8061 \times 10^{-13}$ & $0.5055 \times 10^{-2}$ & & \\
\hline & Column 8 & $0.7105 \times 10^{-12}$ & $0.3774 \times 10^{-2}$ & & \\
\hline & Column 9 & $0.1138 \times 10^{-11}$ & $0.3369 \times 10^{-2}$ & & \\
\hline & Column 10 & $0.4032 \times 10^{-12}$ & $0.2189 \times 10^{-2}$ & & \\
\hline & Column 11 (upper) & $0.6838 \times 10^{-12}$ & $0.2016 \times 10^{-2}$ & & \\
\hline & Column 12 (upper) & $0.1557 \times 10^{-11}$ & $0.1398 \times 10^{-2}$ & & \\
\hline & Rest rock mass & $0.1326 \times 10^{-11}$ & $0.1398 \times 10^{-2}$ & & \\
\hline & Column 1 (lower) & $0.5012 \times 10^{-12(a)}$ & $0.1000 \times 10^{-1}$ & & \\
\hline & Column 6 (lower) & $0.5012 \times 10^{-12(a)}$ & $0.6408 \times 10^{-2}$ & & \\
\hline & Column 11 (lower) & $0.5012 \times 10^{-12(a)}$ & $0.4187 \times 10^{-2}$ & & \\
\hline & Column 12 (lower) & $0.5012 \times 10^{-12(a)}$ & $0.9854 \times 10^{-2}$ & & \\
\hline
\end{tabular}

Source: Output DTN: LB0602A8N3FTR0.001.

(a) These properties are not varied during model calibration. 
Table 6.3-2. Calibrated Rock Properties for the Alternative Conceptual Model

\begin{tabular}{|c|c|c|c|c|c|}
\hline & Model Layer & $\begin{array}{c}\text { Permeability } \\
\left(\mathrm{m}^{2}\right)\end{array}$ & $\begin{array}{c}\text { van } \\
\text { Genuchten } \\
\alpha\left(\mathrm{Pa}^{-1}\right)\end{array}$ & van Genuchten m & Porosity \\
\hline \multirow{13}{*}{ tsw33 } & Column 1 & $0.1396 \times 10^{-12}$ & \multirow{12}{*}{$0.5873 \times 10^{-3}$} & \multirow{13}{*}{$0.608^{(a)}$} & \multirow{13}{*}{$0.066^{(\mathrm{a})}$} \\
\hline & Column 2 & $0.2370 \times 10^{-12}$ & & & \\
\hline & Column 3 & $0.4163 \times 10^{-13}$ & & & \\
\hline & Column 4 & $0.4425 \times 10^{-13}$ & & & \\
\hline & Column 5 & $0.8968 \times 10^{-13}$ & & & \\
\hline & Column 6 & $0.2596 \times 10^{-13}$ & & & \\
\hline & Column 7 & $0.1849 \times 10^{-13}$ & & & \\
\hline & Column 8 & $0.9505 \times 10^{-13}$ & & & \\
\hline & Column 9 & $0.3474 \times 10^{-13}$ & & & \\
\hline & Column 10 & $0.1377 \times 10^{-12}$ & & & \\
\hline & Column 11 & $0.2622 \times 10^{-12}$ & & & \\
\hline & Column 12 & $0.4687 \times 10^{-13}$ & & & \\
\hline & Rest rock mass & $0.1224 \times 10^{-11}$ & $0.2287 \times 10^{-2}$ & & \\
\hline \multirow{17}{*}{ tsw34 } & Column 1 (upper) & $0.1497 \times 10^{-12}$ & $0.1821 \times 10^{-2}$ & \multirow{17}{*}{$0.608^{(a)}$} & \multirow{17}{*}{$0.010^{(\mathrm{a})}$} \\
\hline & Column 2 & $0.2796 \times 10^{-12}$ & $0.2719 \times 10^{-2}$ & & \\
\hline & Column 3 & $0.4060 \times 10^{-12}$ & $0.4776 \times 10^{-2}$ & & \\
\hline & Column 4 & $0.2304 \times 10^{-12}$ & $0.4114 \times 10^{-2}$ & & \\
\hline & Column 5 & $0.8821 \times 10^{-13}$ & $0.2982 \times 10^{-2}$ & & \\
\hline & Column 6 (upper) & $0.4008 \times 10^{-12}$ & $0.1653 \times 10^{-2}$ & & \\
\hline & Column 7 & $0.2448 \times 10^{-12}$ & $0.2042 \times 10^{-2}$ & & \\
\hline & Column 8 & $0.7955 \times 10^{-12}$ & $0.2295 \times 10^{-2}$ & & \\
\hline & Column 9 & $0.2874 \times 10^{-11}$ & $0.2428 \times 10^{-2}$ & & \\
\hline & Column 10 & $0.6997 \times 10^{-12}$ & $0.1472 \times 10^{-2}$ & & \\
\hline & Column 11 (upper) & $0.2642 \times 10^{-11}$ & $0.1425 \times 10^{-2}$ & & \\
\hline & Column 12 (upper) & $0.4687 \times 10^{-13}$ & $0.5873 \times 10^{-3}$ & & \\
\hline & Rest rock mass & $0.4704 \times 10^{-12}$ & $0.4233 \times 10^{-3}$ & & \\
\hline & Column 1 (lower) & $0.5012 \times 10^{-12(a)}$ & $0.1000 \times 10^{-2}$ & & \\
\hline & Column 6 (lower) & $0.5012 \times 10^{-12(a)}$ & $0.6059 \times 10^{-2}$ & & \\
\hline & Column 11 (lower) & $0.5012 \times 10^{-12(a)}$ & $0.5175 \times 10^{-2}$ & & \\
\hline & Column 12 (lower) & $0.5012 \times 10^{-12(a)}$ & $0.3911 \times 10^{-2}$ & & \\
\hline
\end{tabular}

Source: Output DTN: LB0602A8N3FTR0.001.

(a) These properties are not varied during model calibration.

\subsubsection{Sensitivity Study of Tracer Transport}

The calibrated flow fields were used as input to tracer transport simulations performed with T2R3D V1.4. The simulation procedure is the same as that used for pre-test prediction. The molecular diffusion coefficients for the tracer shown in Table 6.2-2 were employed in the simulations. Based on analyses of the relevant diffusion experiment results, Moridis et al. (2003 [DIRS 161902], Table 1) reported that the tortuosity factor for the tuff matrix could be approximated by the corresponding matrix porosity. Like the pre-test predictions, this 
approximation is followed in this study. The effective diffusion coefficient for the matrix diffusion process is the product of the molecular diffusion coefficient and tortuosity factor. In addition to the effective matrix diffusion coefficients calculated using the above procedure, a set of increased coefficients was also used in this sensitivity study. In the modeling interpretation of tracer transport in Alcove 8/Niche 3 fault tests, UZ Flow Models and Submodels (BSC 2004 [DIRS 169861], Section 7.6) reported the need to increase effective matrix diffusion coefficients by 45 times to match the experiment observations. The increased coefficient for a given tracer is therefore determined by multiplying the original effective diffusion coefficient by a factor of 45 . As discussed in Section 6.2.4, the focus of this sensitivity study is on comparisons between simulated tracer transport results and those observations before the infiltration pulse resulting from scrubbing infiltration plots. Figures 6.3-3 through 6.3-5 show simulated breakthrough curves at Niche 3 for different tracers and the two different conceptual models. The simulated maximum concentrations monitored at Niche 3 for increased matrix diffusion coefficients are presented in Table 6.3-3. Shown in these figures and the table are the relative concentrations that, for a given tracer, are defined as the simulated tracer concentrations divided by the applied tracer concentrations (at the infiltration plots) averaged over the application period. The breakthrough curves shown in Figures 6.3-3 through 6.3-5 are qualitatively similar to those from pre-test predictions (Figures 6.2-6 through 6.2-8). The differences come from changes in flow fields as a result of recalibration. Again, while essentially no concentrations of the applied tracer (excluding the background concentrations) were observed during the time period before the infiltration pulse, considerable concentrations for different tracers as a function of time are simulated. Table 6.3-3 (output DTN: LB0602A8N3FTR0.001, file: HdfcasePeakConcv2.xls) shows very small (essentially zero) peak concentration values that are consistent with experiment observations, although the factor of 45 used here is not necessarily the optimum value for the problem under consideration. (Note that, as discussed in Section 6.2.4, the comparisons between simulated and observed tracer concentration are made only for the time period before the infiltration pulse due to scrubbing infiltration plots.) 

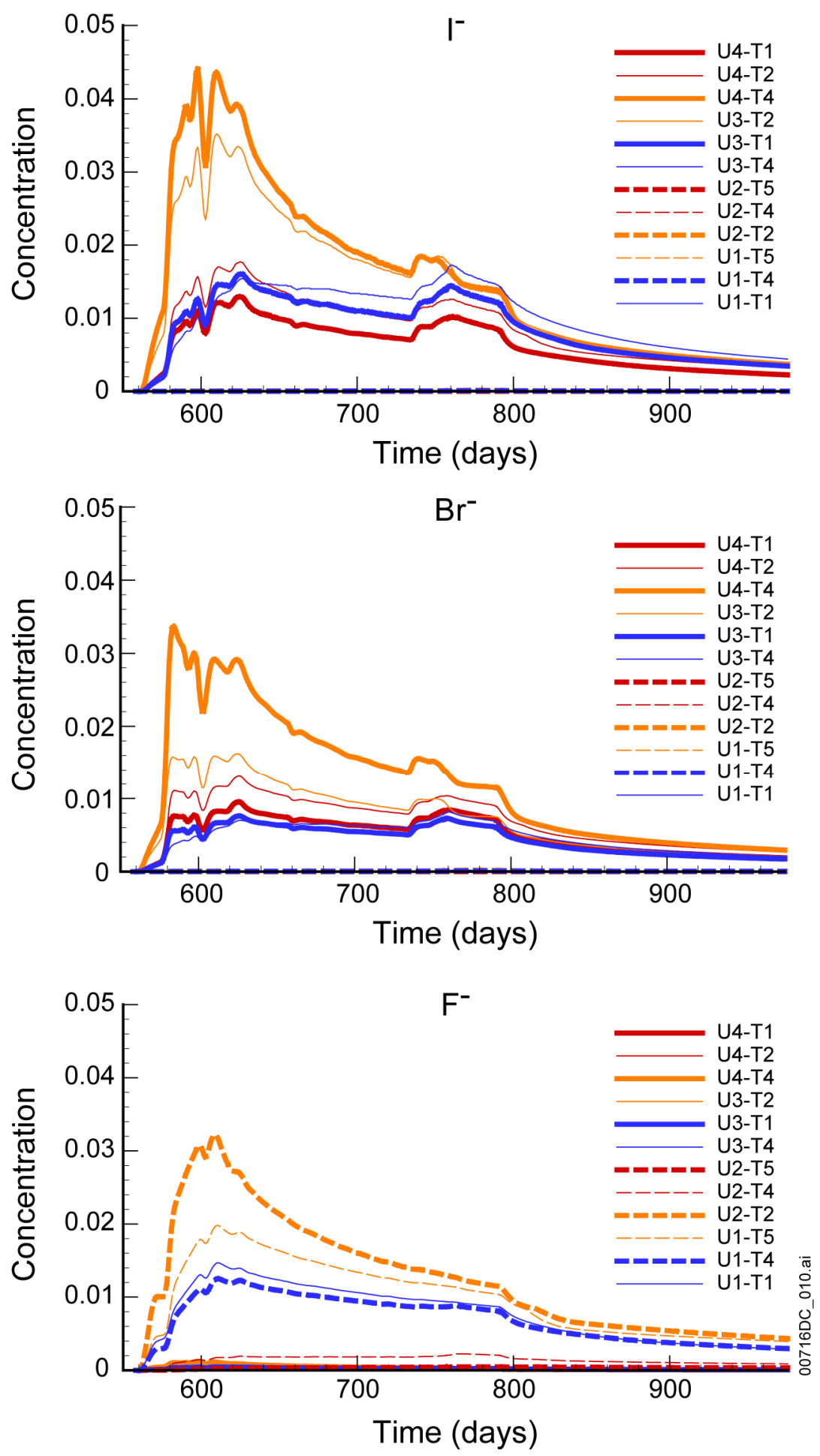

Source: Output DTN: LB0602A8N3FTR0.001.

NOTE: The concentration refers to the relative concentrations that, for a given tracer, are defined as the simulated tracer concentrations divided by the applied tracer concentrations (at the infiltration plots) averaged over the application period.

Figure 6.3-3. Simulated Tracer Breakthrough Curves at Niche 3 without Using the Increased Matrix Diffusion Coefficients for the Base-Case Flow Conceptual Model (Inorganic Tracers) 

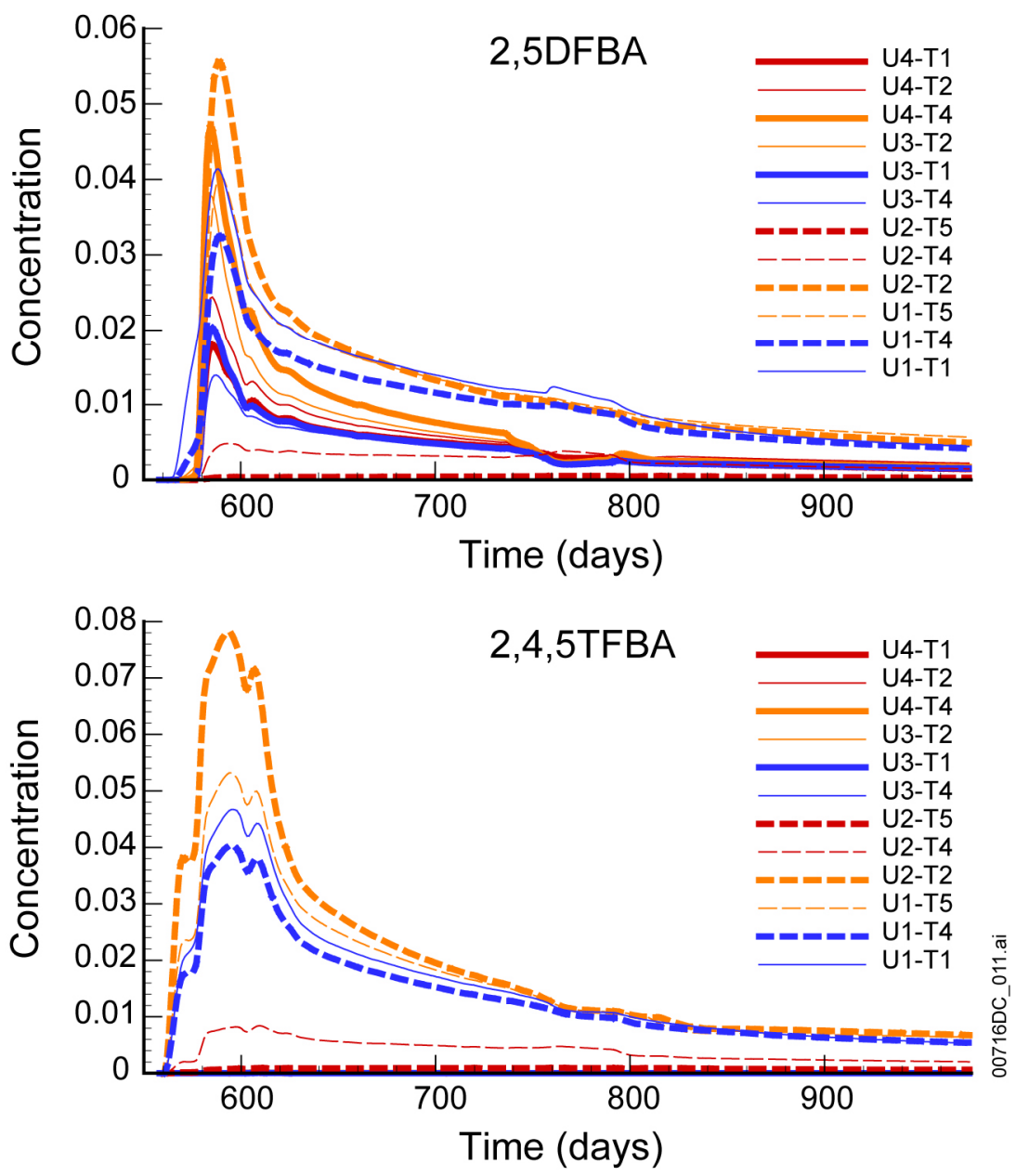

Source: Output DTN: LB0602A8N3FTR0.001.

NOTE: The concentration refers to the relative concentrations that, for a given tracer, are defined as the simulated tracer concentrations divided by the applied tracer concentrations (at the infiltration plots) averaged over the application period.

Figure 6.3-4. Simulated Tracer Breakthrough Curves at Niche 3 without Using the Increased Matrix Diffusion Coefficients for the Base-Case Flow Conceptual Model (Organic Tracers) 

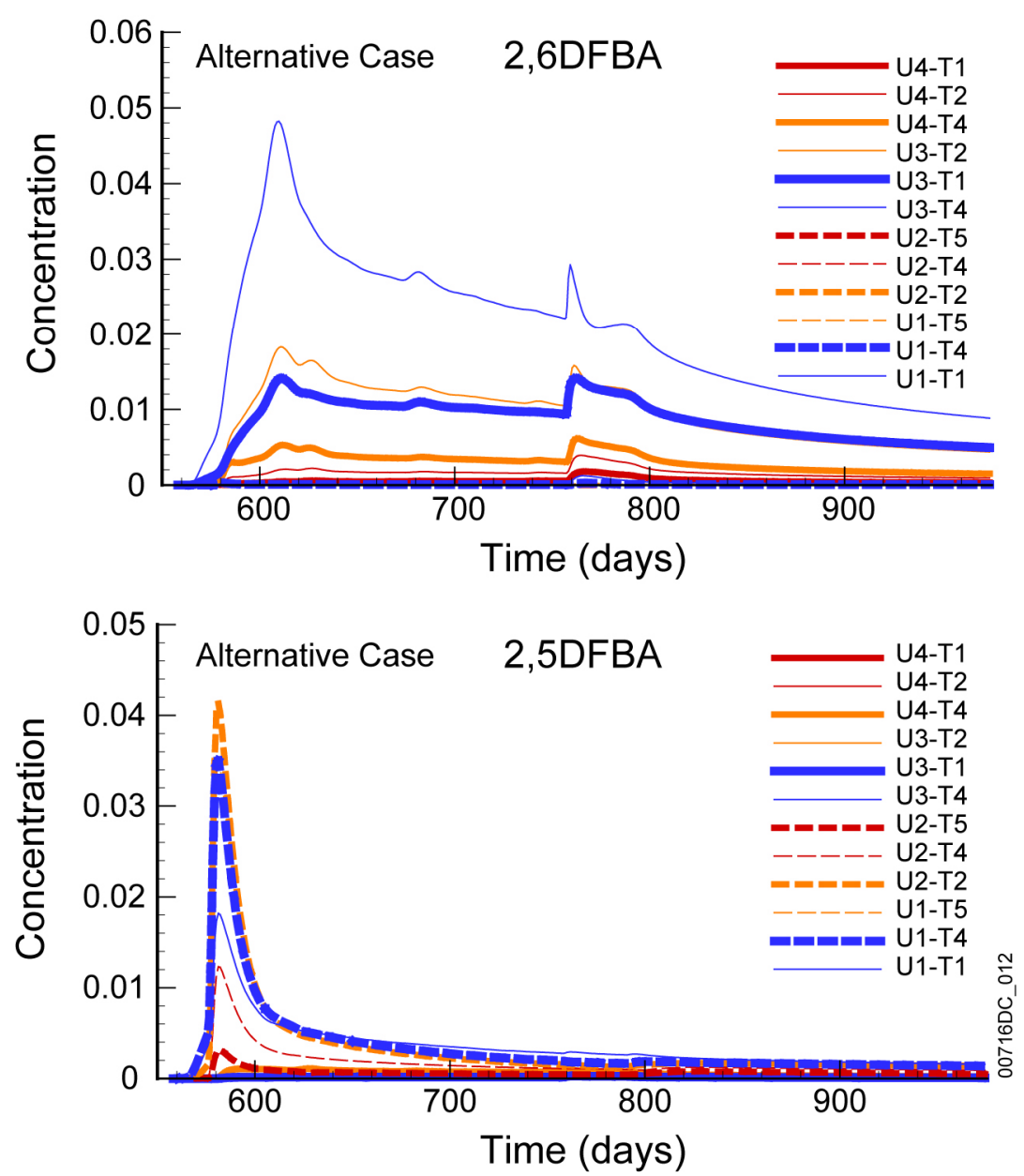

Source: Output DTN: LB0602A8N3FTR0.001.

NOTE: The concentration refers to the relative concentrations that, for a given tracer, are defined as the simulated tracer concentrations divided by the applied tracer concentrations (at the infiltration plots) averaged over the application period.

Figure 6.3-5. Simulated Tracer Breakthrough Curves at Niche 3 without Using the Increased Matrix Diffusion Coefficients for the Alternative Flow Conceptual Model

For the original matrix diffusion coefficients, full breakthrough curves for 2,6 DFBA (for the base-case conceptual model) and for 2,4,5 TFBA (for the alternative conceptual model) could not be obtained from simulations, because the time steps (automatically adjusted by T2R3D V1.4) are so small that it is practically impossible to obtain the full breakthrough curves within a reasonable time period (output DTN: LB0602A8N3FTR0.001, files: Trun3dtracer26DFBqaLargeIteration_out and try1Trun3dtracer245TFBAqaLargeIteration_outFeb17; Lu 2006 [DIRS 176702], pp. 44 and 45). Therefore, they are not presented in Figures 6.3-3 through 6.3-5. From the available simulation results, the maximum simulated relative concentrations are 0.13 for 2,6 DFBA and 0.16 for $2,4,5$ TFBA (Lu 2006 [DIRS 176702], pp. 46 and 48) and considerably higher than the observations, which is consistent with the comparisons discussed above for the case without using the increased matrix diffusion coefficient. 
For the alternative conceptual model, only the organic tracers were used in simulations because they have smaller matrix diffusion coefficients than those for inorganic tracers. For a given zone (Table 6.2-2), a smaller diffusion coefficient is expected to give a higher peak concentration value, as demonstrated in Figures 6.3-3 and 6.3-4. Since the purpose here is to show the conditions under which tracer concentrations are so low that they might not be detected in practice, it is adequate to simulate tracers with lower diffusions only (for a given zone). It also should be noted that the discussed relation between the peak concentration and diffusion coefficient is not always observed from Table 6.3-3 for the base-case conceptual model. This is because the simulated tracer concentrations are so low that round-off errors in the simulations may considerably impact the simulation results, which, however, does not change the finding that the increased matrix diffusion coefficient is needed to explain the field observation.

Table 6.3-3. Simulated Peak (Relative) Concentrations Monitored at Niche 3 for the Increased Matrix Diffusion Coefficients

\begin{tabular}{|c|c|c|}
\hline Tracer & Base-Case Conceptual Model & Alternative Conceptual Model \\
\hline $\mathrm{I}^{-}$ & $1.60 \times 10^{-4}$ & - \\
\hline $\mathrm{Br}^{-}$ & $7.30 \times 10^{-6}$ & - \\
\hline $\mathrm{F}^{-}$ & $7.14 \times 10^{-5}$ & - \\
\hline $2,6 \mathrm{DFBA}$ & $1.71 \times 10^{-3}$ & $1.17 \times 10^{-4}$ \\
\hline $2,5 \mathrm{DFBA}$ & $6.05 \times 10^{-5}$ & $2.37 \times 10^{-3}$ \\
\hline $2,4,5$ DFBA & $3.98 \times 10^{-6}$ & $1.04 \times 10^{-3}$ \\
\hline
\end{tabular}

Source: Output DTN: LB0602A8N3FTR0.001.

\subsection{DISCUSSIONS}

Modeling analysis of the Alcove 8/Niche 3 test provides an important opportunity to improve the current understanding of UZ flow and transport at the Yucca Mountain site, although a considerable degree of uncertainty remains. While a number of issues related to the tests and modeling analyses have been touched on in previous subsections, this subsection documents further discussions of the test and modeling results and their implications.

\subsubsection{Effective Matrix Diffusion Coefficient and Its Enhancement}

The comparison of observed and simulated test results (Section 6.3) suggests that the use of a small-scale matrix diffusion coefficient underestimates the retardation of tracer transport at the test site. The effective matrix diffusion coefficient (molecular diffusion coefficient in free water multiplied by matrix tortuosity) is a key parameter for describing matrix diffusion that generally results in retardation. Matrix diffusion refers to solute transport from fracture networks into the surrounding matrix blocks resulting from molecular diffusion (Neretnieks 1993 [DIRS 123099], pp. 47 to 48). Mass transfer between fractures and the tuff matrix plays an important role in transport within the UZ. Because the flow velocity in the matrix is much slower than in fractures, transfer of tracer from fractures to the matrix can significantly retard overall tracer transport. 
This result is consistent with findings from a number of studies published in the literature (Shapiro 2001 [DIRS 162132]; Neretnieks 2002 [DIRS 162140]; Liu et al. 2003 [DIRS 162470]; BSC 2004 [DIRS 169861], Section 7.6). Effective matrix-diffusion-coefficient values have been estimated from a number of field test sites characterized by different rock types. Neretnieks (2002 [DIRS 162140]) reported matches to tracer test data collected from the Äspö site with a test scale of $5 \mathrm{~m}$ and found a need for a factor 30 times larger for the fracture-matrix interface area (or effective matrix-diffusion coefficient) than expected. Note that the increase in fracture-matrix interface area is equivalent to the increase in effective diffusion coefficient (for a given interface area in a model). Interestingly, Neretnieks (2002 [DIRS 162140]) also indicated that nine other research groups had also independently evaluated the tracer test data from the site using different modeling approaches. Nearly all the groups found the need for a factor 30 to 50 times larger effective fracture-matrix interface area (or effective matrix-diffusion coefficient) than expected.

Liu et al. (2003 [DIRS 162470]) and UZ Flow Models and Submodels (BSC 2004 [DIRS 169861], Section 7.6) presented model analyses of two different sets of field test data, collected in the unsaturated zone of Yucca Mountain. Unlike studies reported by other researchers mentioned in this subsection, Liu et al. (2003 [DIRS 162470]) and UZ Flow Models and Submodels (BSC 2004 [DIRS 169861], Section 7.6) matched both the flow field (characterized by water travel time and/or seepage into subsurface openings) and tracer breakthrough curves. They reported that increased fracture-matrix interface areas (or effective matrix diffusion coefficients) were needed for both tests.

Becker and Shapiro (2000 [DIRS 169947]) and Shapiro (2001 [DIRS 162132]) reported analyses of tracer test data from fractured crystalline rock at the Mirror Lake site. Becker and Shapiro (2000 [DIRS 169947]) showed that laboratory measurement of the effective diffusion coefficient should be replaced by the coefficient in free water to match the bromide data in their Test $\mathrm{C}$ with a test scale of about $36 \mathrm{~m}$. However, they were not able to match all the breakthrough curves for different tracers, and argued that advective transport processes contribute to this discrepancy. An alternative explanation may be that a simple model used by those authors cannot capture all the importance processes (such as effects of subsurface heterogeneity), even when matrix diffusion is a dominant process. Shapiro (2001 [DIRS 162132]) found that matrix diffusion coefficient values three to five orders of magnitude greater than the estimates of the matrix diffusion coefficient from laboratory experiments were needed to match the tracer data observed at a kilometer scale. His analysis probably provides the first estimate for kilometer-scale effective diffusion coefficient.

In the studies mentioned above, the matrix diffusion coefficients were estimated by fitting the observed breakthrough curves, which generally involves a certain degree of parameter uncertainty due to the non-uniqueness of the curve-fitting procedure. Most recently, Lofgren and Neretnieks (2004 [DIRS 176479]) reported directly measured in situ formation factor values (for two boreholes in a fractured rock test site) as compared with lab measurements for rock samples. (The formation factor is proportional to the matrix diffusion coefficient.) The measurement was based on the Einstein analogy between molecular diffusion and ionic mobility, and the formation factor was estimated from measured electrical conductivity data. As indicated in their study (Lofgren and Neretnieks 2004 [DIRS 176479], Figures 3 and 4, Table 1), the in situ formation factor (or effective matrix diffusion coefficient) values are larger than those measured from rock 
matrix sample or measurement intervals (within the boreholes) without connecting to a fracture network. Lofgren and Neretnieks (2004 [DIRS 176479]) also suggested that increased formation factors result from the existence of open, but hydraulically non-conducting fractures containing immobile water that acts as a preferential diffusion path.

Enhancement of the effective matrix diffusion coefficient reported in this study is also consistent with study results in the saturated zone near the Yucca Mountain site. Two crosshole tracer tests involving the simultaneous injection of different tracers with different molecular diffusion coefficients were conducted in two different intervals at the C-wells complex near the Yucca Mountain site (Reimus et al. 2003 [DIRS 162950]). The test scale (the distance between injection and monitoring boreholes) is on the order of $30 \mathrm{~m}$. Transport parameters were estimated from the test results. In the original analysis by Reimus et al. (2003 [DIRS 162950]), a dimensionless parameter (combining effects of molecular diffusion coefficient, fracture aperture, and matrix porosity), rather than effective matrix diffusion coefficient, was estimated from fitting the test results. Values for the ratio of the effective matrix diffusion coefficient to the coefficient determined from rock matrix samples are determined using these estimated flow and transport parameters (Reimus et al. 2003 [DIRS 162950]), and by assuming intervals of flow channels observed from the corresponding boreholes to be the same as the spacing of conductive fractures (Appendix A). These ratios range from 5 to about 8, indicating the possible enhancement of effective matrix diffusion coefficient for the test site.

A number of researchers have attempted to explain why the effective matrix diffusion coefficient determined from field data is larger than the corresponding laboratory value (Shapiro 2001 [DIRS 162132]; Neretnieks 2002 [DIRS 162140]; Liu et al. 2003 [DIRS 162470]; BSC 2004 [DIRS 169861], Section 7.6). Shapiro (2001 [DIRS 162132]) suggested that kilometer-scale "effective matrix diffusion" is not a diffusive process, but actually an advective process between high and low permeability zones, resulting in a significantly large "effective diffusion coefficient." While this may be a plausible explanation, further confirmation is still needed. For example, Liu et al. (2003 [DIRS 162470]; see also BSC 2004 [DIRS 169861], Section 7.6) used a dual-permeability model involving both fast flow in fractures and slow flow in the matrix (as well as the advective transport between the two) and still found the need to use increased effective diffusion coefficients for matching the tracer test data. Neretnieks (2002 [DIRS 162140]) argued that existence of fracture in-filling creates relatively large areas for solute to diffuse into rock matrix, which, together with the process of diffusion into stagnant water, contributes to the need for increasing the effective diffusion coefficient to match the data. Wu et al. (2001 [DIRS 156399]) and Liu et al. (2003 [DIRS 162470]) indicated that the existence of many small-scale fractures (which considerably increase the fracture-matrix interface area, but are not considered in numerical models) may be the major reason for the relatively large effective diffusion coefficient calculated from field data. Lofgren and Neretnieks (2004 [DIRS 176479]) also suggested that the observed enhancement of effective matrix diffusion coefficient results from the existence of open, but hydraulically nonconducting fractures containing immobile water that acts as a preferential diffusion path.

It is very likely that the enhancement is due to a combination of different mechanisms (including those mentioned above). The major mechanism may be the complexity of flow path geometry in a fracture network that is largely ignored in the current modeling practices. Water flow in a single flow path (or channel) has often been simplified as a flow process within a single straight 
fracture (e.g., Neretnieks 2002 [DIRS 162140]). In reality, however, flow structure is more complicated, owing to the complexity of fracture-network geometry. Percolation models (that study network connectivity and characteristics of cluster structures) provide more realistic representation of flow-path geometry (e.g., Stauffer and Aharony 1994 [DIRS 160846]; Renshaw 1999 [DIRS 169853]). For example, a two-dimensional statistically isotropic bond percolation network at the percolation threshold (Renshaw 1999 [DIRS 169853]) is shown in Figure 6.4-1. A bond can be considered as a single fracture within a fracture network. At percolation threshold, a network forms a single connected path from the inlet (top) to the outlet (bottom), as shown by heavy links in Figure 6.4-1. Obviously, the backbone (consisting of heavy links) corresponds to an individual major flow path in a fracture network. The backbone has some useful features. For example, not all the bonds on the backbones are singly connected. It is clear from Figure 6.4-1 (or other figures for bond percolation) that the singly connected segments are often separated by structures which contain several routes in parallel that are called loops by Stauffer and Aharony (1994 [DIRS 160846]). As previously indicated, bonds in Figure 6.4-1 can be considered as individual fractures (Renshaw 1999 [DIRS 169853]). Therefore, these loops are also major features for flow pathways in fracture networks, as demonstrated, for example, by Liu et al. (2002 [DIRS 160230]).

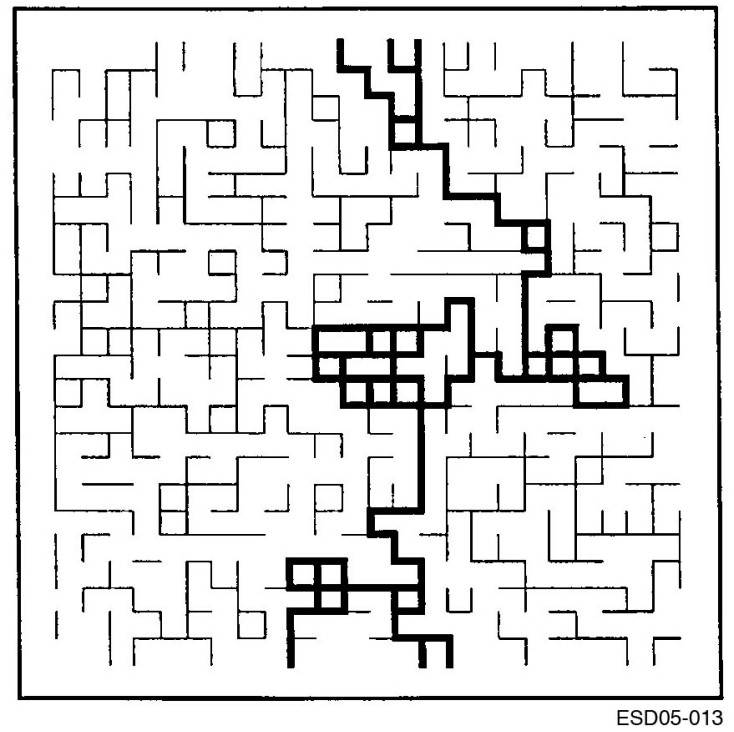

NOTE: The heavy links correspond to the backbone.

Figure 6.4-1. Two-Dimensional Bond Percolation Network at the Percolation Threshold (after Renshaw 1999 [DIRS 169853]).

These flow loops would significantly increase fracture-matrix interface area (affecting matrix diffusion calculation), compared with a simplified model treating a flow path as a straight fracture. In some cases, this simplified model also gives estimated fracture aperture values much larger than expected (Appendix A). This is simply because a flow path consists of a group of fractures, rather than a single straight fracture, while the latter is actually used in determining flow and transport parameters from test observations. 
It needs to be emphasized that the above discussion is valid only if the enhancement of the effective matrix diffusion coefficient is a result of the simplification of flow path geometry. In this case, the degree of the observed enhancement depends on the degree of flow-path geometry considered in a model used to interpret the corresponding test results. If the complexity is fully captured in an interpretation model, the enhancement should disappear. Therefore, the finding regarding the enhancement of the effective matrix diffusion coefficient (reported in this study) needs to be discussed or evaluated within the context of the UZ modeling approach and parameters used. This argument is supported by a recent study by Neretnieks and Moreno (2003 [DIRS 176478]). They noted that matrix diffusion coefficient values much larger than the lab data were needed to match the results of tracer tests conducted at Äspö Hard Rock Laboratory in previous studies. Based on transmissivity measurements in five boreholes at the test site, they concluded that there were many more conductive fractures than those assumed in previous studies. By including these new fractures in their model, they were able to reasonably reproduce the tracer test results with matrix diffusion coefficient values measured from the rock matrix samples. In the other words, because they were able to realistically capture the flow path geometry (related to fracture-matrix interaction) in their model, the enhancement of effective matrix diffusion disappears.

The enhancement of the effective matrix diffusion coefficient may be related to its potential scale dependence as suggested by Liu et al. (2004 [DIRS 169948]). Based on estimates of effective matrix diffusion coefficient from a number of test sites, Liu et al. (2004 [DIRS 169948]) indicated that the coefficient might be scale dependent and increase with the test scale, and also acknowledged that many uncertainties might exist in the estimates of the coefficient used in their study. More studies, especially theoretical studies, are needed to confirm or refute the scale dependence (Liu et al. 2004 [DIRS 169948]). Therefore, further discussion of the potential scale dependence is beyond the scope of this report.

Finally, this study indicates that matrix diffusion is an important process for radionuclide transport in the UZ. This study, together with studies published in the literature, also implies that field-scale effective matrix diffusion coefficient values are generally larger than the lab-scale ones for a given solute. This enhancement of the effective matrix-diffusion coefficient should be considered for modeling the site-scale radionuclide transport in the UZ.

\subsubsection{Uncertainties}

Modeling interpretation of water flow and solute transport processes is a challenging task, involving two major uncertainties. Limitations of this scientific analysis are largely determined by uncertainties involved in conceptually understanding the temporal variability of observed seepage rates and the tracer breakthrough signals observed (especially those observed right after the occurrence of the infiltration pulse due to scrubbing infiltration plots). Based on experimental observations and test conditions, the most plausible conceptual models are implemented in modeling analyses of the testing data. The first uncertainty is related to the temporal variability of observed seepage rates. As indicated in Section 6.2.4, between 550 days and the time when some infiltration plots got scrubbed, the observed seepage rates were dramatically reduced and considerably different from the prediction, while the total infiltration rates did not show a significant drop. In particular, observed seepage rates essentially become zero from 680 to 740 days. In the current study, potential movements of the dust particles 
(and/or infilling materials) due to construction of Alcove 8 may be responsible for temporal variability in both infiltration rates and seepage rates. Initially the particles were close to infiltration plots, causing a significant temporal variability of infiltration rates at the early stage of the tests (although constant water pressure head was maintained at the infiltration plots). At the late stage of the tests, these particles were carried out by water to locations near Niche 3 , resulting in reduction in seepage rates (between 550 to 700 days). Based on this conceptual understanding, effects of these particles were localized and limited to locations near Niche 3 during tracer tests. As a result, the potential particle movements should not have a significant effect on tracer concentrations (as a function of time) observed at Niche 3, because a large portion of a tracer transport path above Niche 3 was not affected. In other words, tracer concentration data observed at Niche 3 can be adequately simulated with a model without considering the potential particle-movement effects. However, the use of this conceptual understanding for capturing infiltration-seepage processes and their temporal variabilities is uncertain, although it is plausible and consistent with experiment observations (as described above).

The second major uncertainty is related to the tracer breakthrough signals observed right after the occurrence of infiltration pulse due to scrubbing infiltration plots. The current understanding is that the signals came from entrapped or adsorbed tracers that were remobilized by the infiltration pulse (Section 6.2.4). (These tracers were carried into Niche 3 along relatively fast flow paths corresponding to the increased infiltration rates, which limited the time for fracture-matrix interaction during the tracer transport.) The majority of tracer mass applied to the infiltration plots was carried by infiltrating water from the plots to Niche 3. Because of the existence of a large degree of matrix diffusion, the tracers diffused into the rock matrix and were not observed at Niche 3. (The plausibility of this conceptual understanding is discussed in Section 6.2.4.) On the other hand, no other mechanisms seem able to explain why the tracer breakthrough could not be observed for such a long time (more than 100 days) while the seepage was continuously observed from Niche 3 (Figures 6.1-7 and 6.1-8). Again, uncertainties exist in interpreting observed breakthrough signals based on the above conceptual understanding, because other possible conceptual models cannot be completely excluded for the given test conditions and experiment observations. For example, it is very unlikely, but possible, that the majority of the tracers applied to the infiltration plots were entrapped (or adsorbed by biofilms) near the plots until these plots got scrubbed. One way to reduce this uncertainty is to directly monitor the potential accumulation of tracers from biofilm near the infiltration plots if biofilm samples can be collected during a test.

While a considerable degree of conceptual model uncertainty exists, efforts are also made in this study to partially capture the uncertainty by using and/or considering alternative conceptual models. In addition to the base-case flow model that considers flow paths from all the infiltration plots to be connected to Niche 3, an alternative flow model was developed to exclude effects of infiltration plots 2 and 12 (Section 6.3). While these two models represent different flow paths from Alcove 8 to Niche 3, they lead to the same conclusion that the enhanced matrix diffusion explains the tracer observations (Section 6.3.2). The alternative conceptual models regarding tracer retention in the rock were also considered. One alternative explanation for the tracer data is that the majority of the tracers applied to the infiltration plots were entrapped (or adsorbed by biofilms) near the plots until these plots got scrubbed. As previously indicated, it is very unlikely because the tracers used this study have been generally regarded as conservative 
tracers. There is not evidence in the literature to support that the tracers can be significantly entrapped by biofilms. Another possible explanation is based on the chaotic (unstable) flow behavior of unsaturated flow. After the tracers were applied, the flow paths to Niche 3 were dramatically shifted (due to unstable flow process) such that these flow paths were not connected to Niche 3. As a result, no tracer was observed in Niche 3 until the connection resumed by scrubbing the infiltration plots. This explanation sounds plausible, but is not supported by field observations. For example, the seepage data show that seepage rates had been stabilized for about 150 days after the tracer was introduced for columns 1 to 6 where the relatively large (relative) tracer concentrations were observed (Figures 6.3-1, 6.1-5, and 6.1-8).

Nevertheless, based on the current conceptual understanding of flow and transport at the test site, simulation results show that the actual, effective matrix diffusion coefficient should be much larger than the lab-scale value, which is consistent with study results published in the literature (Section 6.4.1). At the same time, it is useful to note that for the given uncertainties, the used enhancement factor of effective matrix diffusion coefficient (Section 6.3.2) may be considered as an upper limit in order to be conservative in modeling radionuclide transport in the UZ. 


\section{CONCLUSIONS}

\subsection{SUMMARY}

This report documents analyses of the Alcove 8/Niche 3 flow and transport tests with an emphasis on the large-infiltration-plot tests. The tests involve infiltration that originated from the floor of Alcove 8 (located in the ECRB Cross Drift) and observations of seepage and tracer transport at Niche 3 (located in the Main Drift of the ESF). The data from these tests are relevant to water flow, drift seepage, and solute transport in the unsaturated zone of Yucca Mountain.

The observed seepage and infiltration rates exhibit a significant degree of temporal variability. The observed tracer concentration data from seeping water collected at Niche 3 are characterized by two stages. The first stage corresponds to the time period between the tracer injection date and the time when an infiltration (and seepage) pulse occurred as a result of scrubbing the infiltration plots. At this stage, essentially zero tracer concentrations (excluding background concentrations) were observed. At the second stage, tracer breakthrough was observed at Niche 3 (with relatively low concentrations) and is generally well correlated with the infiltration pulse. It is believed that the observation comes from remobilization of tracers trapped (or adsorbed) by biomaterials near the infiltration plots as a result of scrubbing the infiltration plots. Because it is difficult, if not impossible, to realistically characterize the amount of tracers responsible for the observed breakthroughs in the second stage, the modeling analysis in this report focuses on the tracer data for the first stage.

A combination of computational intensity and the complex features observed in the tests makes the modeling analyses of test results quite a challenging task. The pre-test predictions of late-stage tests were made using a model calibrated against the early stage of infiltration/seepage data. While the predicted seepage rates are on average comparable with the observed values, tracer concentrations are considerably overestimated for the first stage of tracer observations. The model is then refined by calibration with all the infiltration/seepage data. This calibrated model is employed to simulate tracer transport with two different sets of matrix diffusion coefficient values. The first set corresponds to the lab-scale diffusion values that were also used in the pre-test prediction. With these values, the simulated breakthrough curves are generally similar to the pre-test prediction. The second set corresponds to matrix diffusion coefficient values increased by a factor of 45 , which was obtained by matching the fault testing results at a test site near the current test site. With the increased values, the observed peak concentration values are very small, such that in practice they may not be detected or may be masked by background concentrations, which is consistent with field observations.

To capture water flow behavior at the test site, two conceptual models regarding infiltration/seepage processes are developed and used for the refined model calibration. The base-case model considers flow paths from all the infiltration plots to be connected to Niche 3, and an alternative model excludes effects of infiltration plots 2 and 12 based on field observations (Section 6.3). The column-based approach is employed for characterizing heterogeneous property distributions. Unlike previous studies (e.g., Liu et al. 2003 [DIRS 162470]), the model calibration considers seepage spatial variabilities. The reasonable matches between simulations and the seepage data for the two conceptual models indicate that the seepage process and its spatial variabilities can be reasonably captured by the continuum 
approaches considering heterogeneous property distributions. The study results also imply that multiple conceptual models are generally needed to better capture (or bound) flow and transport behavior for a field test.

The current model analyses are subject to uncertainties involved in conceptually understanding the temporal variability of observed seepage rates and the tracer breakthrough signals observed right after the occurrence of the infiltration pulse due to scrubbing infiltration plots. Nevertheless, the need to increase the matrix diffusion coefficient to match field observations, reported herein, is consistent with results published in the literature by a number of researchers. At the same time, it is useful to note that for the given uncertainties, the enhancement factor used for effective matrix diffusion coefficient (Section 6.3.2) may be considered as an upper limit when using the MINC gridding method in order to be conservative in modeling radionuclide transport in the UZ.

In summary, this study indicates that matrix diffusion is an important process for radionuclide transport in the UZ. To accurately capture this process, a MINC-based approach may be needed for more accurately modeling the site-scale radionuclide transport in the UZ. This study, together with studies published in the literature, also implies that field-scale effective matrix diffusion coefficient values are generally larger than the lab-scale ones for a given solute. This enhancement of the effective matrix diffusion coefficient should be considered for modeling site-scale radionuclide transport in the UZ.

The modeling analyses results are submitted to Technical Data Management System under DTN: LB0602A8N3FTR0.001.

\subsection{HOW ACCEPTANCE CRITERIA ARE ADDRESSED}

The following information describes how this analysis addresses the acceptance criteria in the YMRP (NRC 2003 [DIRS 163274], Sections 2.2.1.3.6 and 2.2.1.3.7). Only those acceptance criteria that are applicable to this report (Section 4.2) are discussed. In most cases, the applicable acceptance criteria are not addressed solely by this report; rather, the acceptance criteria are fully addressed when this report is considered in conjunction with other analysis and model reports that describe flow and transport in the UZ. Where a subcriterion includes several components, only some of those components may be addressed. How these components are addressed is summarized below.

\section{Acceptance Criteria from Section 2.2.1.3.6, Flow Paths in the Unsaturated Zone}

\section{Acceptance Criterion 2-Data Are Sufficient for Model Justification:}

(1) Hydrological and thermal-hydrological-mechanical-chemical values used in the license application are adequately justified. Adequate descriptions of how the data were used, interpreted, and appropriately synthesized into the parameters are provided.

The increase in effective matrix diffusion coefficient is justified in Section 6.3. Other rock parameter values were determined directly from model calibrations (Sections 6.2 and 6.3). Section 6 provides descriptions of how the data were used, interpreted, and appropriately synthesized into the parameters. 
(2) The data on the geology, hydrology, and geochemistry of the unsaturated zone, are collected using acceptable techniques.

Approved QA procedures identified in the TWP (BSC 2006 [DIRS 177465], Section 4) have been used to conduct and document the activities described in this analysis report.

(3) Estimates of deep-percolation flux rates constitute an upper bound, or are based on a technically defensible unsaturated zone flow model that reasonably represents the physical system. The flow model is calibrated, using site-specific hydrologic, geologic, and geochemical data. Deep-percolation flux is estimated, using the appropriate spatial and temporal variability of model parameters, and boundary conditions that consider climate-induced change in soil depths and vegetation.

The numerical models used in this study were calibrated against infiltration and seepage rate data to determine the site-specific rock property data (Sections 6.2 and 6.3).

(6) Accepted and well-documented procedures are used to construct and calibrate numerical models.

Approved QA procedures identified in the TWP (BSC 2006 [DIRS 177465], Section 4) have been used to conduct and document the activities described in this analysis report.

(7) Reasonably complete process-level conceptual and mathematical models are used in the analyses. In particular: (i) mathematical models are provided that are consistent with conceptual models and site characteristics; and (ii) the robustness of results from different mathematical models is compared.

The conceptual model used in this report incorporates processes that describe subsurface flow and transport in a heterogeneous unsaturated zone. A discussion of these processes is provided in Conceptual Model and Numerical Approaches for Unsaturated Flow and Transport (BSC 2004 [DIRS 170035], Section 6). The software used in this study is iTOUGH2 V5.0 and T2R3D V1.4, which have been baselined through QA procedure IT-PRO-0011.

\section{Acceptance Criterion 3-Data Uncertainty Is Characterized and Propagated through the Model Abstraction:}

(1) Models use parameter values, assumed ranges, probability distributions, and bounding assumptions that are technically defensible, reasonably account for uncertainties and variabilities, and do not result in an under-representation of the risk estimate.

The parameters values were determined by model calibrations against site-specific field observations (Sections 6.2 and 6.3), and therefore are technically defensible and reasonably account for uncertainties and variabilities.

(4) The initial conditions, boundary conditions, and computational domain used in sensitivity analyses and/or similar analyses are consistent with available data. Parameter values are consistent with the initial and boundary conditions and the assumptions of the conceptual models for the Yucca Mountain site. 
The initial and boundary conditions and computational domain were determined from the site-specific data (Sections 6.2 and 6.3). They are consistent with available data.

(6) Uncertainties in the characteristics of the natural system and engineered materials are considered.

Different conceptual models for water flow at the test site were used to capture the uncertainties (Section 6.3).

\section{Acceptance Criteria from Section 2.2.1.3.7, Radionuclide Transport in the Unsaturated Zone}

\section{Acceptance Criterion 2 - Data Are Sufficient for Model Justification:}

(1) Geological, hydrological, and geochemical values, used in the license application are adequately justified (e.g., flow-path length, sorption coefficients, retardation factors, colloid concentrations, etc.). Adequate descriptions of how the data were used, interpreted, and appropriately synthesized into the parameters are provided.

The increase in effective matrix diffusion coefficient is justified in Section 6.3. Other rock parameter values were determined directly from model calibrations (Sections 6.2 and 6.3). Section 6 provides descriptions of how the data were used, interpreted, and appropriately synthesized into the parameters.

(2) Sufficient data have been collected on the characteristics of the natural system to establish initial and boundary conditions for the total system performance assessment abstraction of radionuclide transport in the unsaturated zone.

The initial and boundary conditions and computational domain were determined based on the site-specific data (Sections 6.2 and 6.3).

(3) Data on the geology, hydrology, and geochemistry of the unsaturated zone, including the influence of structure features, fracture distributions, fracture properties, and stratigraphy, used in the total system performance assessment abstraction are based on appropriate techniques. These techniques may include laboratory experiments, sitespecific field measurements, natural analog research, and process-level modeling studies. As appropriate, sensitivity or uncertainty analyses, used to support the U.S. Department of Energy total system performance assessment abstraction, are adequate to determine the possible need for additional data.

The numerical models used in this study were calibrated against infiltration and seepage rate data to determine the site-specific rock property data (Sections 6.2 and 6.3).

\section{Acceptance Criterion 3-Data Uncertainty Is Characterized and Propagated through the} Model Abstraction:

(1) Models use parameter values, assumed ranges, probability distributions, and bounding assumptions that are technically defensible, reasonably account for uncertainties and variabilities, and do not result in an under-representation of the risk estimate. 
The parameter values were determined by model calibrations against site-specific field observations (Sections 6.2 and 6.3), and therefore are technically defensible and reasonably account for uncertainties and variabilities.

(2) For those radionuclides where the total system performance assessment abstraction indicates that transport in fractures and matrix in the unsaturated zone is important to waste isolation: (i) estimated flow and transport parameters are appropriate and valid, based on techniques that may include laboratory experiments, field measurements, natural analog research, and process-level modeling studies, conducted under conditions relevant to the unsaturated zone at Yucca Mountain; and (ii) models are demonstrated to adequately reproduce field transport test results. For example, if a sorption coefficient approach is used, the assumptions implicit in that approach are verified.

The rock parameters used to calculate water flow were determined by directly calibrating against test results conducted at the Yucca Mountain site (Section 6). The matches between simulated and observed results are reasonable (Sections 6.2 and 6.3).

(4) Uncertainty is adequately represented in parameter development for conceptual models, process-level models, and alternative conceptual models, considered in developing the abstraction of radionuclide transport in the unsaturated zone. This may be done either through sensitivity analyses or use of conservative limits.

Different conceptual models for water flow at the test site were used to capture the uncertainties (Section 6.3). 


\section{INTENTIONALLY LEFT BLANK}




\section{INPUTS AND REFERENCES}

The following is a list of the references cited in this document. Column 2 represents the unique six-digit identifier (the Document Input Reference System number), which is placed in the text following the reference callout (e.g., BSC 2006 [DIRS 177465]). The purpose of these numbers is to assist in locating a specific reference. Within the reference list, multiple sources by the same author (e.g., BSC 2004) are sorted alphabetically by title.

\subsection{DOCUMENTS CITED}

Becker, M.W. and Shapiro, A.M. 2000. "Tracer Transport in Fractured Crystalline 169947 Rock: Evidence of Nondiffusive Breakthrough Tailing." Water Resources Research, 36, (7), 1677-1686. Washington, D.C.: American Geophysical Union. TIC: 252313.

BSC (Bechtel SAIC Company) 2001. Pre-Test Predictions of Alcove 8 -Niche 3 155827 Cross-Over Test. Las Vegas, Nevada: Bechtel SAIC Company.

ACC: MOL.20010904.0434.

BSC 2004. Conceptual Model and Numerical Approaches for Unsaturated Zone 170035 Flow and Transport. MDL-NBS-HS-000005 REV 01. Las Vegas, Nevada: Bechtel SAIC Company. ACC: DOC.20040922.0006; DOC.20050307.0009.

BSC 2004. In Situ Field Testing of Processes. ANL-NBS-HS-000005 REV 03. Las Vegas, Nevada: Bechtel SAIC Company. ACC: DOC.20041109.0001; DOC.20051010.0001; DOC.20060508.001.

BSC 2004. Probability Distribution for Flowing Interval Spacing. 170014 ANL-NBS-MD-000003 REV 01. Las Vegas, Nevada: Bechtel SAIC Company. ACC: DOC.20040923.0003.

BSC 2004. Saturated Zone In-Situ Testing. ANL-NBS-HS-000039 REV 01. 170010 Las Vegas, Nevada: Bechtel SAIC Company. ACC: DOC.20041115.0008; DOC.20060116.0006.

BSC 2004. UZ Flow Models and Submodels. MDL-NBS-HS-000006 REV 02. 169861 Las Vegas, Nevada: Bechtel SAIC Company. ACC: DOC.20041101.0004; DOC.20050629.0003.

BSC 2005. Q-List. 000-30R-MGR0-00500-000-003. Las Vegas, Nevada: Bechtel 175539 SAIC Company. ACC: ENG.20050929.0008.

BSC 2006. Technical Work Plan for: Unsaturated Zone Flow, Drift Seepage and 177465 Unsaturated Zone Transport Modeling. TWP-MGR-HS-000004 REV 04. Las Vegas, Nevada: Bechtel SAIC Company. ACC: DOC.20060824.0001. 
Flint, L.E. 1998. Characterization of Hydrogeologic Units Using Matrix

100033

Properties, Yucca Mountain, Nevada. Water-Resources Investigations Report 97-4243. Denver, Colorado: U.S. Geological Survey.

ACC: MOL.19980429.0512.

Liu, H-H. 2006. YMP-LBNL-GSB-LHH-3 Unsaturated Zone Modeling \& Synthesis [partial submittal]. Scientific Notebook SN-LBNL-SCI-215-V1. Pages 1-53, 64-130, 134-140, and 160-165. ACC: MOL.20010724.0089;

MOL.20020807.0436; MOL.20030721.0182; MOL.20040602.0210;

MOL.20060410.0232.

Liu, H-H.; Haukwa, C.B.; Ahlers, C.F.; Bodvarsson, G.S.; Flint, A.L.; and Guertal, 162470 W.B. 2003. "Modeling Flow and Transport in Unsaturated Fractured Rock: An Evaluation of the Continuum Approach." Journal of Contaminant Hydrology, 62-63, 173-188. New York, New York: Elsevier. TIC: 254205.

Liu, H.H.; Bodvarsson, G.S.; and Finsterle, S. 2002. "A Note on Unsaturated Flow in Two-Dimensional Fracture Networks." Water Resources Research, 38, (9), 15-1 to 15-9. Washington, D.C.: American Geophysical Union.

TIC: 253307.

Liu, H.H.; Bodvarsson, G.S.; and Zhang, G. 2004. "Scale Dependency of the Effective Matrix Diffusion Coefficient." Vadose Zone Journal, 3, (1), 312-315. Madison, Wisconsin: Soil Science Society of America. TIC: 256150.

Lofgren, M. and Neretnieks, I. 2004. "Formation factor distributions from the Oskarshamn site investigations." Section V of Diffusive properties of granitic rock as measured by in-situ electrical methods. Lofgren, M. Doctoral Thesis. Stockholm, Sweden: KTH Chemical Engineering and Technology. Copyright Requested.

Lu, G. 2006. YMP-LBNL-HHL-GL-1 - Unsaturated Zone Modeling \& Synthesis 176702 [partial submittal]. Scientific Notebook SN-LBNL-SCI-246-V1. Pages 1-5 and 19-57. ACC: MOL.20050906.0037; MOL.20060410.0239.

Moridis, G.J.; Hu, Q.; Wu, Y-S.; and Bodvarsson, G.S. 2003. "Preliminary 3-D 161902 Site-Scale Studies of Radioactive Colloid Transport in the Unsaturated Zone at Yucca Mountain, Nevada." Journal of Contaminant Hydrology, 60, (3-4), 251-286. New York, New York: Elsevier. TIC: 253921.

Neretnieks, I. 1993. "Solute Transport in Fractured Rock - Applications to 123099 Radionuclide Waste Repositories." Chapter 2 of Flow and Contaminant Transport in Fractured Rock. Bear, J.; Tsang, C.F.; and de Marsily, G., eds. p. 39-127. San Diego, California: Academic Press. TIC: 235461. 
Neretnieks, I. 2002. "A Stochastic Multi-Channel Model for Solute

Transport-Analysis of Tracer Tests in Fractured Rock." Journal of Contaminant Hydrology, 55, (3-4), 175-211. New York, New York: Elsevier. TIC: 253977.

Neretnieks, I. and Moreno, L. 2003. "Prediction of Some In Situ Tracer Tests with 176478 Sorbing Tracers Using Independent Data." Journal of Contaminant Hydrology, 61, 351-360. New York, New York: Elsevier. TIC: 258122.

NRC (U.S. Nuclear Regulatory Commission) 2003. Yucca Mountain Review Plan, Final Report. NUREG-1804, Rev. 2. Washington, D.C.: U.S. Nuclear Regulatory Commission, Office of Nuclear Material Safety and Safeguards. TIC: 254568.

Pruess, K. and Narasimhan, T.N. 1985. "A Practical Method for Modeling Fluid and Heat Flow in Fractured Porous Media." Society of Petroleum Engineers Journal, 25, (1), 14-26. Dallas, Texas: Society of Petroleum Engineers. TIC: 221917.

Reimus, P.W.; Haga, M.J.; Adams, A.I.; Callahan, T.J.; Turin, H.J.; and Counce, D.A. 2003. "Testing and Parameterizing a Conceptual Solute Transport Model in Saturated Fractured Tuff Using Sorbing and Nonsorbing Tracers in Cross-Hole Tracer Tests." Journal of Contaminant Hydrology, 62-63, 613-636. New York, New York: Elsevier. TIC: 254205.

Renshaw, C.E. 1999. "Connectivity of Joint Networks with Power Law Length Distributions." Water Resources Research, 35, (9), 2661-2670. Washington, D.C.: American Geophysical Union. TIC: 256597.

Salve, R. 2005. "Observations of Preferential Flow During a Liquid Release Experiment in Fractured Welded Tuffs." Water Resources Research, 41, 1-14. Washington, D.C.: American Geophysical Union. TIC: 258071.

Shapiro, A.M. 2001. "Effective Matrix Diffusion in Kilometer-Scale Transport in Fractured Crystalline Rock." Water Resources Research, 37, (3), 507-522. Washington, D.C.: American Geophysical Union. TIC: 253979.

Stauffer, D. and Aharony, A. 2001. Introduction to Percolation Theory. 163274 2nd Edition. Philadelphia, Pennsylvania: Taylor \& Francis. TIC: 253585.

Weisbrod, N.; Dahan, O.; and Adar, E.M. 2002. "Particle Transport in 177044 Unsaturated Fractured Chalk under Arid Conditions." Journal of Contaminant Hydrology, 56, 117-136. New York, New York: Elsevier. TIC: 258403.

Wu, Y.S.; Liu, H.H.; Bodvarsson, G.S.; and Zellmer, K.E. 2001. $A$ 156399 Triple-Continuum Approach for Modeling Flow and Transport Processes in Fractured Rock. LBNL-48875. Berkeley, California: Lawrence Berkeley National Laboratory. TIC: 251297. 


\subsection{CODES, STANDARDS, REGULATIONS, AND PROCEDURES}

10 CFR (Code of Federal Regulations) 63. 2005 Energy: Disposal of High-Level 173273 Radioactive Wastes in a Geologic Repository at Yucca Mountain, Nevada. ACC: MOL.20050405.0118.

IT-PRO-0011, Rev. 0, ICN 0. Software Management. Washington, D.C.: U.S. Department of Energy, Office of Civilian Radioactive Waste Management. ACC: DOC.20060301.0007.

LP-SIII.9Q-BSC, Rev. 1, ICN 0. Scientific Analyses. Washington, D.C.: U.S. Department of Energy, Office of Civilian Radioactive Waste Management. ACC: DOC.20060518.0006.

LS-PRO-0203, Rev. 1, ICN 0. Q-List and Classification of Structures, Systems, Components and Barriers. Washington, D.C.: U.S. Department of Energy, Office of Civilian Radioactive Waste Management. ACC: ENG.20060808.0011.

\subsection{SOURCE DATA, LISTED BY DATA TRACKING NUMBER}

GS040308312242.001. Large Plot Infiltration in Alcove 8 Using 176441 Permeameters in Plot 2 and Plot 12 from March 24, 2003 to August 4, 2003. Submittal date: 03/23/2004.

GS050408312242.002. Surface Infiltration of Tracer Water in a Large Plot in 176443 Alcove 8 from March 1, 2004 to March 17, 2004 (Plots 3 thru 9) and March 1, 2004 to April 13, 2004 (Plots 1, 2, 10, 11, and 12). Submittal date: 05/25/2005.

GS050608312242.003. Surface Infiltration in a Large Plot in Alcove 8 176442 Using Permeameters from August 28, 2003 to March 01, 2004. Submittal date: $06 / 16 / 2005$.

GS050608312242.004. Surface Infiltration of Water in a Large Plot in 176444 Alcove 8 from March 17, 2004 (Plots 3 thru 9) and April 13, 2004 (Plots 1, 2, 10, 11, and 12) to October 18, 2004. Submittal date: 07/12/2005.

LB0208UZDSCPLI.002. Drift-Scale Calibrated Property Sets: Lower Infiltration 161788 Data Summary. Submittal date: 08/26/2002.

LB0210AMRU0035.002. Model Validation and Parameter Uncertainty: Data Summary. Submittal date: 10/10/2002.

166712

LB0303A8N3MDLG.001. Alcove 8 - Niche 3 Seepage Modeling: Simulations. 162773 Submittal date: 03/31/2003.

LB0308A8N3SEEP.001. Niche 3 Seepage (10/16/2002-04/02/2003). Submittal 166090 date: $08 / 29 / 2003$ 
LB0308A8N3TRTM.001. Seepage Travel Times in Niche $3(9 / 4 / 02-3 / 29 / 03)$.

LB0312A8N3MDLG.001. Pre-Test Prediction Results for Alcove 8/Niche 3:

169761

Simulations. Submittal date: 12/17/2003.

LB0507A8N3SEEP.001. Niche 3 Seepage (3/26/2003-01/29/2004). Submittal date: $08 / 16 / 2005$.

LB0507A8N3SEEP.002. Niche 3 Seepage (01/29/2004-09/22/2004). Submittal date: $08 / 16 / 2005$.

LB0507A8N3SEEP.003. Niche 3 Seepage (9/22/2004-1/07/2005). Submittal date: $08 / 16 / 2005$.

MO0511UCC011JB.002. Fluoride, Bromide, Iodide, 2,6, Difluorobenzoic Acid (2,6 DFBA), 2,5, Difluorobenzoic Acid (2,5 DFBA), and 2,4,5 Trifluorobenzoic Acid (2,4,5 TFBA) Concentration Data for the Alcove 8/Niche 3 Tracer Test for Samples Collected 10/2003 through 12/2004. Submittal date: 11/04/2005.

\subsection{SOFTWARE CODES}

T2R3D V. 1.4. 1999. UNIX, Windows 95/98NT 4.0. STN: 10006-1.4-00.

iTOUGH2 V. 5.0. 2002. SunOS 5.5.1, OSF1 V5.1, RedHat V7.2 and V7.3.

160106 STN: 10003-5.0-00. 


\section{INTENTIONALLY LEFT BLANK}


APPENDIX A

ESTIMATION OF FIELD-SCALE EFFECTIVE MATRIX DIFFUSION COEFFICIENT FROM RESULTS OF TRACER TESTS CONDUCTED AT THE C-WELLS COMPLEX 


\section{INTENTIONALLY LEFT BLANK}


Two crosshole tracer tests involving the simultaneous injection of different tracers with different molecular diffusion coefficients were conducted in two different intervals at the C-wells complex near the Yucca Mountain site (Reimus et al. 2003 [DIRS 162950]). The test scale (the distance between injection and monitoring boreholes) is on the order of $30 \mathrm{~m}$. Details of the tests can be found in the study by Reimus et al. (2003 [DIRS 162950]).

By fitting tracer breakthrough curves observed at the monitoring borehole, Reimus et al. (2003 [DIRS 162950]) estimated values of flow and transport parameters for the test site. They include parameter A:

$$
A=\frac{\phi_{m}}{b} \sqrt{D_{m}}
$$

where $b$ is the half fracture aperture, $\varphi_{m}$ is the matrix porosity, and $D_{m}$ is the effective matrix diffusion coefficient. For the given values for field-scale $A_{F}$ and $\varphi_{m}$ and based on Equation A-1, one can have:

$$
F_{d}=\frac{D_{m, F}}{D_{m, L}}=\frac{\left(\frac{A_{F} b_{F}}{\phi_{m}}\right)^{2}}{D_{m, L}}=\frac{b_{F}{ }^{2}}{\left(\frac{\phi_{m} \sqrt{D_{m, L}}}{A_{F}}\right)^{2}}=\left(\frac{b_{F}}{b^{*}}\right)^{2}
$$

where $F_{d}$ is the ratio of the field-observed effective matrix diffusion coefficient $\left(D_{m, F}\right)$ to the corresponding value obtained from rock matrix samples at the lab $\left(\mathrm{D}_{\mathrm{m}, \mathrm{L}}\right)$. The subscripts $\mathrm{F}$ and $\mathrm{L}$ correspond to field and lab scales, respectively. The $b_{\mathrm{F}}$ and $b^{*}$ are calculated based on $\mathrm{D}_{\mathrm{m}, \mathrm{F}}$ and $\mathrm{D}_{\mathrm{m}, \mathrm{L}}$, respectively, for the given field-scale $\mathrm{A}_{\mathrm{F}}$ and $\varphi_{\mathrm{m}}$ and other flow and transport parameters. (The parameter $b^{*}$ is not a lab-scale fracture aperture.) The upper bound values for $2 \mathrm{~b}^{*}$ are $1.06 \mathrm{~cm}$ for the Prow Pass geological unit and $1.28 \mathrm{~cm}$ for the Bullfrog unit (Reimus et al. 2003 [DIRS 162950], Table 6). (Note that the use of the upper bound values is to avoid overestimating $F_{d}$ values.) The tests were performed for the two geological units.

Assuming the conductive horizontal fractures to be represented by two perpendicular sets of identical parallel infinite fractures with a fracture spacing L, one can approximate the flow porosity $\varepsilon$ by:

$$
\mathcal{E}=\frac{4 b_{F}}{L}
$$

By analyzing flow and tracer transport data, Reimus et al. (2003 [DIRS 162950], Table 6) obtained $\varepsilon=0.003$ for both geological units when radial flow test conditions were assumed. While parameter values are also available for the assumed linear flow test condition (Reimus et al. 2003 [DIRS 162950]), it is believed that radial flow more appropriately represents the actual test conditions for the given test configuration. 
The probability distribution for flow interval spacing in the saturated zone of Yucca Mountain was discussed and documented in Probability Distribution for Flowing Interval Spacing (BSC 2004 [DIRS 170014]). The geometric mean flow interval spacing is $10^{1.29} \mathrm{~m}=19.50 \mathrm{~m}$ (BSC 2004 [DIRS 170014], Table 6-7). Considering the mean flow interval spacing to be the same as the average value for $\mathrm{L}$, one can use Equation A-3 to estimate $b_{F}$ and further use Equation A-2 to estimate $F_{d}$. The estimated values for $F_{d}$ are 8 and 5 for the Prow Pass and Bullfrog units, respectively. $F_{d}$ values larger than one indicate the enhancement of the effective matrix diffusion coefficient discussed in Section 6.4.

Note that a number of assumptions or simplifications were used to estimate $b_{F}$ (and therefore $F_{d}$ ) in the above discussion, which may involve a relatively large degree of uncertainty. The mass transfer parameter $A_{F}$ is estimated directly from the tracer breakthrough curves, but the underlying parameters $\phi_{m}, b_{F}$, and $D_{m, F}$ cannot be uniquely and independently estimated from the tracer testing results alone. These parameter values could also be estimated from other measurements combined with the tracer test results. For example, $\phi_{m}$ and $D_{m, L}$ can be estimated from laboratory core measurements (these estimates were used to obtain the estimate of $b^{*}$ given the value of $\mathrm{A}_{\mathrm{F}}$ determined from $\mathrm{C}$-wells tracer testing), and $b_{F}$ can be estimated from flow porosity estimates assuming a given flow path geometry. There is generally a small degree of uncertainty in the parameter $\phi_{m}$ for a given rock unit, but estimates of $b_{F}$ (and hence the calculated value of $D_{m, F}$ for a given value of $\mathrm{A}_{\mathrm{F}}$ ) involve significant uncertainty because of the uncertainties in flowing interval measurements and in the assumption that a flowing interval consists of one large-aperture fracture. However, the best available information from the test analysis results and other sources has been used in estimating $F_{d}$ here. Also note that the estimated fracture aperture from Equation A-3 is $2.93 \mathrm{~cm}$, which is considerably larger than expected for a single fracture. This can be explained by the notion that a flow path consists of a group of fractures, rather than a single fracture. This issue was further discussed in Section 6.4.1.

Note that the analyses from this appendix are not inconsistent with the results discussed in Saturated Zone In-Situ Testing (BSC 2004 [DIRS 170010], Section E 4.2). The study in that report (BSC 2004 [DIRS 170010], Section E4.2) focuses on parameter A (Equation A-1) and showed that values for lab-scale A are larger than the corresponding field-scale values. This is because rock samples used for the lab tests generally contain much smaller fractures than those important for field-scale tracer transport as a result of sample collection procedures and the scarcity of conductive fractures associated with flow channels in the field. In this case, a larger field aperture gives a smaller A value. This, however, does not necessarily suggest that field-scale matrix diffusion coefficient is smaller than the lab-scale value, but indicates that changes in apertures have a large effect on A values. This analysis also shows that if saturated zone transport models assume the expected value of the flowing interval spacing, L, and a value of $b$ that is calculated from Equation A-3 (using L and the flow porosity inferred from tracer testing; i.e., $b_{F}$ ) as the "true" large-scale field values of these parameters, then the laboratorymeasured matrix diffusion coefficient, $D_{m, L}$, must be multiplied by a factor of $\mathrm{b}_{\mathrm{F}}^{2} / \mathrm{b}^{* 2}$ (in this case, 5 to 8) to obtain an effective matrix diffusion coefficient $D_{m, F}$ that will yield a large-scale A value that is equal to the $\mathrm{A}$ value determined in the $\mathrm{C}$-wells tests. However, it is uncertain how representative the A values determined in the $\mathrm{C}$-wells tests are for much larger scales. 


\section{APPENDIX B}

\section{DESCRIPTION OF DATA FILES AND PROCESSING PROCEDURES}




\section{INTENTIONALLY LEFT BLANK}


This appendix describes data files used in this report and the details of their processing procedures. All the files mentioned in this section are provided in output DTN: LB0602A8N3FTR0.001, except those from input DTNs.

\section{B.1 INFILTRATION DATA}

\section{B.1.1 Source Files from Input DTNs}

The infiltration data are obtained from five input DTNs:

- Microsoft excel file alcove 8 daily infiltration Rates.xls from DTN: LB0312A8N3MDLG.001 [DIRS 169761] for period 8/20/2002 to 3/22/2003

- Microsoft excel file LrgPlot_2_12_Data.xls from DTN: GS040308312242.001 [DIRS 176441] for period 3/24/2003 to 8/04/2003

- Microsoft excel file DataLrgPlotThru030104.xls from DTN: GS050608312242.003 [DIRS 176442] for period 8/28/2003 to 3/01/2004

- Microsoft excel file DataLargePlotTracerFinal072205.xls from DTN: GS050408312242.002 [DIRS 176443] for period 3/01/2004 to 3/17/04

- Microsoft excel file DataLargePlot(Thru10182004)060905 (FINAL).xls from DTN: GS050608312242.004 [DIRS 176444] for period 3/17/2004 to 10/18/2004.

\section{B.1.2 Processed Files}

The above source files are renamed and processed as the following intermediate files:

- LrgPlot_2_12_Datav2.xls

- DataLrgPlotThru030104v2.xls

- DataLargePlotTracerFinal072205v2.xls

- DataLargePlot(Thru10182004)060905 (FINAL)v2.xls.

The original infiltration data files document the water volume released for varying lengths of time periods. The starting time and measurement time periods for releasing water vary from one time to another for a given plot and also vary from one plot to another. In order to obtain consistent time periods for all the plots, the water volumes were rearranged into uniform time periods of 24 hours, separated by midnight time 00:00:00. The data processing procedure is given below.

\section{B.1.3 Data Processing for Plots 1 to 12 (i.e., AL810 to AL821)}

- Microsoft excel file alcove 8 daily infiltration Rates.xls. This file was already processed by 24-hour interval and ready for use. No further processing is made. 
- Microsoft excel file LrgPlot_2_12_Datav2.xls. Infiltration was applied to plots 2 and 12 only. Original infiltration rates were already in L/day. The data of these two plots is combined in a newly created spreadsheet "processed" in this file.

- Microsoft excel file DataLrgPlotThru030104v2.xls. The measured water volume data (for different time intervals) are combined and arranged into water volumes for a daily 24-hour interval. The processed data for all the 12 plots are combined in a newly created spreadsheet called "compiled."

- Microsoft excel file DataLargePlotTracerFinal072205v2.xls. The measured water volume data (for different time intervals) are combined and arranged into water volumes for a daily 24-hour interval. The processed data for all the 12 plots are combined in a new spreadsheet "compiled."

- Microsoft excel file DataLargePlot(Thru10182004)060905 (FINAL)v2.xls. The measured water volume data (for different time intervals) are combined and arranged into water volumes for a daily 24-hour interval. The processed data for all the 12 plots are combined in a new spreadsheet "compiled."

- Microsoft excel file InfiltrationRatesItough.xls. This file assembles all infiltration rates organized in 24-hour intervals for each of the 12 infiltration plots. The data sources are the five data file listed above (alcove 8 daily infiltration Rates.xls, and the four processed Excel files). The steps in assembling the data are:

- Step 1. Combine the measurement data from all the five files into spreadsheet "Infiltration_spreadsheetStep1"

- Step 2. Fill non-flow dates with zero flow rates in spreadsheet "infilStep2"

- Step 3. Remove all text notes in spreadsheet "generStep3"

- Step 4. Convert time into seconds and infiltration rate into $L /$ second. Then convert the infiltration rates into gridblock flow rates (each infiltration plot was subdivided into four gridblocks in the numerical model) in spreadsheet "itough2GENERstepFinal."

\section{B.1.4 Data Plotting}

The plotting data file for the infiltration measurement data is infilQA.txt. The infiltration rates as a function of time for each plot are plotted in tecplot file infilallQA.lay and exported as infilallQA.wmf. The total infiltration data are contained in file infilQA.txt, and plotted in tecplot file infil-seeptotalQA.lay and exported as Windows metafile infil-seeptotalQA.wmf. 


\section{B.1.5 Infiltration Data for ITOUGH2 Simulations}

The measured infiltration rates are organized in the file InfiltrationRatesItough.xls in output DTN: LB0602A8N3FTR0.001 and were used to generate the GENER block for iTOUGH2 and T2R3D runs.

\section{B.2 SEEPAGE DATA PROCESSING}

\section{B.2.1 Source Files from Input DTNs}

The seepage data were obtained from the following five input DTNs:

- Text file dailyseepage.txt from DTN: LB0312A8N3MDLG.001 [DIRS 169761] for period $8 / 20 / 2002$ to $3 / 22 / 2003$

- Microsoft excel file Niche3 Seepage Data 032603-012904.xls from DTN: LB0507A8N3SEEP.001 [DIRS 176445] for 3/26/2003 to 1/29/2004

- Microsoft excel file Niche 3 Seepage 012904-092204.xls from DTN: LB0507A8N3SEEP.002 [DIRS 176446] for 1/29/2004 to 9/22/2004

- Microsoft excel file Niche 3 Seepage 092204-010705.xls from DTN: LB0507A8N3SEEP.003 [DIRS 176447] for 9/22/2004 to 1/07/2005.

(The seepage rates in the text file dailyseepage.txt were already processed by 24-hour intervals.) The infiltration rate data in the above Excel files are listed in spreadsheets "UNIT-1," "UNIT-2," "UNIT-3," and "UNIT-4" and are located in the column "total” for each seepage collection unit. The start and end times for a measurement period are the same for all the seepage collection units. The time intervals of measurement are generally 10 minutes.

\section{B.2.2 Processed File}

The above source files are processed into a data file called seepplotQA.plt that contains seepage rates with time intervals of about one day for the seepage trays. The data processing procedure is given below.

\section{B.2.3 Data Processing Procedure}

The seepage data files from input DTNs document the cumulated water volume collected from every 10 minutes. The seepage rates are processed using the following steps:

- Step 1. Select seepage measurement data that are closest to midnight. The purpose is to obtain the seeping water volumes over time intervals of approximately 24 hours.

- Step 2. Determine seepage water amount within a time interval close to 24 hours. For a time interval, the starting cumulated seepage volume is denoted V1 at time $\mathrm{t} 1$, and ending cumulated seepage volume V2 at time t2; the seepage water volume (Vt) is then obtained as V2 - V1. 
- Step 3. Determine the actual length of time interval $t$ (day) as $\mathrm{t} 2-\mathrm{t} 1$.

- Step 4. Determine seepage rate as $\mathrm{Vt} / \mathrm{t}$.

Next, convert seepage rate for seepage trays into rates for model columns (T1 to T12) based on an approximation of uniform seepage rates over a coverage area for seepage tray. Specifically, seepage rates are calculated using:

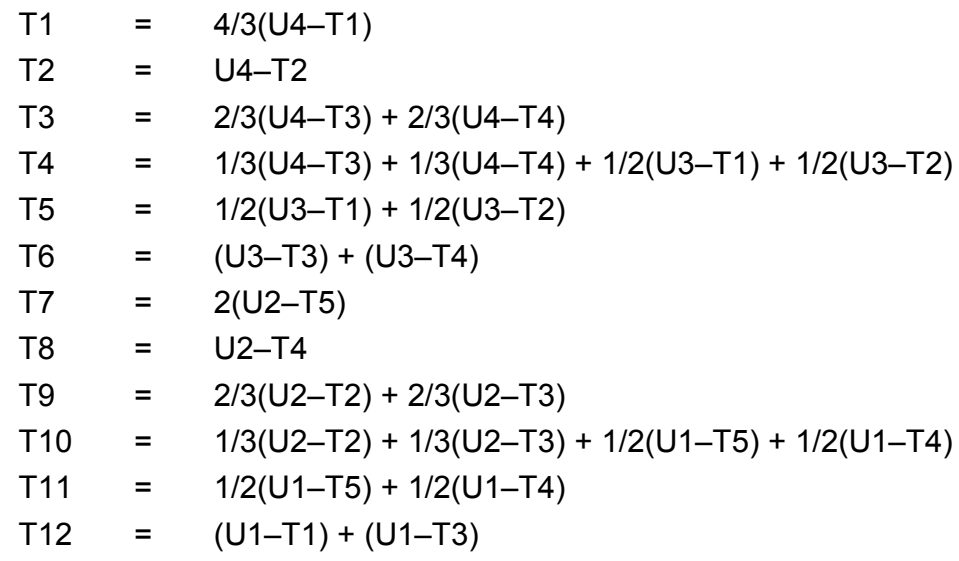

(Note that the naming convention for seepage collection units U\#-T\# corresponds to that of U\#-B\# in DTN: LB0312A8N3MDLG.001 [DIRS 169761].)

The above formulations result from relations between coverage areas for model columns and seepage collection trays. In these formulations, tray and column names refer to their corresponding seepage rates.

\section{B.2.4 Data Plotting}

The plotting file for the seepage measurement data is seepplotQA.plt. The infiltration rates for each infiltration plot are plotted in tecplot file seepallQA.lay and exported as Windows metafile seepallQA.wmf. The total seepage data are contained in file seepplotQA.txt and plotted as tecplot file infil-seeptotalQA.lay and exported as Windows metafile infil-seeptotalQA.wmf in output DTN: LB0602A8N3FTR0.001.

\section{B.2.5 Seepage Measurement Data for ITOUH2 Simulations}

The processed seepage data in file seepplotQA.plt are used to form a seepage data file for iTOUGH2 calibration runs. 


\section{B.3 TRACER BREAKTHROUGHS}

\section{B.3.1 Source File from Input DTNs}

The tracer data were obtained from file A8N3_Tracer_Data.xls in DTN: MO0511UCC011JB.002 [DIRS 176334].

The file contains all the concentration data for six tracers $\left(\mathrm{I}^{-}, \mathrm{Br}^{-}, \mathrm{F}^{-}, 2,6 \mathrm{DFBA}, 2,5 \mathrm{DFBA}\right.$, and 2,4,5TFBA) for the infiltration plots at Alcove 8 and seeping water collected in the seepage units at Niche 3. In the original data file A8N3_Tracer_Data.xls, the measurement time for each plot and tray unit varies from one tracer to another.

\section{B.3.2 Processed File}

The above source file was processed into file A8N3_Tracer_Datav21d.xls. This file contains the tracer data that have uniform time intervals of approximately one day for the 12 infiltration plots (in spreadsheets named "plotI-", etc.) and the 12 seepage configuration trays (in spreadsheets named "U-TF-," etc.). The processing procedure is given below.

\section{B.3.3 Data Processing for Tracer Data}

In the original data file A8N3_Tracer_Data.xls, the concentrations are reported for varying measurement time intervals for each infiltration plot and tray unit. The data processing involves the following steps:

- Step 1. Extract measurement time points to form a complete list of the measurement times at each of which measured concentration data are available for at least one tracer.

- Step 2. Normalize the concentration data with the corresponding maximum measurement concentration (in spreadsheet "U-TforPostProcessing" of the file A8N3_Tracer_Datav21d.xls).

\section{B.3.4 Concentration Data Plotting}

The plotting data file for the concentration data is tracerseepplotQAamr.txt, which is from the spreadsheet "tracerProcessedForFigure" in file A8N3_Tracer_Datav21d.xls. The tracer concentrations are plotted in tecplot files tracerseepalllof2AMR.lay and tracerseepall2of2AMR.lay and exported as Windows metafiles tracerseepalllof2AMR.wmf and tracerseepall2of2AMR.wmf.

\section{B.3.5 Concentration Data for T2R3D Runs}

The tracer data were processed in the file A8N3_Tracer_Datav21d.xls (spreadsheet "t2r3dGenerCOM3forAll") for generating the GENER block for T2R3D runs. In T2R3D simulations, the GENER's concentration block "COM3" requires the mass rate of the tracers as input. In order to get the mass rate of a tracer at a specific time, the corresponding tracer application rates (documented in DataLargePlotTracerFinal072205v2.xls) are multiplied by the corresponding tracer concentration. 


\section{B.3.5 Presentation of the Simulated Tracer Breakthrough Curves}

For the base case, the simulated breakthrough data files are:

- GASOBSsortedTrun3dtracerIqaplot.txt

- GASOBSsortedTrun3dtracerFqaplot.txt

- GASOBSsortedTrun3dtracerBrqaplot.txt

- GASOBSsortedTrun3dtracer26DFBAqaiterplot.txt

- GASOBSsortedTrun3dtracer25DFBAqaplot.txt

- GASOBSsortedTrun3dtracer245TFBA qaplot.txt.

For the alternative case, the simulated breakthrough data files are:

- GASOBSsortedtry1Trun3dtracer26DFBAqaplot.txt

- GASOBSsortedtry1Trun3dtracer25DFBAqaplot.txt

- GASOBSsortedtry1Trun3dtracer245TFBAqa270iterplot.txt.

They were plotted in tecplot files and exported as Windows metafiles listed below:

- TracerIplotlof $2 A M R v 2 . l a y$

- TracerIplot2of2AMRv2.lay

- try1Tracer26DFBAplotAMR.lay

- TracerIplot lof $2 A M R v 2 . w m f$

- TracerIplot2of2AMRv2.wmf

- trylTracer26DFBAplotAMR.wmf.

In these plots, breakthrough curves correspond to middle locations of model columns at Niche 3 ceilings. Since one rock column may cover more than one seepage tray, the breakthrough curves shown in Figures 6.3-3 and 6.3-4 for U4-T4, U3-T4, U2-T2, and U1-T3 actually correspond to those for boundaries of U4-T4 and U4-T3, U3-T4 and U3-T3, U2-T2 and U2-T3, and U1-T1 and U1-T3, respectively. 